\title{
DISEASES \\ OF FIELD CROPS \\ in the Prairie Provinces
}

CANADA DEPARTMENT OF AGRICULTURE 


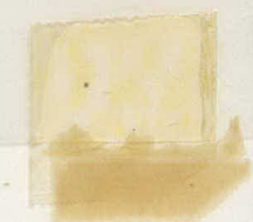

*

et.

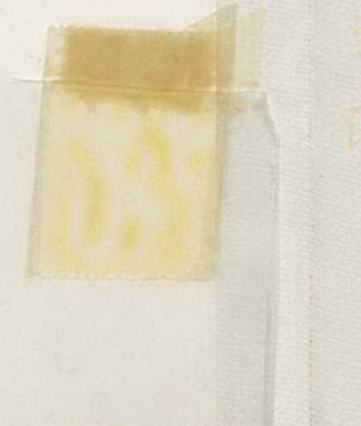




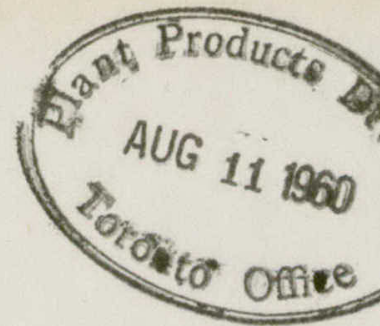

oronto Laboratony 





\title{
DISEASES OF FIELD CROPS IN THE PRAIRIE PROVINCES
}

\author{
Prepared by the \\ Staff of the Plant Pathology Laboratories \\ at Winnipeg, Man.; Saskatoon, Sask.;
}

Edmonton, Alta; and Lethbridge, Alta.

\section{CANADA DEPARTMENT OF AGRICULTURE Ottawa, Ontario}





\section{Contents}

PAGE

\section{INTRODUCTION}

Aims and Scope of this Bulletin .................................................. 7

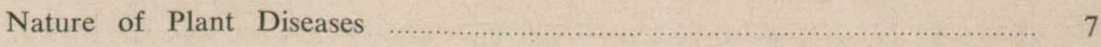

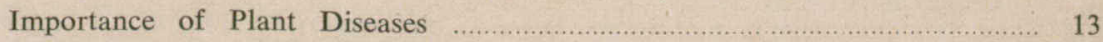

Savings from the Use of Control Measures ……...................................... 14

GENERAL MEANS OF CONTROL

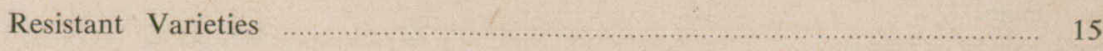

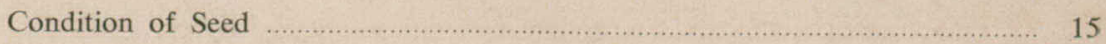

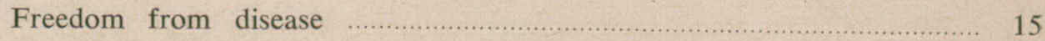

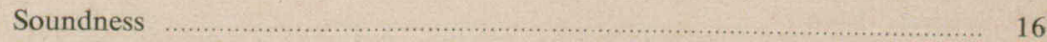

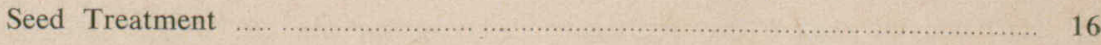

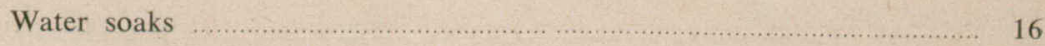

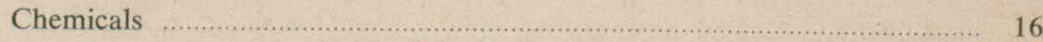

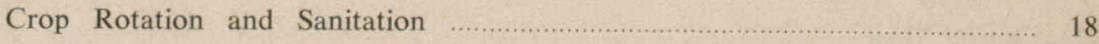

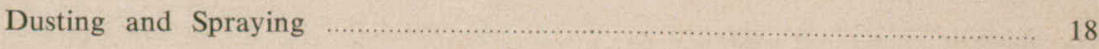

DISEASES OF WHEAT

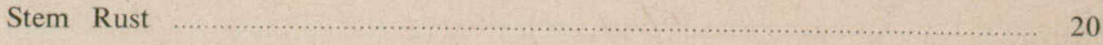

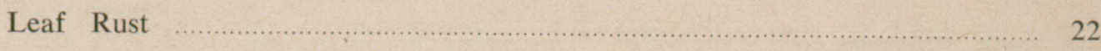

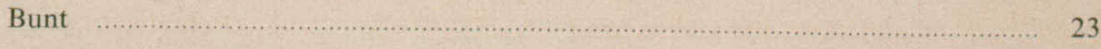

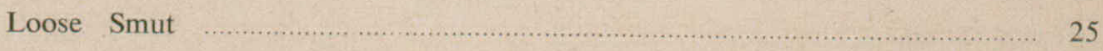

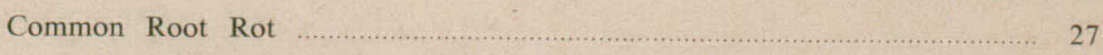

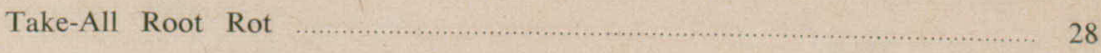

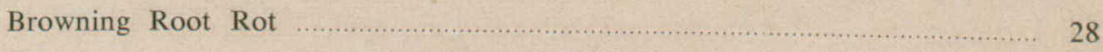

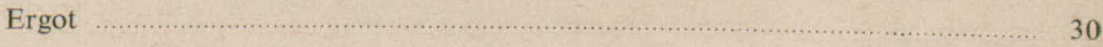

Bacterial Blights _................................. 30

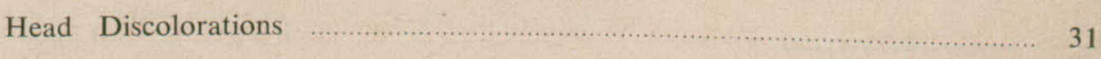

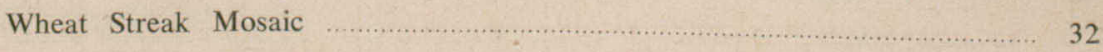

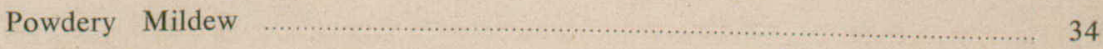

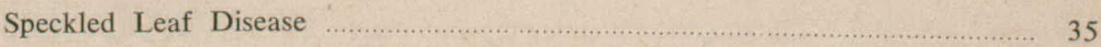

$88467-1 \frac{1}{2}$ 


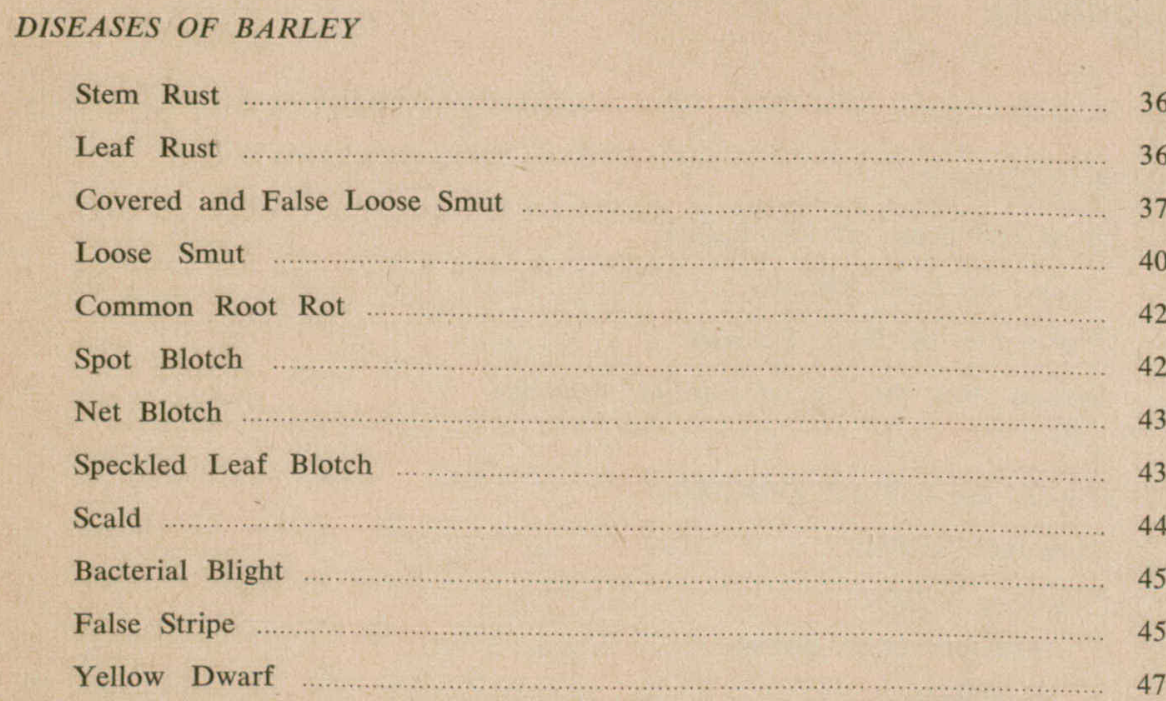

\section{DISEASES OF OATS}

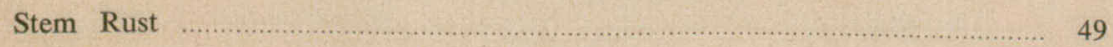

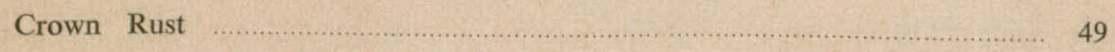

Smuts ……

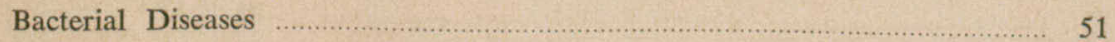

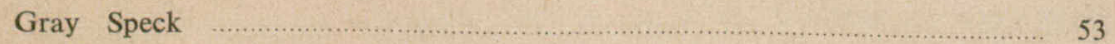

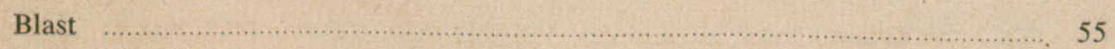

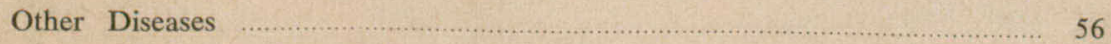

DISEASES OF RYE

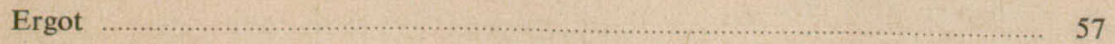

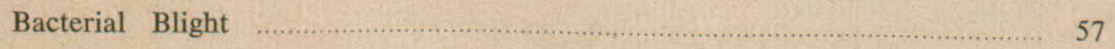

Leaf Rust ……

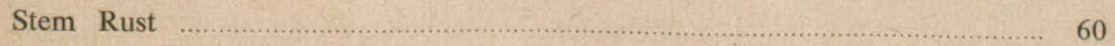

DISEASES OF CORN

Rust

Smut 
DISEASES OF FLAX

Rust …

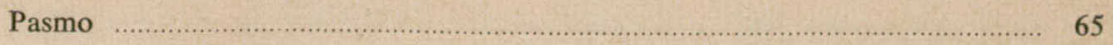

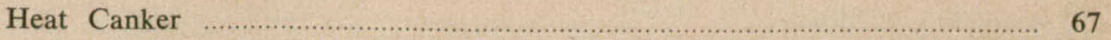

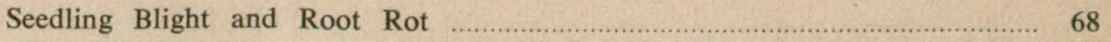

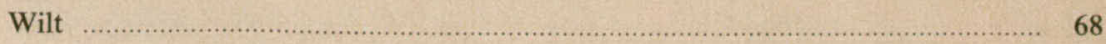

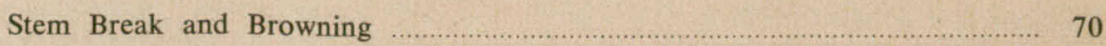

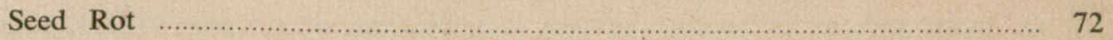

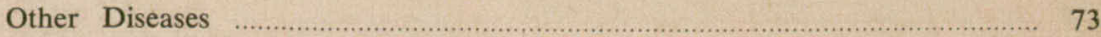

DISEASES OF SUNFLOWERS

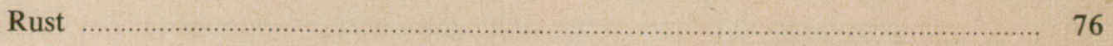

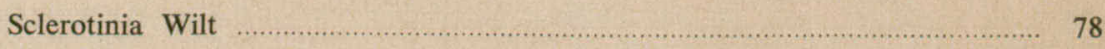

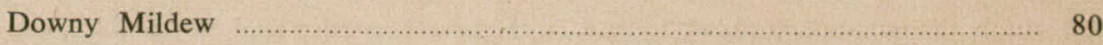

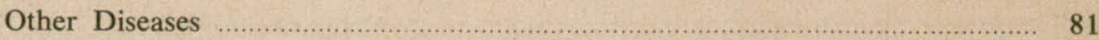

DISEASES OF PEAS

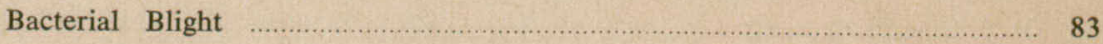

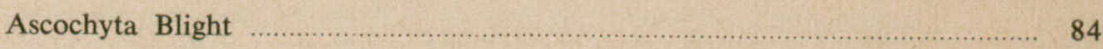

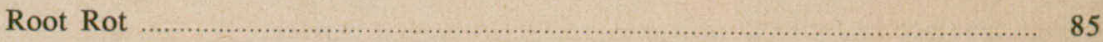

DISEASES OF ALFALFA AND SWEET CLOVER

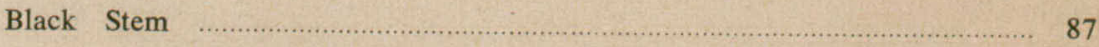

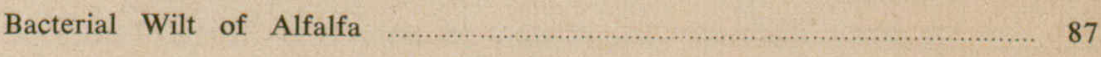

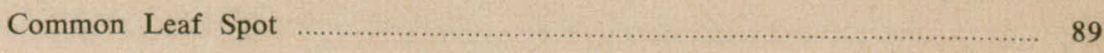

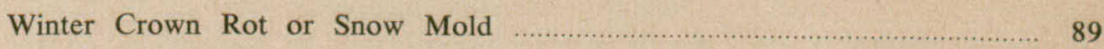

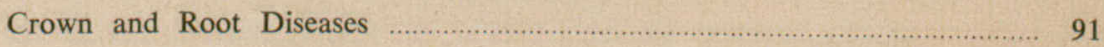

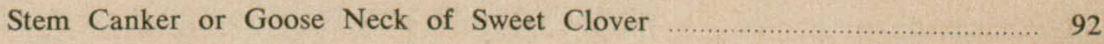

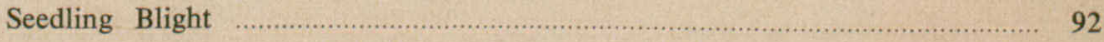

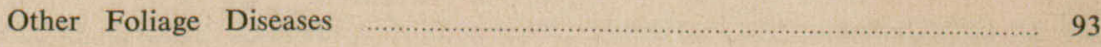

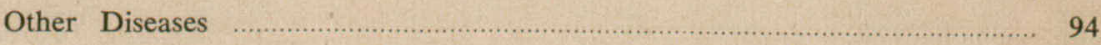




\section{DISEASES OF CLOVER}

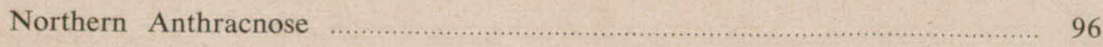

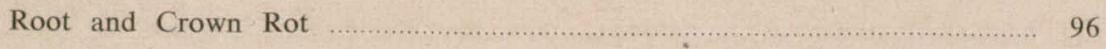

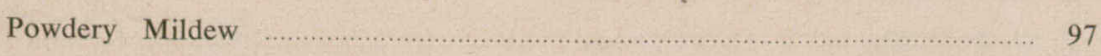

Other Diseases …………… 97

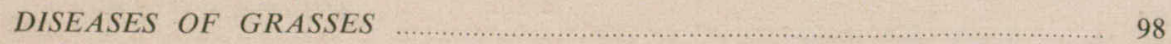

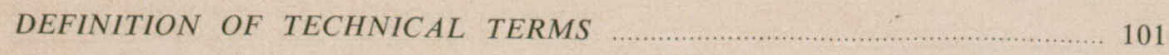

INDEX 


\section{Introduction}

\section{Aims and Scope of this Bulletin}

Plant diseases take a large toll of our crops every year. Some of the damage done by them is preventable, but only if the diseases are recognized and appropriate control measures are taken. The purpose of this bulletin is to describe and illustrate the more important diseases of the field crops grown in the Prairie Provinces, to indicate their relative importance, and to give an account of the means that can be taken for their control.

\section{Nature of Plant Diseases}

Most of the diseases of our agricultural plants are caused by microorganisms that have established a parasitic relationship with these plants. Of these microorganisms, the fungi are the most important. The fungi or molds, as they are sometimes called, are actually minute plants that do not have the capability to produce chlorophyll, the green coloring matter that enables the higher plants to use the energy of light to manufacture food from air, water and the minerals of the soil. The fungi are thus dependent on food produced by green plants. Some have become able to grow on dead plant matter in the soil. The mushrooms are examples of this type of fungus. Other fungi have adapted themselves to a parasitic existence by which they extract nutrition from the plants on which they grow and thereby often do severe damage to them.

To the student of plant diseases, and to one who attempts to devise measures for their control, it is important to understand how these microorganisms invade the plants, how they grow in them, and how they survive from year to year. Usually, these matters have to be understood before a counter measure against a disease can be found.

Stem rust of wheat is an example of a plant disease caused by a fungus. The characteristic red appearance of the rusted plant is caused by masses of spores, the reproductive units of the fungus. Individually, these spores are too small to be seen with the naked eye, for each spore is only one thousandth of an inch in diameter. Collectively, they make up conspicuous, red, powdery masses containing millions of spores. These spores are readily carried great distances by winds and, though many of them are wasted, some fall on leaves or stems of wheat plants. In the presence of moisture, such as dew or raindrops, these spores germinate by sending out germ tubes (Fig. 1), which grow along the surface of the leaf or stem and penetrate the plant through the numerous breathing pores on the plant surface. Once inside the plant, the germ tube grows and branches into a network of tubular structures that absorb food materials from the plant. In eight or ten days 
this fungus network sporulates, that is, produces a mass of new spores. In this manner, a single spore can infect a plant and produce, in a little more than a week, one hundred thousand or more spores. This process is repeated over and over again during the summer so long as the wheat plants remain green. If spores are plentiful and moisture is abundant, a rust epidemic can build up in a few weeks. The damage to the plant is done partly by absorption of food by the fungus but chiefly by the drying up of the plant caused by evaporation of water through the numerous ruptures of the plant surface by the spore masses of the fungus.

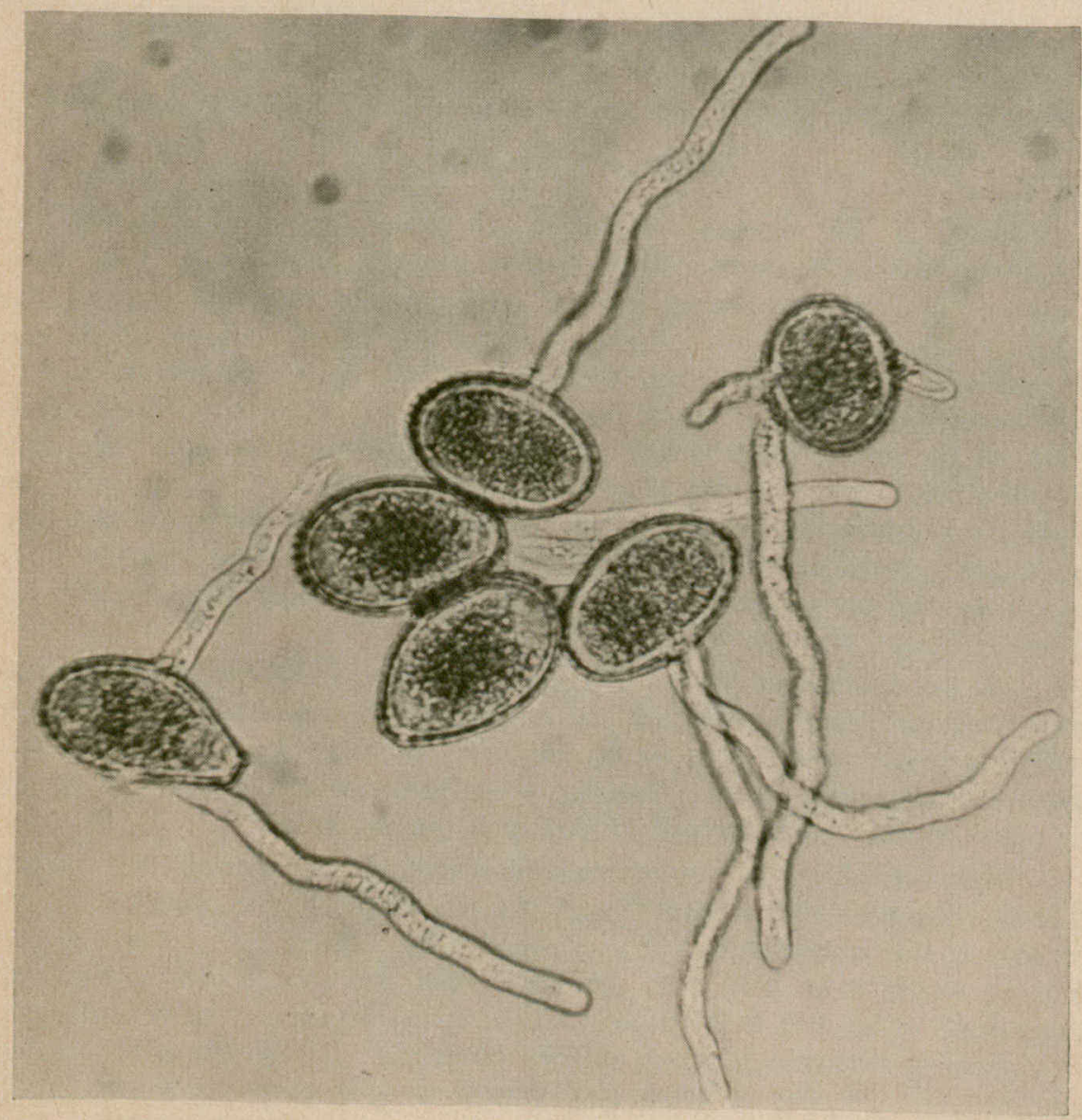

Figure 1.-Germinating spores of the red or summer stage of stem rust.

Numerous other fungi attack our cereal and field crops and it is characteristic of these parasitic organisms that each produces its own distinctive type of spore, each has a life cycle that differs somewhat from that of any other fungus, and each has preferences for particular kinds of 


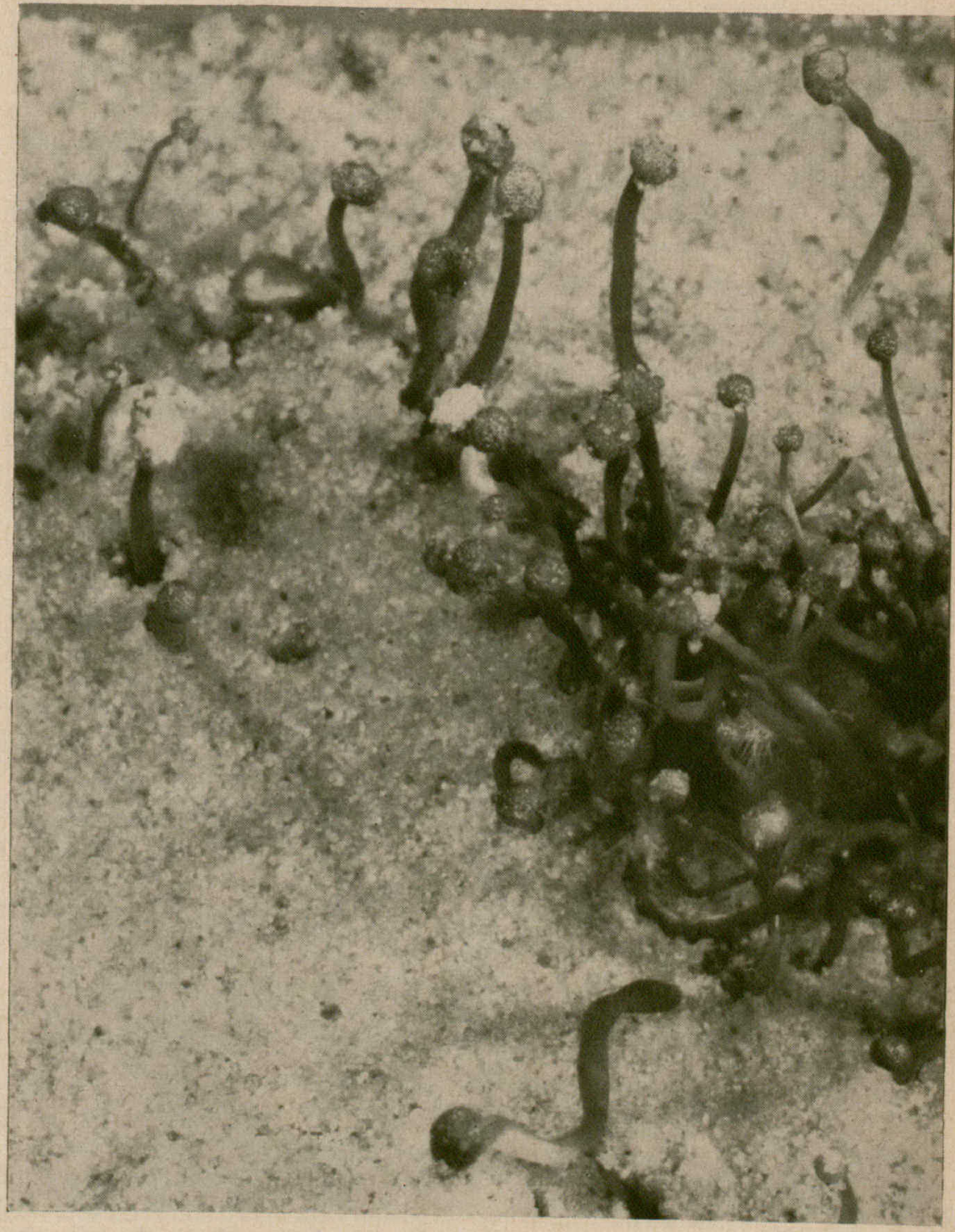

Figure 2.-The fruiting structures produced by germinating ergot bodies. The knoblike structures at the tips of the stalks discharge very small spores into the air. 
crop plants. The fungi that cause bunt attack wheat but not other plants. They infect the young seedling shortly after germination, and do their damage after heading out by filling the young seed with fungus growth, which becomes converted into masses of bunt spores. These contaminate healthy seeds and start the same process over again when that seed is sown. The fungus that causes loose smut of barley infects the barley heads when they are in flower and grows in the developing barley seed without showing any evidence of damage to it. But when the infected seed is planted the fungus keeps pace with the growing plant, though there is no sign that it infected until the whole head of the barley plant is converted into a mass of black fungus spores. The fungus that produces ergot of rye, wheat, barley and grasses, survives the winter by means of the ergot bodies, which are often so conspicuous in rye. These germinate on or just under the surface of the soil at the time the cereals and grasses are in bloom (Fig. 2) and discharge into the air masses of small spores, which infect the heads in which new ergot bodies are formed. The root-rotting fungus

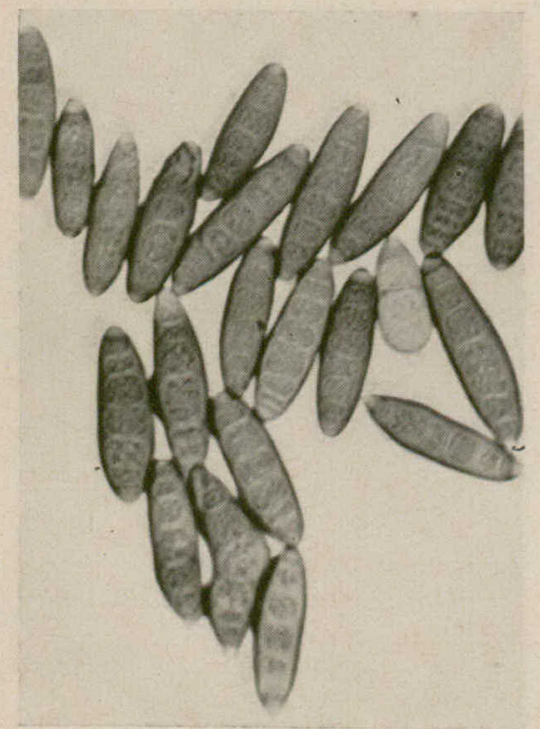

Figure 3.-Spores of the fungus Helminthosporium sativum. These spores infect stems, roots and leaves of wheat and barley.

Helminthosporium sativum attacks chiefly the roots, the bases of stems, and the leaves of wheat and barley on which are produced its characteristic spores (Fig. 3). These spores survive the winter in the soil and on stubble and cause new infections the following spring. These are only a few examples of the great variety of devices by means of which the fungi adapt their parasitic existence to our growing crop plants. 
Bacteria, though less important than the fungi, cause diseases on many plants. The bacteria that cause plant diseases are rod-shaped and about one ten-thousandth of an inch long. One of the most conspicuous of the diseases caused by bacteria is the "black chaff" of wheat. The bacteria that cause it attack the leaves of the wheat plant but the disease shows its most striking symptoms on the glumes of the heads on which dark brown blotches are formed. Like many other disease organisms, the bacteria can survive the winter on plant remains and reproduce the disease next spring.

Diseases caused by viruses have been investigated less than those caused by fungi and bacteria but they are nevertheless of considerable importance. The question of whether or not viruses are to be regarded as microorganisms is debatable. Some prefer to look upon them as nonliving structures of a chemical nature. However that may be, these extremely small particles, so small that they can be seen only by means of the electron microscope, which magnifies many thousands of times, can thrive only in the living tissues in which they multiply and produce various disease conditions. There are several virus diseases of cereals. The most common is probably the false stripe of barley (Fig. 4). This disease can be transmitted from plant to plant merely by the rubbing of one leaf against another. Some of the virus particles get into the seed and so serve to re-establish the disease in the next generation of plants. Some viruses cannot infect by the mere rubbing of one leaf against another but are transmitted by insects such as green bugs which during their feeding absorb the virus from one plant and transmit it to another. One such disease, transmitted by a tiny mite, is the streak mosaic of wheat which occurs in southern Alberta.

Besides diseases caused by parasitic organisms there are a number of unhealthy conditions of the growing plant, regarded as diseases, that are caused by improper nutrition. Improper nutritional conditions can sometimes be corrected, but only if the cause of the disease is understood. Fortunately, the appearance of the affected plants usually provides the clue to the cause.

To grow properly, all plants require mineral elements from the soil in certain quantities that must not be too small or too large. Most of our nutritional diseases result from one or the other, either an underdose or an overdose of particular soil chemicals. Too little nitrogen in the soil, in the spring, before the nitrifying soil bacteria have built the nitrogen up to its usual level, gives the plants a yellow, 'chlorotic', appearance. In cereals, this condition can be prevented by applying a nitrogenous fertilizer with the grain. In certain districts patches of alkaline ground are common. These result from the accumulation of certain chemicals to a level at which they interfere with plant growth. This soil condition is not easy to cure but it is well to remember that certain plants can tolerate alkalinity better than others. For instance, barley can grow satisfactorily in alkaline patches in which wheat will not thrive. Some types of chlorosis, or yellowing of the 


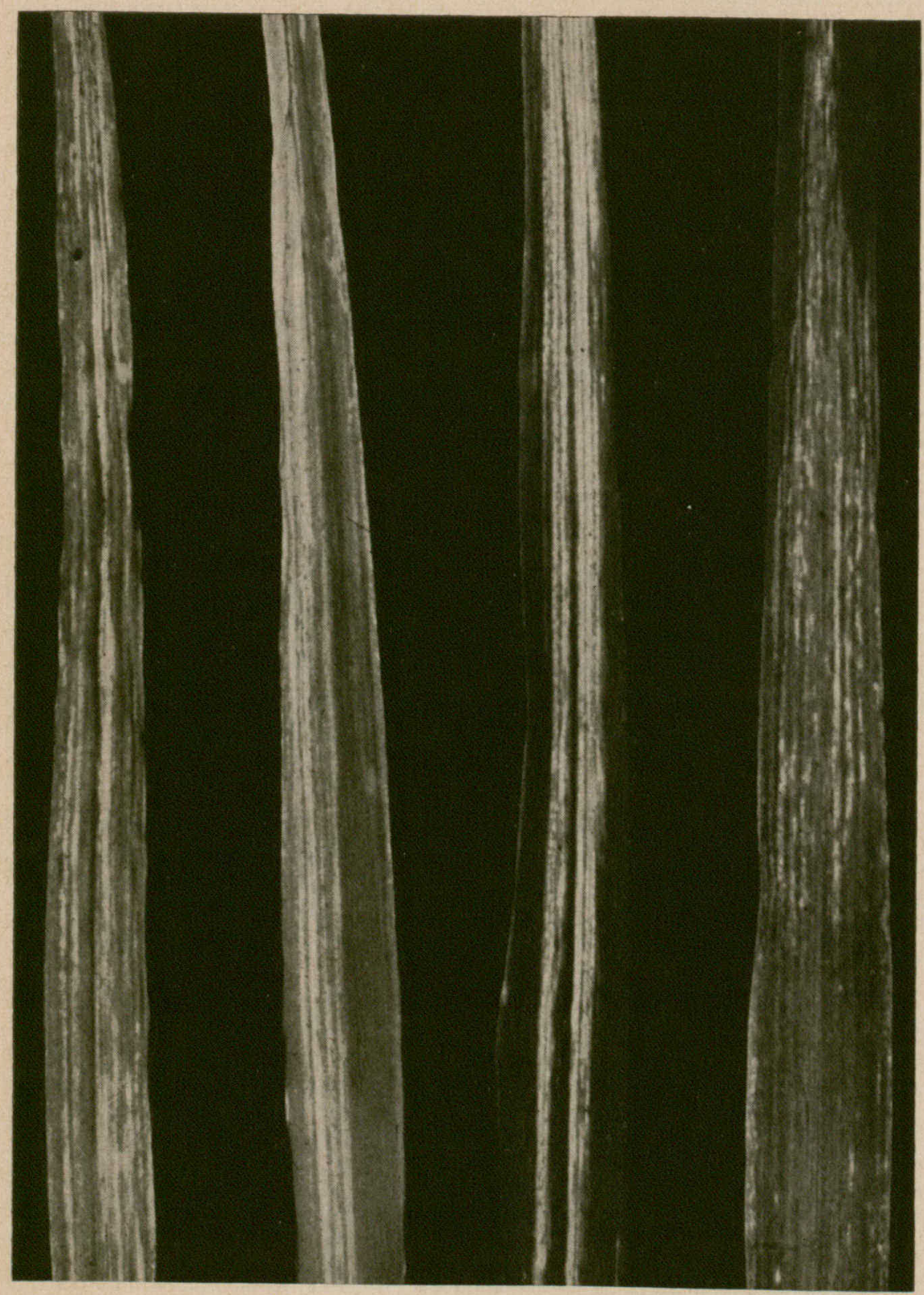

Figure 4.-False stripe of barley; a common disease caused by a virus. 
leaves, are caused by an overabundance of one chemical which tends to render another chemical unavailable. Overabundance of lime tends to 'bind' iron, that is, to hold it chemically in a form that the plant cannot use. This may sometimes be remedied by spraying the affected plants with a solution of iron sulphate. Some soils are deficient in a particular chemical element. Deficiency of manganese causes the gray speck disease of oats (page 53) which can be prevented by drilling manganese sulphate into the soil with the seed.

\section{Importance of Plant Diseases}

The Prairie Provinces of Canada contain an immense area of fertile agricultural land which, chiefly for reasons of climate, is devoted to the growing of a few crops, the most important of which are wheat, barley, and oats. The cereals, particularly wheat and barley, have certain diseases in common. When these crops are grown over and over again on the same land there is a tendency for the diseases that attack them to accumulate. The practice of summerfallowing the land every two or three years, though it retards the build-up of some plant diseases, does not by any means put a stop to it. The importance that plant diseases have assumed in our agricultural economy is clearly shown by the great and growing emphasis that is being placed on the breeding of new cereal varieties resistant to various diseases.

History contains many examples of devastating plant disease epidemics of which the most famous and the most tragic are the late blight epidemics that ravaged the potato crop of Ireland in the forties of the last century with the result that the country lost a million people from starvation and a million and a half from emigration to other countries. These tremendous consequences from a single plant disease arose mainly from the fact that the Irish people had come to depend for their livelihood very largely upon a single crop, the potato, and thereby gave unique opportunities for the development of the late blight disease when it, unfortunately, was introduced into Europe. It is a general rule, which applied then as it does now, that when the growing of a crop is greatly intensified in any region the multiplication of its diseases is still more greatly intensified.

We, in the interior of North America, have made ourselves vulnerable to the diseases of cereal crops by the intensive growing of these crops over the whole of the immense territory stretching from the Gulf of Mexico to northern Alberta. This circumstance provides a favorable opportunity to several plant diseases, especially the rusts. For example, stem rust and leaf 
rust of wheat survive the winter on winter wheat in southern Texas and from there work their way north every summer into the spring wheat region which extends northwards from central Nebraska. In certain years, when the weather favored rust development, such as in 1916, 1927, 1935, and 1954, Western Canada's wheat crop suffered losses averaging about 100 million bushels. So long as this intensive wheat cultivation is continued, losses of this order can be expected periodically unless rust resistant wheat varieties are grown or other means of rust control are found.

\section{Savings from the Use of Control Measures}

In Western Canada, the most spectacular savings from disease control measures have come from the growing of rust-resistant wheat varieties during the period 1939-1949. It is probable that the savings amounted to 40 million bushels a year. Additional savings have come from the production and growing of oat and flax varieties much more resistant to rust than those used in earlier years. These are, however, by no means the only benefits that the farmers of Western Canada have reaped from such measures of plant disease control. Bunt of wheat, which in the absence of seed treatment would cause considerable losses, is now relatively unimportant partly because some wheat varieties are resistant to it but mainly because farmers commonly treat their wheat seed with disinfectants before sowing. Many farmers do not treat their barley and oat seed with disinfectants and consequently the seedling-infecting smuts of these crops still take their toll.

Plant disease control measures enrich our lives more than most people realize. The high-quality apples that we take for granted appear on our tables only because the fruit grower sprays his orchard with a fungicide to control apple scab. The clusters of luscious grapes that we buy in the stores are there only because the grape grower protects them from various diseases by spraying his vines with bordeaux mixture and other plant protectants. The same applies to most of the fruits and vegetables that are shipped to our markets from distant places. Western Canada's grain growers lag behind the more highly specialized fruit and vegetable growers in the application of plant disease control measures; but just as the latter have found it profitable to understand and control their plant diseases so, also, it will pay our farmers to understand their plant diseases and take intelligent measures for their control. 


\section{General Means of Control}

\section{Resistant Varieties}

The ideal means of control of a crop disease is to replace a susceptible variety with one that is resistant to the disease and at the same time good in all other respects. If such a variety is available the grower does not have to resort to such expensive practices as dusting or spraying with fungicides.

The long and arduous task of producing satisfactory disease-resistant varieties is performed largely by institutions supported by public funds. One of the main undertakings of agricultural research organizations is to produce such varieties. The scientists in such institutions must search the world for resistant breeding stocks. With their knowledge of the laws of heredity they are able to combine such resistance with the good qualities of the varieties grown in their own area. An example of control by the use of resistant varieties occurred after the severe cereal rust epidemic of 1935 . Within five years most of the acreage of wheat and oats in Manitoba and eastern Saskatchewan was sown to resistant varieties.

As explained below under the section on stem rust (page 20) resistance is often of only temporary value because of the birth of new races of disease-producing organisms. Nevertheless very valuable and outstanding results have been achieved in the development of varieties resistant to many diseases of cereals and other field crops. In a publication such as this it would not be worth while to list such varieties because frequent revisions would be necessary. To find which varieties are currently most useful, the grower should get in touch with his local agricultural representative.

\section{Condition of Seed}

When the grower has chosen a variety the next consideration is the condition of the seed to be sown. Two things are important: not only should the seed be free from actual seed-borne disease organisms, but it should be as sound as possible, that is, free from cracks and breaks. This is an ideal that can seldom be achieved in commercial seed. Therefore, it is usually advisable to treat the seed with a fungicide. First, let us consider what can be done about soundness and freedom from disease.

Freedom from Disease - Seed-borne disease organisms may occur on the surface of the seed or within the seed. Organisms on the surface of the seed can usually be killed by the ordinary chemical treatments but those present within the seed require a different treatment. For example, it is possible, by steeping infected seed in hot water, to destroy the internally borne organism without injury to the seed. Treatments for internally borne seed infections are more difficult to apply than those for surface-borne 
organisms, and for this reason, it is sometimes preferable to produce disease-free seed rather than to rely on seed treatment. With peas and beans this practice has been followed successfully by canning firms for many years. By importing seed grown in irrigated areas of low summer rainfall, much of the seed-borne infection by bacterial and fungal diseases can be avoided. A modification of the same idea has been adopted in the production of barley seed free of loose smut. Under the direction of the Plant Pathology Laboratory, Saskatoon, the commercial production of loose-smut-free barley seed has been undertaken by the Kelvington Seed Growers' Association.

Seed infested internally is often reduced in size and weight. Therefore it is good practice to remove shrunken seed by careful cleaning.

The idea of freedom from disease is applicable to some extent also to diseases borne on the surface of the seed. Some seed-testing laboratories maintained by grain elevator companies will, free of charge, test seed samples for the presence of surface-borne spores of smut and seedling blights. A few laboratories will make similar tests for a fee. Treatment should not be neglected unless the seed has been properly tested and found satisfactory.

Soundness-Soundness of the seed is very important in flax, but it is also important in other crops. Cracks and other fractures are most severe in seeds that have been threshed under very dry conditions. These fractures serve as points of entry for soil-borne microorganisms after the seed is sown. The blistering of seed by frost may have the same effect.

The harmful effects of fractures can be largely offset by appropriate seed treatment before sowing, but if there is a choice between sound and unsound seed, the choice should, of course, be made in favor of the sound seed. Fracturing of the seed can be reduced by care in adjusting the threshing equipment.

\section{Seed Treatment}

Water Soaks-Most of the seed on farms on the prairies requires treatment of some kind before it is sown. For diseases that are borne internally, two general methods have been used successfully, short soaks in hot water and long soaks in cool water. Both of these methods require care and exactness for satisfactory results. The operator should not attempt either of them without first acquainting himself thoroughly with all details of the procedure. These details are given in special leaflets available from the Canada Department of Agriculture. (See also pages 41-42.)

Chemicals-Seed treatment with chemicals is desirable for much of the seed sown in the Prairie Provinces. All types of crop plants are subject to diseases that may be controlled by seed treatments. This method of control is twofold in action. It acts first against the disease organisms on the surface of the seed and, secondly, against the entry of harmful microorganisms into fractured seed. 
Recommendations approved on February 15, 1955, by the Associate Committee on Plant Diseases of the National Research Council and the Canada Department of Agriculture are as follows:

1. All wheat seed should be treated with an appropriate fungicide before sowing unless it is sound, healthy and free from surface-borne smut.

2. Growers may wish to have their wheat seed samples tested for germination and smut. If the examining service reports that a sample possesses high germination $(90 \%)$ and freedom from smut spores, the seed may be sown without treatment. However, freedom from smut alone does not imply that seed treatment may not be of value.

3. All seed of oats, barley and flax should be treated with a suitable fungicide.

4. In the treatment of wheat, oats, barley and flax, growers should ensure that the seed is properly cleaned before treatment, that the fungicide is carefully applied to secure thorough coverage of the seed and that the directions supplied by the manufacturer are precisely followed.

In view of the large number of chemicals now available for seed treatment, a farmer's choice may depend on the disease he wishes to control or it may depend on whether he prefers to apply the chemical in the form of liquid, slurry or dust. Chemicals in which the active ingredient is organic mercury are obtainable in the form of liquid, such as Panogen 15, or as powder, such as Ceresan $M$ which can be used dry or as a slurry. These chemicals will control surface-borne smut of wheat, oats and barley and seedling blight and seed rot of the same crops as well as flax. The same type of chemical with lindane or aldrin added will, in addition, give protection against wireworm injury.

Products such as Anticarie SD and Bunt-no-more which contain hexachlorobenzene, or Tritisan $\mathrm{C}$, which contains pentachloronitrobenzene, will control bunt of wheat but not the other diseases mentioned above. Compounds such as Spergon SL, containing chloranil and obtainable as dusts or slurry, will control wheat bunt and seedling blight of oats and barley. Captan, as dust or slurry, controls seedling blight and seed rot of wheat, oats, barley and flax. Formaldehyde, a liquid, controls surface-borne smut of wheat, oats and barley but has the disadvantage of reducing germination, particularly in wheat. New products for seed treatment are constantly being developed. The Pest Control Products Act, administered by the Plant Products Division, Canada Department of Agriculture, gives assurance that any products on sale in Canada are suitable for the purposes for which they are sold. For further information on seed treatment consult Publication 834, Treatment of Cereal Seed, Canada Department of Agriculture. 


\section{Crop Rotation and Sanitation}

Plant sanitation or plant hygiene is a well-recognized means of control for diseases of orchard crops, but it is not very well known in relation to field crops because in most of them the crop is renewed each year and the spread of diseases from the old dead plants to the new crop is less easily noticed. The practice of burning alfalfa stubble in seed fields before growth starts in the spring is a good illustration of control through sanitation. Most of the fungi causing leaf and stem diseases of this crop overwinter on dead foliage, and removing such material reduces early spring infection of the new growth. Even in cereal crops special conditions may result in such a rank growth that other methods of disposal become very difficult and burning may be necessary. Destruction of plant debris by burning or by covering it by means of deep plowing tends to limit the build-up of disease but these measures are not always advisable from the point of view of soil conservation. The straw-cutter will permit disposal of the straw of most cereal crops, but recommendations for the maintenance of a trash cover, which are highly commendable in the control of soil drifting, pose a problem in the control of plant diseases. Perhaps the most effective answer to the danger from a trash cover is found in crop rotation. It provides for the destruction by natural means of the sources of infection in the remains of the old crop. When there is more than a year between plantings of the same kind of crop, there is time for the diseased stubble to decompose and the disease organisms to be destroyed by other microorganisms or by antibiotics produced by them.

If crop rotation is not practiced with a crop such as barley, the bad effects are quickly evident. Leaf-spotting and root-rotting diseases overwinter readily on the old stubble, especially if it is not plowed under. If barley is sown a second year the leaf-spotting diseases may produce serious losses in yield.

Fortunately most farmers are fully aware of the advantages of crop rotations. The one most suited to a particular district can be ascertained on request from the local agricultural representative.

\section{Dusting and Spraying}

The use of fungicides plays a prominent part in the control of many kinds of plant diseases, especially where the value per acre of the crop plant is high. Even with the cereal crops noteworthy control of rusts was obtained several years ago in extensive experiments with sulphur dust. Such control proved useful for increasing yields of seed stocks and other valuable crops but was too costly for widespread use by farmers. Another drawback to 
the use of sulphur was that it required frequent applications, especially in rainy weather. Although some newer chemicals that may be applied in spray form give control at least equal to that of sulphur and at a lower cost, control of the cereal rusts with any of the chemicals now available is still too expensive to be used on a large scale. As the development of new fungicides continues, rust control with chemicals will probably become cheaper and more effective. 


\section{Diseases of Wheat}

\section{Stem Rust \\ Puccinia graminis var. tritici}

Stem rust is the most destructive of the diseases of cereals that occur in the Prairie Provinces. It attacks not only wheat but also barley, oats, rye, and certain grasses. The rust on the different cereals looks much alike but differs in its ability to attack different crops. Stem rust of wheat attacks wheat, barley and wild barley but does not attack oats or rye. Stem rust of rye attacks rye, barley, wild barley and couch grass but not wheat or oats. The rust on oats attacks not only oats but also wild oats and meadow fescue though not wheat, barley, or rye.

This tendency to break up into units that differ parasitically is carried to extraordinary lengths in stem rust. Not only is wheat stem rust parasitically different from oat stem rust, but within the stem rust that attacks wheat there are a great many parasitically distinct strains (races) that can be distinguished from one another by their ability or inability to attack various wheat varieties. This characteristic of the rust is economically important because there is a strong tendency for the races that can attack a given wheat variety to increase from year to year where that variety is widely grown. Thus race 56 , which could attack Ceres, increased so greatly in the years 1930 to 1935 that farmers in the Red River Valley abandoned its cultivation. The durum wheats provide another example. They were rust resistant before the advent of race 15B, in 1950. From 1950 onwards, this race, which could attack them heavily, increased to such an extent that the durum wheats became even more rust susceptible than the bread wheats. The change did not take place in the wheats but rather in the rusts that attacked them.

Appearance-During summer, stem rust is recognizable by brick-red eruptions (pustules) on both leaves and stems, but particularly on the latter (Fig. 5). These pustules are made up of masses of spores that have ruptured the surface of the plant. This is the red or summer stage of the rust. Each pustule contains hundreds of thousands of spores each of which may infect a plant to produce a new rust pustule in about a week or 10 days. As the wheat plants ripen, the rust pustules darken until they are almost black. This change in appearance is due to the formation of thick-walled, dark-brown spores designed to resist the severest winter. This is the black or winter stage of the rust which is responsible for the name "black stem rust." The two stages are, however, not two distinct kinds of rust but are merely two phases of the same rust. 
WHEAT

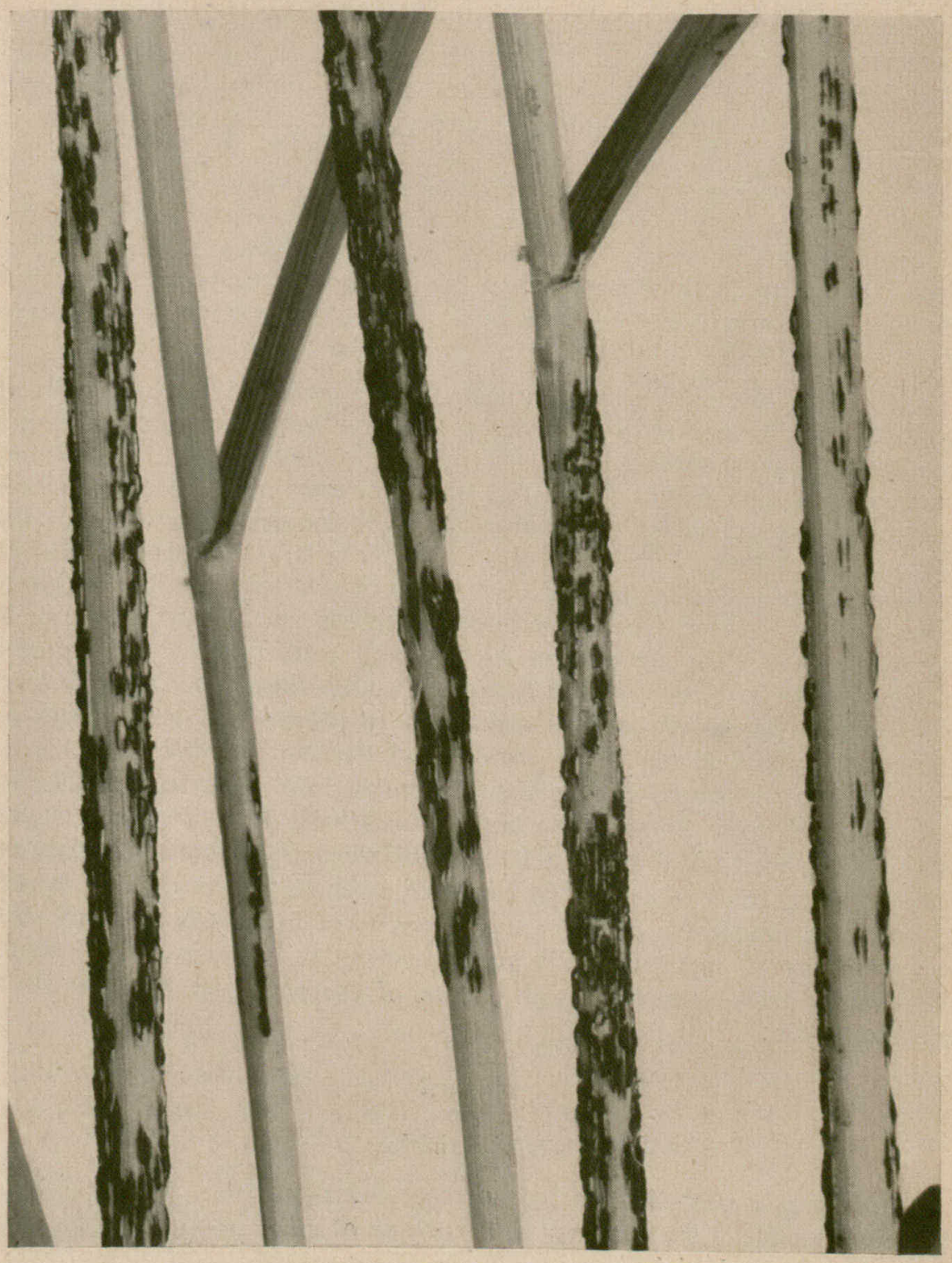

Figure 5.-Stem rust of wheat; the red or summer stage of the rust. 
Disease Cycle-The black spores survive the winter and germinate in the spring, each spore producing four or sometimes eight smaller spores known as sporidia. These sporidia cannot infect wheat or any other plant except various species of barberry, of which the most important is the common barberry. The rust thus produced on the barberry cannot reinfect barberry but infects wheat, giving rise to the red, summer stage of the rust. The barberry is important for two reasons. First, it spreads the rust to grain and grasses in early summer. Secondly, while the rust is on the barberry the various races of it can interbreed to produce new races. In North America, a factor of importance is the capability of the red or summer stage of the rust to survive the winter in southern Texas and Mexico. Our stem-rust epidemics come mostly from this source by wind-borne spores and, therefore, barberry is not essential to the survival of the rust from year to year in Canada.

Control-The chief control measure is the growing of stem-rust-resistant varieties. In this and other countries where stem rust is important there are continuing plant breeding programs for the production of rust-resistant varieties. Experience has shown that such varieties cannot be depended on to remain resistant indefinitely because of the development of new rust strains that can attack them. Therefore, the varieties grown are changed from time to time. Information on the best varieties to grow in any district at a given time can be obtained from experimental stations and district agricultural representatives. The destruction of barberry bushes is another control measure. The barberry is not a native plant but was introduced from Europe and became widespread in the eastern United States and some parts of Eastern Canada. It was never grown much in the Prairie Provinces. A great barberry eradication campaign, began in 1918, has resulted in the destruction of most barberry bushes in the Mississippi Valley states and Western Canada. A third possible control measure is the application to growing grain fields of protective chemicals such as sulphur. This is not at present a practicable control measure for most farmers because of cost and problems of application. A partial control measure is early sowing. Grain sown early stands a better chance of escaping rust infection than late-sown grain.

\section{Leaf Rust}

\section{Puccinia triticina}

Leaf rust is probably the second most destructive disease of wheat in Western Canada. Like stem rust it is made up of many parasitically distinct strains known as physiologic races. Some wheat varieties, such as Thatcher, are susceptible to nearly all the North American races of this rust. Other varieties, such as Regent and Redman, are resistant to some races but susceptible to others. At first a variety may be classed as resistant, but as 
it becomes more widely grown those races that can attack it tend to become more prevalent year by year until that variety has to be regarded as susceptible.

Appearance-Leaf rust is largely confined to the leaves of the wheat plant but occurs also to a lesser extent on the stem area just below each leaf. The rust pustules are much smaller than those of stem rust, nearly round, yellowish-red, and may be so closely spaced on heavily rusted plants as to give the leaves an orange-red appearance (Fig. 6). As the plants ripen, the rust pustules darken until they become black. As in stem rust, the dark color is due to the formation of thick-walled, dark-brown winter spores. These can survive our winter whereas the red or summer stage survives the winter only in areas in which winter wheat is grown and then only to a slight extent, except in the southern states.

Life History-The black spores live through the winter and germinate in spring, each spore producing four or eight smaller spores called sporidia. These sporidia cannot infect wheat. They can, however, infect certain other plants, particularly certain kinds of meadow rue (Thalictrum spp.) that occur in Europe and Asia. The rust on meadow rue can infect wheat and produce on it the red, summer stage. The kinds of meadow rue that are native to America are so highly resistant that they are not a factor in the spread of the rust. The persistence of the rust from year to year, in America, is due to the overwintering of the red or summer stage in the southern United States and Mexico.

Control-The chief control measure is the growing of resistant varieties. It is not easy to breed varieties resistant to all stem-rust races and all leaf-rust races. The well-known variety Thatcher, which was resistant to stem-rust races for many years, was never resistant to leaf rust. The value of leaf-rust resistance was clearly shown in 1954 when the variety Lee, which was resistant to leaf rust but susceptible to stem rust, greatly outyielded Thatcher which was susceptible to both rusts.

\section{Bunt}

\section{Tilletia caries and Tilletia foetida}

Bunt of wheat is caused by two closely related smut organisms but, because the development of the disease, its appearance, and control methods are alike in each case, no distinction between the organisms will be made. A third kind of bunt, called "dwarf bunt" is now known to occur in British Columbia and Ontario on winter wheat.

Bunt occurs wherever wheat is grown, and before effective control methods were discovered it was a very serious disease in some wheat-producing countries. With the use of modern seed disinfectants, bunt of wheat has been practically eliminated in the Prairie Provinces except on farms where the control of this disease is neglected and in the winter-wheat 


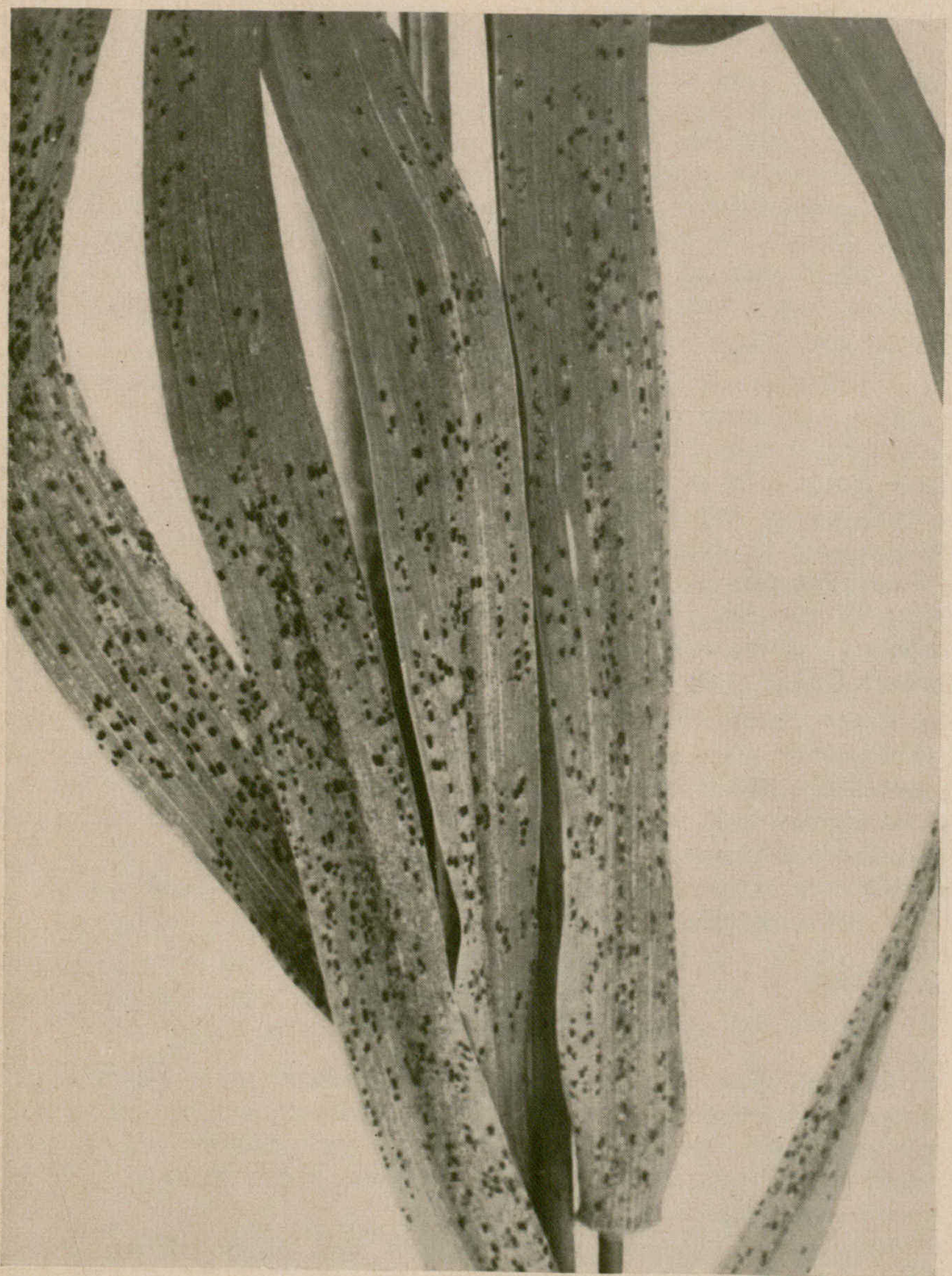

Figure 6.-Leaf rust of wheat; the red or summer stage of the rust.

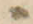


area of southern Alberta where soil-borne smut spores may reproduce the disease. Although in recent years the losses caused by bunt of wheat have been very low, they still amount to many thousands of dollars annually. A high proportion of this loss is due to discounts on smutty wheat.

The fungi causing bunt of wheat are each composed of several races which are indistinguishable in their appearance but differ in their ability to attack different varieties of wheat and may also differ in the presence or absence of the characteristic bunt odor.

Appearance-Smutted heads of wheat are usually bluish green in appearance and remain green longer than healthy heads. Awns may fail to develop, or may fall off as the smutted heads ripen. Sometimes all the heads of a plant are affected and at other times only one or two. The heads themselves may be partially smutted, both normal grains and bunt balls occurring in the same head. Bunt balls resemble wheat kernels but they are at first bluish green, then change to various shades of brown as they reach maturity.

Disease Cycle-Bunt balls, each of which may contain up to nine million spores, are broken during the threshing operation and the spores thus set free adhere to the surface of sound grain. Smut spores may be carried by air currents to nearby fields that would otherwise be free from smut. When smutted seed is planted the spores germinate simultaneously with the seed and their tiny germ tubes penetrate the young seedling. Once inside, the smut fungus develops together with the growing point of the host plant until the head begins to form. Within the young head the fungus threads branch profusely and replace the tissues of the young wheat kernels, except the outer skin. These threads inside infected kernels change into spores and thus produce bunt balls.

Control-Modern seed disinfectants, if properly applied to the seed, give good control of bunt. Disinfectants containing organic mercury are generally superior to other kinds because they control other seed-borne diseases as well and also provide some protection to the young seedling in the soil. For the control of bunt alone, however, some seed disinfectants not containing mercury are quite efficient and less toxic to animals and man. The most important thing is to use the right amount of disinfectant and distribute it evenly throughout the seed so that each kernel is thoroughly covered. Treated seed should be left for at least one day before seeding.

For further information see Publication 887, Smut Diseases of Cultivated Plants in Canada, Canada Department of Agriculture.

\section{Loose Smut}

\section{Ustilago tritici}

Loose smut of wheat (Fig. 7) is almost identical in appearance with loose smut of barley and the causal organisms of these two diseases are very closely related. Since loose smut is more prevalent in barley than in wheat 


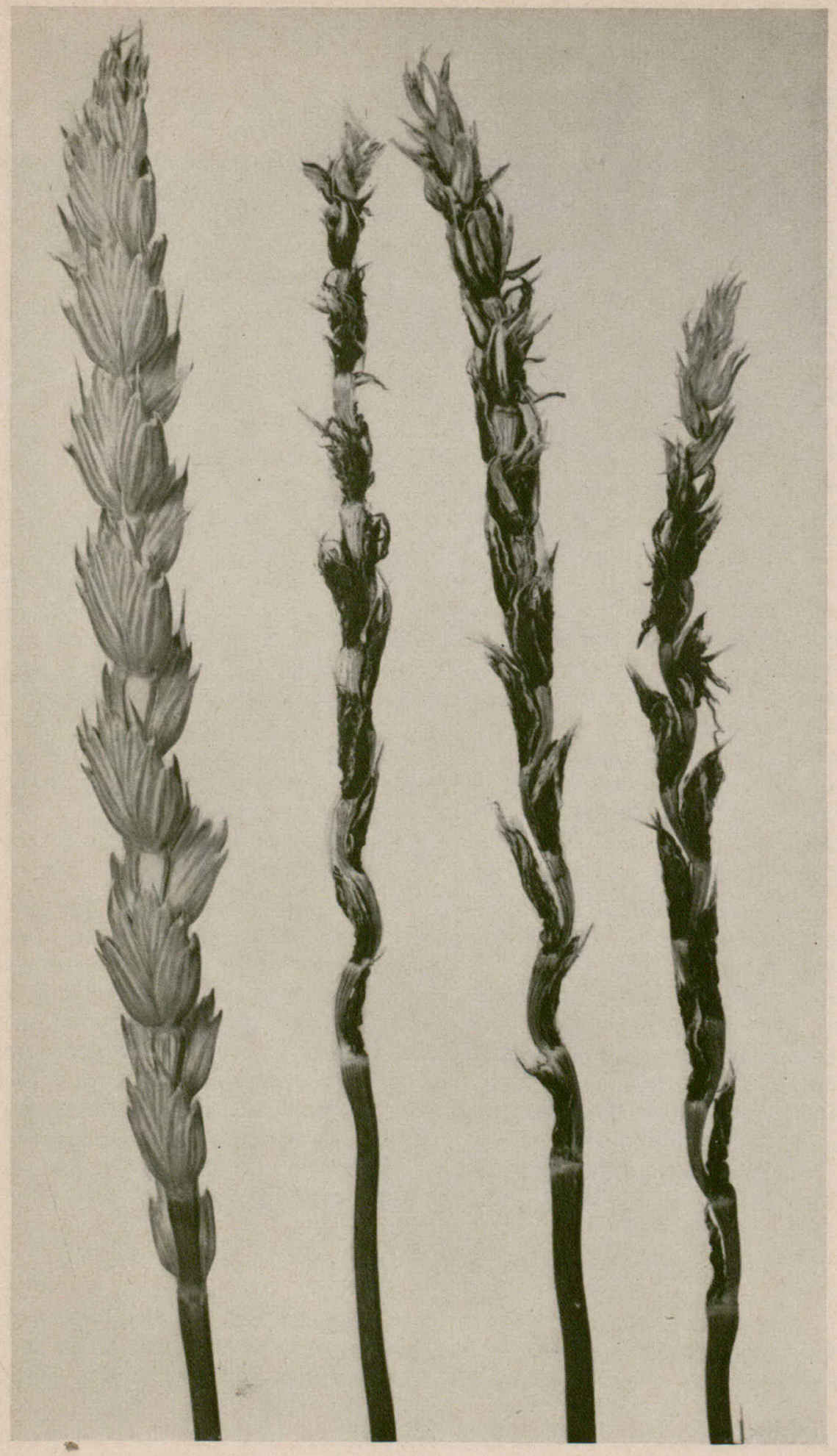

Figure 7.-Loose smut of wheat. 
in the Prairie Provinces, it is dealt with in detail under "Diseases of Barley" (see p. 40). The hot-water treatment is recommended for the control of this disease, and the method of applying it is the same as in barley, except that the temperature of the water bath is maintained at $129^{\circ} \mathrm{F}$. instead of $126^{\circ} \mathrm{F}$.

Schedules for the application of the water-soak and the dip-and-pile treatments for loose smut of wheat have not yet been standardized and, therefore, cannot be definitely recommended for wheat.

Most of the varieties of wheat in common use are moderately resistant to loose smut, but Lee is susceptible.

\section{Common Root Rot}

\section{Helminthosporium sativum and Fusarium spp.}

Common root rot is very prevalent in wheat and it also affects other cereals and some grasses. It is particularly injurious to wheat in hot, dry seasons but causes little damage when moisture is plentiful.

Appearance-Early infections may be seen in the seedling stage as small brown spots or blotches at the base of the plant. As the crop approaches maturity, diseased plants are frequently noticeable because most of their leaves, especially the lower ones, are brown and dead. Such plants may be found in patches scattered through a field. When pulled up and examined they show rotted crown roots and discolored areas above and below the crown. If the crown is cut through with a sharp knife the internal tissues appear discolored. In healthy plants the internal crown tissues are white.

The most conspicuous form of root rot is the so-called pre-maturity blight. Bleached, blighted plants with rotted crowns appear here and there in the crop before maturity when they are very noticeable.

Disease Cycle-Wheat plants may become infected at any time during the season. Most root rot fungi can attack any part of the plant but the invasion of the crown and crown roots is the most injurious. These fungi produce spores in abundance on invaded tissues as the plant reaches maturity. Spore production continues in the fall and spring on the stubble of diseased plants. Therefore, a field in which there was even a slight amount of root rot may have on its surface a considerable sprinkling of spores. The spores and plant fragments bearing the fungi, which are spread about by wind, rain, and surface water, are sources of new infections in the spring and early summer.

Control-The following recommendations should help to reduce the occurrence of common root rot:

1. Spring plowing to turn down the stubble and contaminated surface soil followed immediately by seeding.

2. Rotation of cereal crops with noncereal crops such as flax, rape, or legumes. 
3. Rotation of wheat or barley with oats, which are less subject to root rot.

Seed treatments are generally of little value for the control of common root rot; however, if seed containing black-point or smudged kernels must be used, it should be treated with a mercury dust or liquid fungicide recommended for smut control.

\section{Take-All Root Rot}

\section{Ophiobolus graminis}

Take-all occurs chiefly in the park land areas of the Black soil zones and infection there is often severe. It may be troublesome if wheat follows wheat for several years and it commonly appears in wheat crops after the breaking of native or cultivated sod land. Losses of twenty or thirty per cent in some fields have been observed. In a few cases the damage has been much greater.

Appearance-Take-all is a conspicuous disease and affected plants are easily recognized. Diseased plants are bleached, stunted, and easily pulled from the soil because of the rotted roots (Fig. 8). The rotted tissues at the base of the plant are shiny black. Sometimes the head does not fill, or bears only shrunken kernels. Patches of affected plants are very conspicuous.

Take-all may be confused with prematurity blight mentioned under common root rot but it can usually be distinguished by the shiny black appearance of the invaded tissues.

Disease Cycle-The stubble left after diseased plants are harvested is the main source of infection. The fungus completes its development on the stubble during the fall and spring and spores are released in time to infect the new crop. The disease develops in all the tissues at the base of the plant, usually causing death well before maturity.

Control-As a rule take-all can be controlled by growing a resistant crop such as oats or by keeping the land fallow for a year. The maintenance of soil fertility is also helpful.

\section{Browning Root Rot \\ Pythium spp.}

Browning root rot is primarily a disease of wheat and most commonly occurs in the crop following summerfallow. It can cause yield reductions up to ten bushels per acre. Diseased crops are delayed in ripening commonly to the extent of one week and frequently for two weeks.

Appearance-Browning is conspicuous only in the seedling stage, usually in June. At this time, the lower leaves turn brown and die. Large affected areas in the field are very noticeable and in some cases the entire 
WHEAT

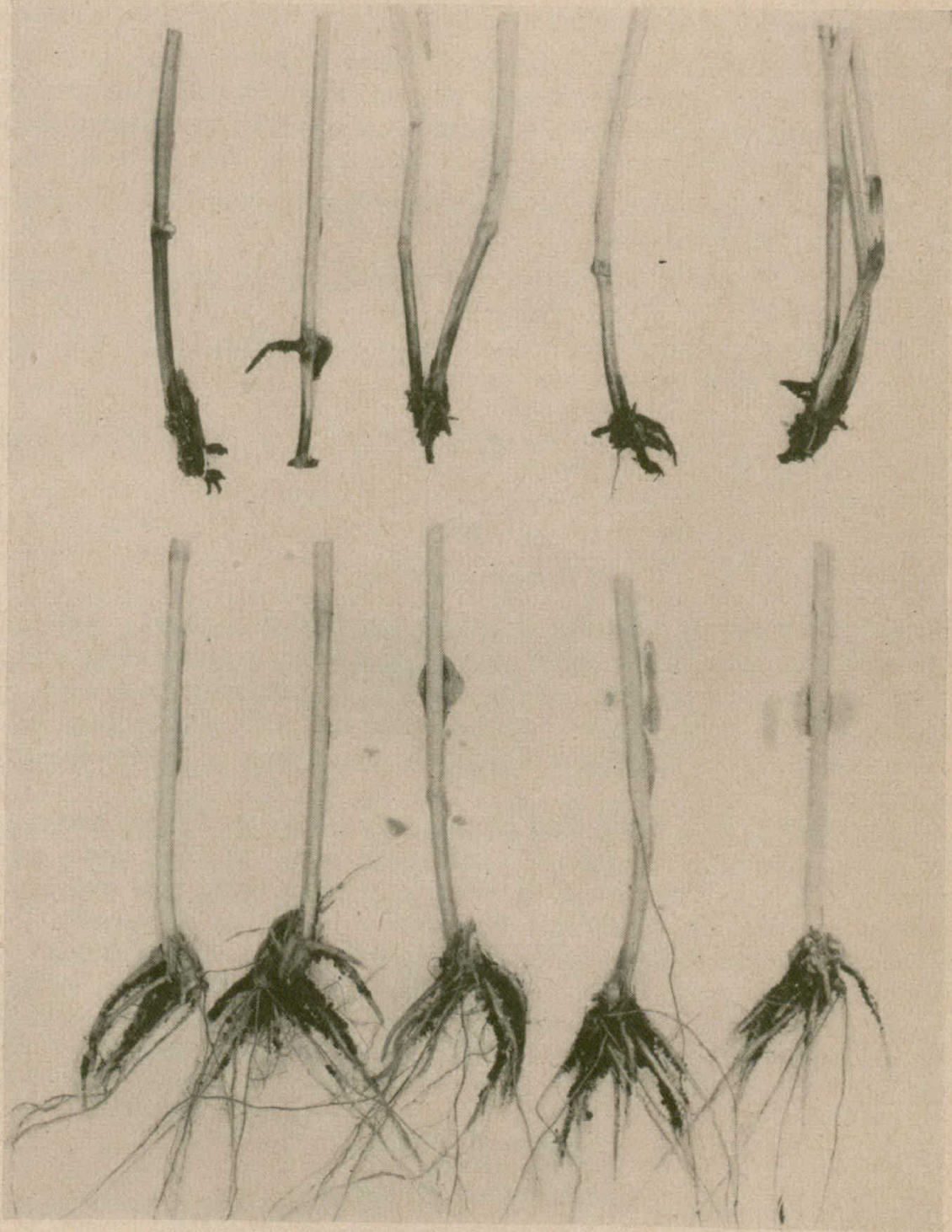

Figure 8.-Upper row: basal parts of wheat stems affected by Take-all root rot. Lower row: roots of healthy plants. 
crop appears to be dying. The plants are greatly retarded and fail to compete successfully with weeds. There are no distinct discolorations at the base of the stem. The infection is entirely in the root system and is difficult to see unless the roots are washed.

Disease Cycle-The fungi causing browning root rot remain in the soil indefinitely. They develop well only when moisture is adequate through spring and early summer. Roots of plants growing under conditions of poor fertility are readily invaded and seriously damaged.

Control-Investigations have shown that browning root rot occurs when soil nutrients are unbalanced.

1. Use phosphate fertilizer as recommended for the district concerned.

2. Sow seed in a firm seedbed.

3. Follow practices that increase the organic matter in the soil, such as working in straw and manure.

4. Avoid burning the stubble.

5. Sow a resistant variety where available. Thatcher shows some resistance.

\section{Ergot}

\section{Claviceps purpurea}

Ergot is a disease occurring on a wide range of crop plants. Although it is most important on rye and a number of grasses, it also attacks wheat, barley and occasionally oats. As a result of its capability to develop on cereal crops and many grasses, both cultivated and wild, and because ergot bodies are poisonous to man and animals, this disease is of considerable importance.

Since wheat is a staple food of man, even a trace of ergot bodies in the grain constitutes a hazard. Although ergot seldom causes any appreciable loss in wheat yield, in some years ergot bodies are sufficiently common in wheat in the Prairie Provinces to cause an appreciable loss through degrading. Ergot bodies or fragments of them are difficult to remove from the grain. It is, therefore, important that all farmers be well acquainted with this disease and make every possible effort to control it. For description of the disease and its control see under diseases of rye, page 57 .

\section{Bacterial Blights}

\section{Xanthomonas translucens \\ Pseudomonas atrofaciens}

The two bacterial diseases of wheat caused by Xanthomonas translucens and Pseudomonas atrofaciens may destroy a considerable proportion of the leaves and leaf sheaths, but their cause may not be recognized because the browned tissues are thought to be dying of old age 
or the result of a vague something called "poor growing conditions." As a rule, neither of these diseases is severe over large areas, although local outbreaks may be intense. The severity of attack is closely related to the amount of wet weather.

Appearance-Both of these diseases give rise to light-brown dead areas on the leaves. Often the dead areas appear near the leaf tips with long streaks extending from them. The proportion of the leaf or leaf-sheath attacked may vary from a small spot to the whole of the plant part concerned. At first the spots are dark green and water-soaked, later a golden brown. When they are viewed against a bright sky, light areas can be seen in the spots. These are caused by masses of bacteria in the leaf tissues. The spots may fade to light brown after a rainy spell.

The two diseases are very similar on the leaves and sheaths, but as a rule quite different on the heads. One of them, bacterial black chaff, appears as dark stripes on the glumes (Color Fig. 5). These stripes often fuse, turning the whole glume black. The other disease produces two distinct symptoms: a light brown spot at the base of the spikelet, hence its one name, basal glume rot, and a black spot at the base of the kernel which accounts for its second name, bacterial black tip. A bacterial exudate is seldom associated with these diseases under field conditions.

Disease Cycle-The bacteria enter the wheat plant through the breathing pores and water pores or through wounds. Once infection is established, the bacteria multiply rapidly and during rains or dews pass out into droplets on the surface of the plants. Insects may spread the bacteria and make wounds for their entry. The splashing of rain drops probably is important in the local spread of infection.

Although the bacteria can overwinter in and on seed, few infections develop from this source. Experimental evidence suggests that overwintering on crop remains may be more important and that perennial grasses are also a source of infection in the spring.

Control-The chief means of control is the growing of resistant varieties. Resistance to bacterial diseases is one basis of selection in the program of producing new rust-resistant varieties of wheat. Such varieties can be expected to possess sufficient resistance to bacterial diseases for satisfactory farm use. General sanitation measures such as crop rotation help to check the disease.

\section{Head Discolorations}

Xanthomonas translucens, Pseudomonas atrofaciens, Helminthosporium sativum, Alternaria tenuis, Septoria nodorum, Puccinia graminis, Stripe mosaic virus, Weather Conditions

The heads, necks and stems of wheat may turn brown to black from a variety of causes when the plants are approaching maturity. The browning is due to the development of an insoluble, dark-brown pigment known as 
melanin. This pigment is formed when certain chemicals found in the plant tissues combine with oxygen. The invasion of several different kinds of disease organisms can bring about this change in color. Weather conditions play an important part in the expression of the disease and there is experimental evidence in greenhouse work that high light intensity alone or high temperature in conjunction with high humidity can cause dark discolorations on the heads, necks and stems of certain varieties. When the discoloration occurs in the late stages of maturation of the tissues, little harm, if any, is done to the kernels. If, on the other hand, it is the consequence of a general attack on the plant, as in bacterial black chaff, it is an indication of the presence of a disease that can cause appreciable losses.

Appearance-Head discolorations vary so much in appearance that a thorough description of all types would be too extensive for the purpose of this publication. Because they are an expression of the reaction of the wheat plant to diseases either alone or in combination, it is sometimes difficult even for a person with long experience to decide which disease or combination of diseases is present.

When present alone four of them can be identified fairly readily: bacterial black chaff, basal glume rot, glume blotch and alternaria blotch; but exceptions have been found where an attack of one resembled that of another. One instance is known where an attack of basal glume rot appeared identical with bacterial black chaff.

Dark purplish discolorations are different in nature. They develop when there is a lack of phosphate in the soil.

Control-The most satisfactory means of control for head discoloration diseases is the use of resistant varieties. The wheat varieties produced in the breeding program for rust resistance are all subjected to tests for resistance to head discoloration diseases and this characteristic is used as one basis of selection.

\section{Wheat Streak Mosaic}

\section{Virus}

Wheat streak mosaic was first recognized in Nebraska and Kansas in 1932. It has since been found in other areas where winter wheat is grown in the great plains region and in the west coast states. Since 1952 it has been recognized in areas of southern Alberta and southwestern Saskatchewan where winter wheat is grown regularly. This disease can cause severe reductions in yield and even complete failure of a wheat crop when local conditions favor it.

The wheat streak mosaic virus can be detected only by the symptoms it causes on infected plants. It cannot survive in ripe seed, mature or dead plants, or in the soil, and it is perpetuated in susceptible living plants, 
principally in wheat. It is carried from plant to plant by a white, four-legged wormlike mite, Aceria tulipae, that is only $1 / 100$ inch long and therefore scarcely visible except with a strong magnifying glass or microscope.

Wheat streak mosaic is primarily a problem of winter wheat, but any variety of spring wheat may also become diseased if grown near diseased winter wheat. Barley may also suffer slight damage from mosaic if grown adjacent to diseased wheat. Although a number of cultivated and wild grasses can be infected with the virus under special conditions, none is seriously affected by it, and none appears important in perpetuating the disease in southern Alberta.

Appearance-The earliest symptoms of wheat streak mosaic are light-green to yellow dashes and streaks in the younger leaves of the plant. The yellowing may increase until there are only islands of green, or no green, left in the leaf, and it dies. Diseased plants are stunted to varying degrees depending on the time of infection, growing conditions, and other factors. Some plants die before heading. Others head and produce low-grade grain. The stunted plants are the most obvious indication of wheat streak mosaic when the crop is nearing maturity. If the proportion of diseased plants is small, these stunted plants will be intermingled with plants of normal or near normal height. In severely diseased crops all plants will be stunted to varying degrees, giving the stand a ragged appearance.

Disease Cycle-The virus which causes wheat streak mosaic, and the mites which transmit the virus are dependent on living plants at all times of the year. Winter wheat that becomes infested in the fall carries the virus and the mites over winter. The mites multiply rapidly on diseased wheat during the spring, summer, and fall seasons when the weather is warm. The mites are wingless and so cannot fly, but they can be blown by the wind and can thus carry the virus to other plants. Spring wheat can thereby become diseased when grown near winter wheat. Volunteer wheat can also become diseased and help carry the virus and mites during the summer and fall. Winter wheat that is sown early in the fall may become infected from any immature wheat growing in the same or nearby fields.

Control-Since both the virus and the mites which transmit it need susceptible living plants to survive and multiply, the disease can be controlled by keeping the land free from all disease-carrying plants for a week or more before wheat is sown in the same or adjacent fields. Winter wheat should not be sown beside spring wheat until the latter is dead ripe. There is much greater danger of mosaic infection in early- than in late-sown winter wheat. The recommended time for seeding winter wheat in southern Alberta is between September 1 and 15 .

Spring wheat should not be planted adjacent to winter wheat that is diseased. Volunteer winter wheat should be destroyed before spring wheat is planted on the same land. If a winter wheat crop is so severely diseased 
with mosaic that it must be destroyed in the spring, it is not safe to reseed spring wheat on the same land until all the diseased winter wheat has been destroyed. It is safer to reseed the field to oats, flax or barley.

No resistant varieties of wheat or suitable chemical treatments are as yet available.

\section{Powdery Mildew \\ Erysiphe graminis tritici}

Powdery mildew is a recurrent disease in Western Canada on wheat, barley and a number of grasses. It occurs mainly during dry, cool seasons and may cause considerable damage under favorable conditions. Although local infections may be observed almost every year, only occasionally do general epidemics develop in the Prairie Provinces.

Powdery mildew of wheat, barley and grasses looks alike but, like rust and smut, it is parasitically specialized to individual or closely related groups of plants. Powdery mildew of wheat does not attack barley or oats, while that of barley does not attack wheat or oats. Moreover, in each of these specialized parasitic kinds of powdery mildew, there are a number of races which can be distinguished from one another only by their capability or incapability to attack different varieties of the host crop.

Appearance-At first the disease may be observed as small grayish-white spots on wheat leaves. These spots resemble very small heaps of white powder on the leaves. The spots increase in number and size until the whole leaf and sheath area is covered with a whitish, powdery mass. The infected plants are stunted and their leaves eventually wither and shrivel up. When infection is heavy, wheat plants may fail to head out. The whitish, powdery spots or areas eventually become spotted with minute black dots which are the sexual fruiting bodies of the fungus.

Disease Cycle-Powdery mildew survives the winter either as the black fruiting bodies or as grayish mats of mycelium on the remains of the infected plants. In the spring the spores produced either in the fruiting bodies or on the mats of mycelium are carried by air currents and when deposited on growing wheat plants they cause infections which develop a new crop of whitish, powdery spots. Unlike spores of many other fungi the spores of powdery mildew may germinate in dry air and, therefore, plant infection and spread of the disease are not dependent on dews and rains. In fact; frequent rains hinder the development of powdery mildew.

Control-Powdery mildew may be controlled by growing resistant varieties and by sulphur dusting. Of varieties in common cultivation at the time of writing, Thatcher is rather susceptible to mildew, while Lee and Selkirk appear to be moderately resistant. Epidemics of this disease, however, are infrequent in the Prairie Provinces and dusting is expensive. Consequently it is only worth while to dust greenhouse crops and particularly valuable seed plots. 


\section{Speckled Leaf Disease}

\section{Septoria avenae f. sp. triticea}

This disease is common on wheat leaves in Manitoba and eastern Saskatchewan. The first signs of the disease are oval or elongated, buff-colored blotches on the leaves (Color Fig. 7). These symptoms appear when the growth of the plant is well advanced. Very small, black dots, the fruiting structures of the fungus, soon appear in the centers of these blotches. In wet weather, these dots discharge large numbers of spores which spread over the leaves and cause new infections at such a rapid rate that the leaves soon become uniformly covered with the black, dotlike fruiting structures, so small that they are not readily seen with the naked eye. As this final phase of the disease does not occur until the plants are beginning to ripen, the effect of the disease is chiefly to hasten the death of the leaves. Therefore the disease, though very widespread, is not highly destructive. The fungus survives the winter on the dead leaves and stems of the wheat plant. Crop rotation and deep plowing to bury crop remains are measures that retard the development of the disease. No wheat varieties that show any appreciable resistance are available. 


\title{
Diseases of Barley
}

\author{
Stem Rust \\ Puccinia graminis var. tritici \\ Puccinia graminis var. secalis
}

Barley is attacked by two distinct kinds of stem rust, wheat stem rust and rye stem rust. In the Prairie Provinces, wheat stem rust is, by far, the more important of the two. The chief control measure is the growing of rust-resistant varieties. At the time of writing there are available some varieties that are resistant to the prevailing wheat stem rust races as, for example, Vantage, Vantmore and Husky. They appear to be somewhat less resistant to rye stem rust, but this is not important so long as rye stem rust remains relatively uncommon. (For a general discussion of stem rust, see under wheat.)

\section{Leaf Rust}

\section{Puccinia hordei}

Leaf rust of barley is one of the least destructive diseases of that crop in the Prairie Provinces but sometimes causes considerable damage in the southern United States where winter barley is grown. It óccurs almost every year in Manitoba and sometimes spreads into eastern or central Saskatchewan, but infection is generally light.

Appearance-The rust pustules of the summer stage occur on leaves and sheaths as small, round eruptions of a deep orange color. When infection is heavy the pustules are spaced so closely together as to give the leaves a golden-brown appearance. As the plants ripen, the summer stage is partly replaced by the dark-gray pustules of the winter stage which are produced just below the surface of the leaf and sheath.

Life Cycle-The thick-walled, dark-colored spores of the winter stage survive the winter and germinate in the spring when each spore discharges several small, colorless spores (sporidia) into the air. These sporidia cannot infect barley; in fact, the only kind of plant they are known to infect is the star-of-Bethlehem (Ornithogalum umbellatum). As this plant does not grow in Western Canada, the rust cannot reproduce itself there in this way. The summer stage of the rust survives the winter on winter barley in the southern United States, and from this source the rust gradually works its way north until it reaches Western Canada, usually early in July.

Control-This rust, like other cereal rusts, is composed of many parasitically different races. The most satisfactory control measure is to grow resistant varieties. There are a number of varieties in existence that 
have shown high resistance to this rust in experimental plots in Western Canada but, unfortunately, none of them are of commercial value. The varieties at present of commercial importance are not resistant to all the prevalent races.

\section{Covered and False Loose Smut}

\section{Ustilago hordei and Ustilago nigra}

Covered and false loose smuts of barley are quite distinct in their appearance but since their method of development and their control are the same, description under the same heading may be in order. These two smuts attack barley and a number of related grasses but they do not attack any other cereal crop. Each of them is subdivided into a number of parasitic races which differ only in their ability to attack certain varieties of barley.

These two barley smuts still cause extensive losses amounting to millions of dollars annually in Western Canada. If farmers would only become aware of the facts about these diseases such losses could be avoided. Both of these smuts can be readily controlled by regular seed treatments with an effective seed disinfectant.

Appearance-Covered smut stunts the affected host plant, particularly the top internode of the stem, and the smutted head usually emerges through the sheath below the boot leaf. Smutted heads are compact, hard, and usually contain vestiges of chaff and deformed awns (Fig. 9). The compacted spores are not readily blown or washed away by wind and rain until time of harvesting and threshing when smutted heads are broken and large numbers of spores are set free to contaminate sound grain.

False loose smut, on the other hand, looks very much like true loose smut (Fig. 10). Smutted heads emerge in the same manner and at the same time, and grow as tall as heads of healthy plants. At first the smutted head is covered by a delicate grayish membrane which soon breaks down setting free the loose, dark-brown, powdery mass of spores. Eventually the spores are blown or washed away leaving an inconspicuous, bare rachis.

Disease Cycle-Both covered and false loose smuts of barley are carried over from season to season as seed-borne spores. Under favorable conditions, during maturation of the crop and storage of the seed, some seed-borne spores may germinate and produce a certain amount of mycelium under the seed hull. Both mycelium and spores remain dormant until such seed is planted and begins to germinate. Then the threadlike germ tubes and mycelium of the smut penetrate the very young seedling and the smut grows together with the infected plant until the heads begin to develop. In the young, developing barley heads the smut mycelium displaces all or most of the plant tissues and by the time the affected head emerges it contains smut spores instead of seed and chaff. 


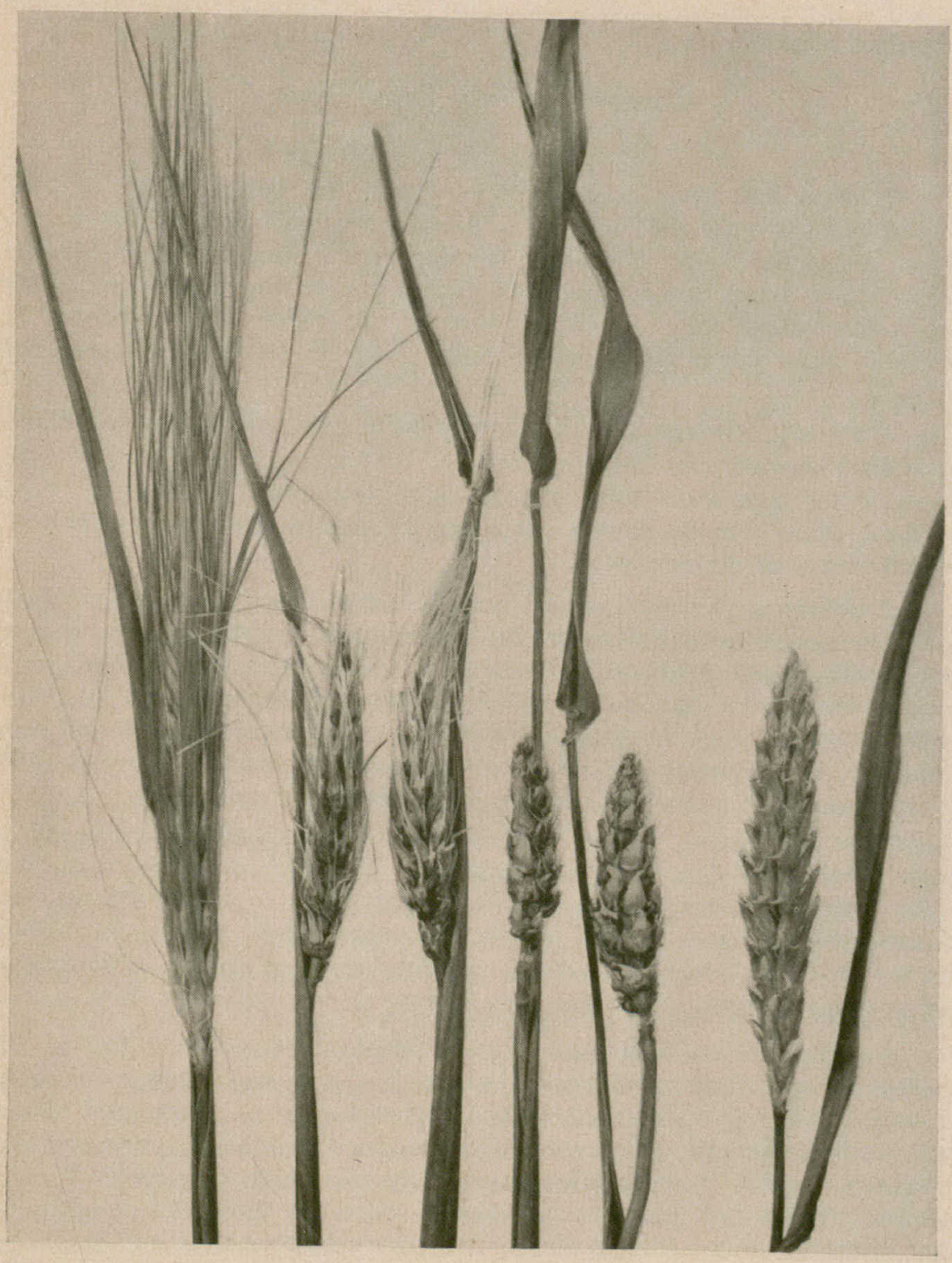

Figure 9.-Covered smut of barley; (left) healthy head and two smutted heads of awned barley, and (right) two smutted heads and healthy head of hooded barley. 
$B A R L E Y$

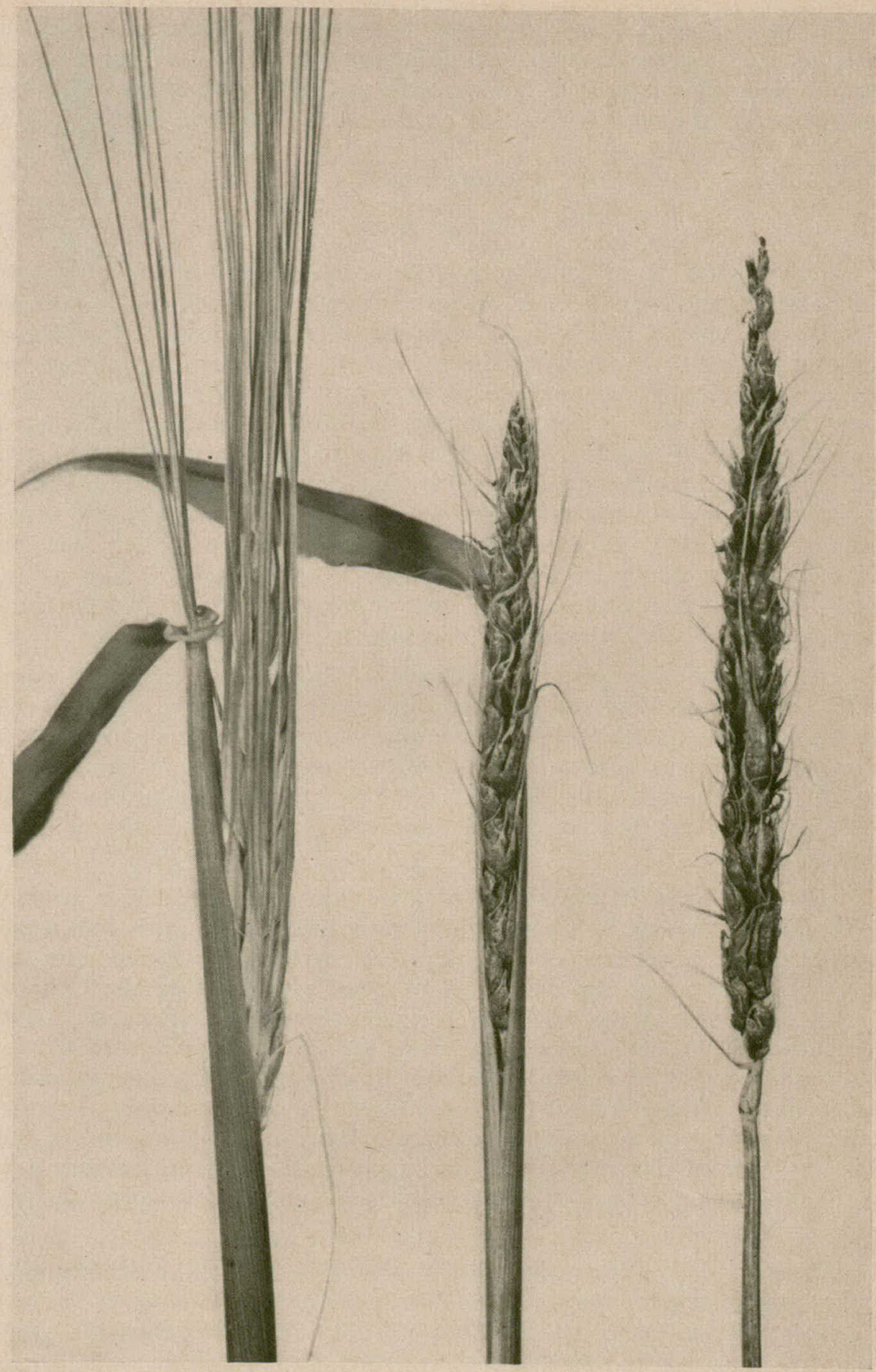

Figure 10.-False loose smut of barley; healthy head and two smutted heads. 
Control-Regular and carefully applied seed treatments with a recommended organic mercury seed disinfectant at least 7 or 8 days before seeding gives good control of both covered and false loose smuts of barley. See smut control under Wheat Bunt (p. 25) and under Oat Smut (p. 50).

\section{Loose Smut}

\section{Ustilago nuda}

Loose smut is an important disease of barley. Under favorable conditions it can destroy a large proportion of the crop. Control by means of seed treatment is difficult and expensive, compared with the treatment for covered smut. In recent years the average loss from this disease in Western Canada has amounted to about 1 to 2 per cent, but occasionally losses as high as 40 per cent have been reported. This disease has been prevalent in the Prairie Provinces ever since barley became widely grown but its severity has fluctuated somewhat with cycles of wet and dry years and with changes in varieties. Since the spores of loose smut are dispersed when the crop is in the flowering stage the spores do not accumulate on the seed and the quality of the grain for feed is not affected. Consequently, the grain is not degraded as in the case of wheat contaminated with bunt. However, the smut does affect the value of the grain for seed.

Appearance-Loose smut manifests itself at heading time. All parts of the head are attacked and destroyed except the rachis (Fig. 11). About the time that the head emerges the thin membrane that surrounds the masses of smut spores breaks down and the dusty, brown spores are blown away so that in a few days only the bare rachis is left. The spore masses are similar to those of false loose smut, but ordinarily they are not quite so dark in color.

Disease Cycle-When spores of loose smut are blown into healthy flowers they germinate by means of long germ tubes, if the air is sufficiently humid and the temperature is suitable. The mycelium developed from the spores penetrates into the ovary and becomes established in the embryo. As the seed matures the mycelium becomes dormant and remains in that condition until the seed germinates. Then the mycelium renews its activity and penetrates the plant tissues near the growing point of the barley plant. As the head begins to form it is attacked by the fungus and a mass of spores develops instead of the normal spikelets. The spores are mature by the time the infected plant heads out and, upon dispersal, those that come to rest in the flowers of healthy plants infect them and thus complete the life cycle of the fungus.

Control-This disease can be controlled either by using smut-free seed or by treating infected seed. The former is the preferable method because it is cheaper and does not interfere with the germination of the seed. Smut-free seed can be identified by an embryo test which is available for 

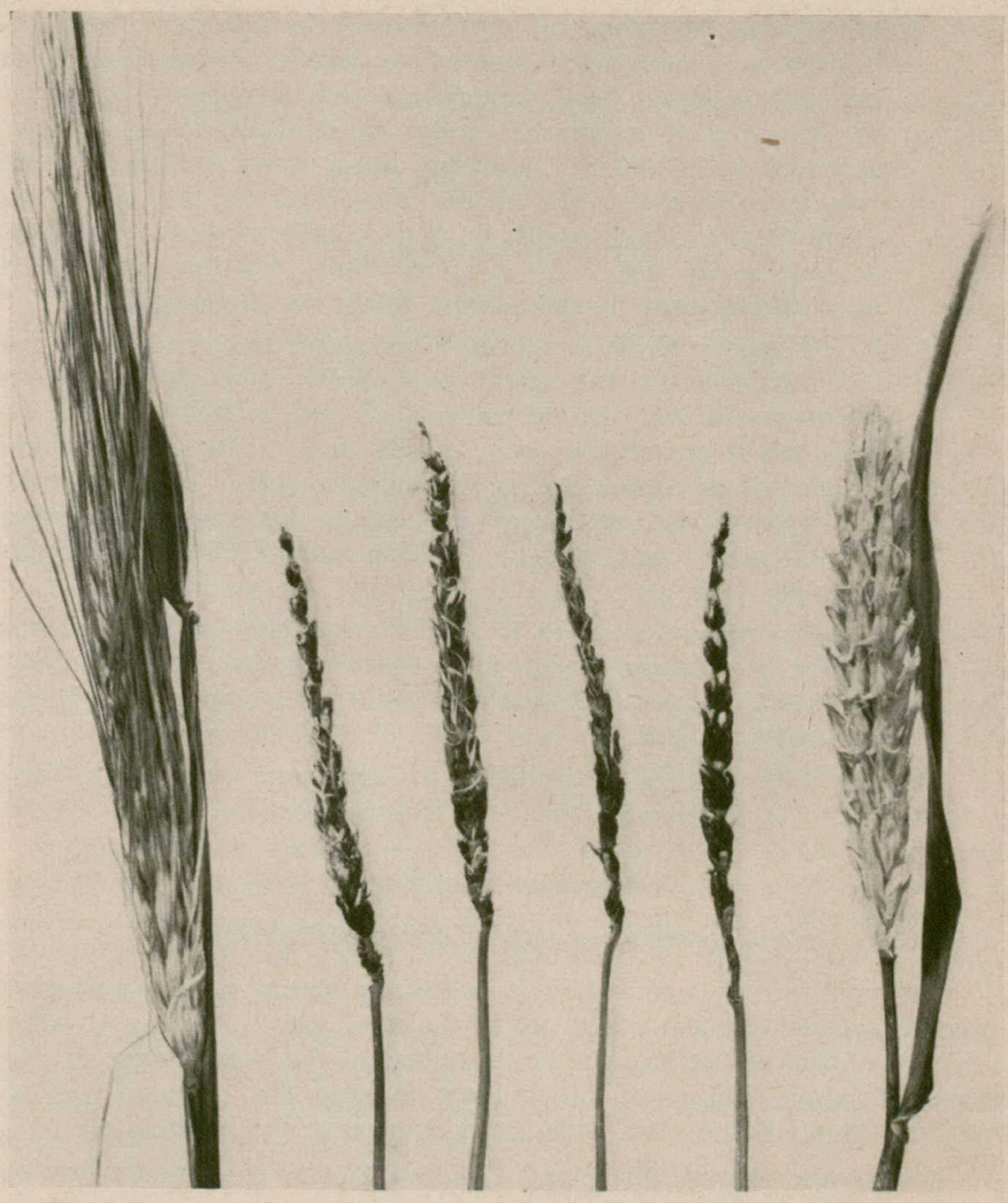

Figure 11.-Loose smut of barley; healthy head and two smutted heads of awned barley (left) and two smutted heads and healthy head of hooded barley (right).

foundation and elite seed and is required for registered barley seed. Until such time as the embryo test is available for all classes of barley seed it is suggested that a few bushels be treated every spring for a seed plot to produce enough seed for one's farm the following year. The following treatments are suggested:

1. Hot-water treatment. Soak in water at $70^{\circ} \mathrm{F}$. for five hours, dip in hot water 11 minutes at $126^{\circ} \mathrm{F}$., dip in cool water and dry thoroughly to prevent molding or premature sprouting. 
2. Water-soak treatment. Place the seed in a tub or barrel (2 bushels is a convenient amount to handle at once) and add sufficient water to keep the seed covered completely during the whole period of treatment. Bring the temperature of the water and seed to $70^{\circ}-75^{\circ} \mathrm{F}$. by adding warm water if necessary, and keep it at this level for 65 hours. Then drain the seed and spread it out to dry. Drying must be done rapidly to prevent sprouting or spoiling the seed. On a warm, windy day the seed may be dried satisfactorily by spreading it thinly out of doors.

There is likely to be some reduction in germination from this treatment but the actual amount will vary greatly between different seed lots. Sound, undamaged seed is likely to suffer less from this treatment than poor quality seed. Treated seed should be planted in a plot that is isolated from other fields of barley but isolation will not always protect the crop from re-infection. The increase can be used for the main barley planting the following year.

These treatments are effective if applied according to the directions, but they require painstaking work unless special equipment is available. They cause a certain amount of injury to the seed but this varies greatly with different stocks of seed.

Varieties differ in their susceptibility to loose smut but most of those in common use at the present time are fairly susceptible.

\section{Common Root Rot}

\section{Helminthosporium sativum and Fusarium spp.}

Common root rot of barley is in almost every respect similar to common root rot of wheat. It is one of the most serious diseases of barley in Western Canada. It has not been studied to the same extent as root diseases of wheat. However, observations indicate that common root rot frequently causes serious and widespread damage in the barley crop.

Appearance, Disease Cycle and Control-Similar to common root rot of wheat. (See p. 27.)

\section{Spot Blotch}

\section{Helminthosporium sativum}

Spot blotch, a leaf disease of barley, is caused by one of the common root-rot fungi. The leaf infections develop under warm, moist conditions, and when these are present damage may be severe. The disease is most serious in the eastern part of the Prairie Provinces.

Appearance-The individual leaf spots are round to oblong, brownish in color, with definite margins. The spots frequently fuse to form blotches. 
Eventually, blotches may cover a large area of a leaf blade and part of the leaf sheath. Heavily infected leaves dry out and die. Disease
(See p. 27.)

\section{Net Blotch}

\section{Helminthosporium teres}

Net blotch is one of the most common leaf-spot diseases of barley in the Prairie Provinces. Crop losses resulting from this disease are proportional to the amount of leaf area destroyed. Often they are slight, but when conditions favor disease development heavy infection may reduce yields considerably.

Appearance-The disease attacks the leaves and also the leaf sheaths and glumes. Typical leaf blotches appear first as light-green or brownish patches. As the blotches develop, irregular lines appear which are darker brown in color than the surrounding area. The lines give the blotch its characteristic, netted appearance. As the blotch grows older its central area becomes uniformly dark brown and the lines forming the net are visible only at the margin of the blotch. (Color Fig. 6) Sometimes, especially on young plants, the net does not develop and the blotches are uniformly deep brown. At first the blotches are small but they develop lengthwise along the leaf and two or more of them may join to form long streaks.

Disease Cycle-The fungus may overwinter on or in seed or on plant remains of the previous crop. In the spring the overwintered fungus on the seed or plant remains grows and infects the young plants of the new crop. Further spread of the disease is brought about by spores produced in the new infections on the young plants.

Control-The disease is seed-borne and hence seed treatment with a recommended seed disinfectant is an important method of control. Crop rotation is also an important control measure because it limits the spread of the disease from remains of previous crops.

\section{Speckled Leaf Blotch}

\section{Septoria passerinii}

Speckled leaf blotch is one of a number of diseases which attack the leaf blades and sheaths of barley. For many years it was considered unimportant and consequently received little attention. In recent years, however, the disease has been prevalent in the Prairie Provinces and probably is responsible for an important part of the damage caused by barley leaf diseases.

Appearance-Speckled leaf blotch appears first on barley leaf blades as grayish-green or straw-colored blotches, which may join to form irregular, 
dead areas on the leaves. In these areas are many very small, black dots, the fungus fruiting structures, which may be seen with the aid of a magnifying glass, or sometimes with the unaided eye. Infections appear later on the leaf sheaths and are most conspicuous on plants approaching maturity. Symptoms on the sheaths consist of darkened areas with rows of the black dots. The disease hastens maturity of the crop and symptoms may be confused with the natural dying of leaves on ripening plants. (Color Fig. 8).

Disease Cycle-The fungus overwinters in crop remains in the soil. In the spring and early summer, spores are produced on the plant remains and are carried to growing plants by wind and water. The spores infect the plants and blotches develop from which spores spread to infect other plants.

Control-Crop rotation is the most practical method of control. Deep plowing to bury crop remains is of value also. Good sanitation practices are helpful. (See section on control of diseases.) None of the barley varieties currently recommended for Western Canada is resistant to the disease.

\section{Scald}

\section{Rhynchosporium secalis}

Scald is one of the major leaf-spotting diseases in the northwestern barley areas of the Prairie Provinces. Losses in yield may be very heavy depending on the extent of the leaf area killed.

Appearance-Scald is primarily a foliage disease, attacking most conspicuously the leaves and to a lesser extent the sheaths. The disease may be recognized by the appearance of oval or lens-shaped spots, which at first are water-soaked and gray green. These areas dry rapidly and the center becomes light gray. This central area is ringed by a dark-brown margin, which is the chief distinguishing feature of the leaf spot. Later these pale central areas may collapse and fall out. The spots often fuse so that the entire leaf may be destroyed by the fungus.

Disease Cycle-The fungus overwinters on the infected, dead leaves and probably on other crop remains. The spores are produced abundantly during the growing season and are carried readily by wind or rain from plant to plant. A cool, humid, growing season favors the disease. Although barley may be attacked at any stage of its growth, the disease is usually most severe just before and during the heading stage.

Control-Elimination of crop remains helps to control the scald disease. However, since the present cultural practices on the prairies tend to make this impractical, rotation of crops offers the best control. 


\section{Bacterial Blight}

\section{Xanthomonas translucens}

Bacterial blight of barley is caused by a bacterium similar to that which causes bacterial black chaff of wheat. The main difference between them is in the kind of crop they can attack.

Bacterial blight of barley has been present on the prairies for at least 25 years, perhaps much longer. At times there are severe local outbreaks and occasionally considerable damage is done over a wide area. For instance, in 1953 it caused extensive leaf destruction over a large part of south-central Manitoba and unquestionably was a factor in depressing yield and quantity.

Appearance-The first sign of an attack of bacterial blight is the development on the leaves of pale-green areas some of which contain small, brown spots in their centers. Later, these areas appear as if water-soaked. They may form stripes several inches in length or may assume rounded or irregular shapes. At that stage, during wet weather or dews, the bacteria ooze out into droplets of water and when they dry may be seen as thin scales of exudate or as tiny amber-colored beads (Fig. 12). Later the infected spots assume a golden yellow color and, finally, turn pale brown.

One of the best means of recognizing the disease at its later stages of development in the field is to hold an affected leaf up against a bright part of the sky. If the disease is bacterial blight, translucent areas will be seen in it.

In severe infections of a susceptible variety the whole plant may become infected and the leaves entirely destroyed.

Disease Cycle - This is a seed-borne disease, the bacteria being carried mainly in the infected hulls. The disease may also be carried over winter on crop remains and on infected grasses. Plant-to-plant spread in the field is rapid in wet weather but crop recovery may occur in dry weather as new uninfected growth develops.

Control-(1) Whenever possible, seed from uninfected fields should be sown. (2) Crop rotation is helpful in controlling the disease and barley should never be sown directly after barley. (3) Most varieties now grown are somewhat resistant but not sufficiently resistant to avoid losses.

\section{False Stripe}

\section{Stripe mosaic virus}

The disease known as false stripe was first described in 1926 from an abundant infection observed in 1924 at Brandon, Man. Although the disease was often reported in both the United States and Canada, it was not until 1950 that the cause was discovered to be a virus. Under exceptional 

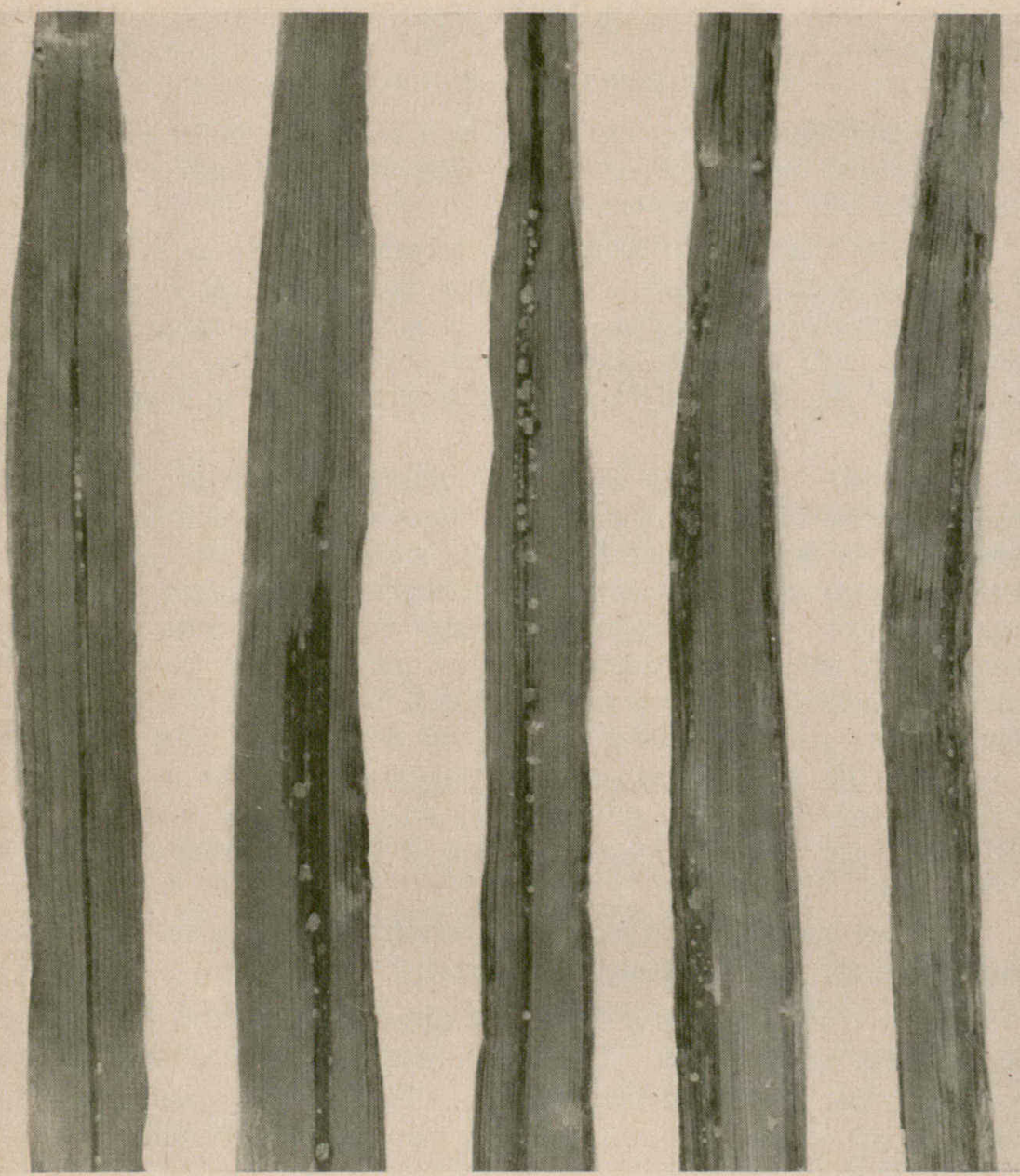

Figure 12.-Bacterial blight of barley. Note droplets of bacterial ooze.

conditions, such as following artificial inoculation, it can reduce the yield by as much as 75 per cent, but under ordinary farm conditions the disease has not been known to cause much damage in Western Canada.

Appearance-Seedlings grown from infected seed are at first chlorotic and become dotted with brown spots. The chlorosis may occur in stripes occupying various proportions of the leaf. Such plants are often stunted, but if they are only lightly affected, the stunting is not very noticeable.

The disease is most easily recognized at heading time. Some of the infected leaves have brown stripes that resemble a V, an inverted V, or W. Such stripes always continue across the leaf from one edge to the other and separate the healthy tip from the diseased base. 
As the plants approach maturity, the disease becomes increasingly difficult to recognize, but affected plants are smaller than healthy ones.

Disease Cycle-This is one of the few seed-borne virus diseases. When diseased seed is sown, most of the resulting seedlings are infected and they develop into poor plants, if they survive at all. Such plants become mottled and pale green, and seldom, if ever, develop the V-shaped stripes. On the other hand, the spread of infection from such plants to nearby healthy plants results in the formation of the $\mathrm{V}$-stripes in the newly infected plants.

The spread of false stripe in the field appears to depend on the direct contact of a diseased and a healthy plant or else on mechanical transfer of infective juice from a diseased to a healthy plant. Such transfers may be made by various farm implements. Transmission by insects has not been established for this disease although it seems likely that several species may transmit it.

Control-The chief means of control is to avoid sowing seed from an infected field. Ordinary seed treatments are useless against false stripe.

\section{Yellow Dwarf}

\section{Yellow dwarf virus}

The yellow dwarf disease is caused by a virus that is carried by several species of grass- and grain-infesting aphids. It was identified for the first time on barley in California where it caused a 10 per cent loss of yield in 1951. Since then it has been recognized as a disease of oats and wheat as well as of barley, not only in California but also on the Great Plains. Limited observations and experiments have indicated its presence on barley, oats, and wheat on the Canadian prairies. No serious damage has been definitely attributed to yellow dwarf in Canada, but it is a potentially serious disease.

Appearance-The first visible evidence of yellow dwarf on barley is a golden yellow color occurring at the tips of the leaves, or sometimes in blotches. The discoloration progresses downward, principally along the leaf margins until the entire leaf is yellow, or striped with green and yellow. The symptoms on oats are similar to those on barley except that the leaves discolor in various shades of red rather than yellow. Wheat infected in the seedling stage becomes chlorotic and severely dwarfed. Barley, wheat, and oats can all be stunted by this disease, but the degree of stunting is dependent on the relative susceptibility of the variety and the earliness of infection. Infection at an early stage usually causes leaf discolorations as described above and severe stunting. Infection at later stages of growth causes yellowing of the upper leaves of barley and wheat and a corresponding reddening of oats, but little stunting. 
Disease Cycle-Perennial wild grasses provide a reservoir of the yellow dwarf virus throughout the year. Several common species of grass-infesting aphids are capable of carrying the virus to grain crops. A severe infection is therefore dependent on factors that favor the migration of large numbers of aphids from wild grasses to grain fields in the spring when the crops are young.

Control-Losses due to yellow dwarf can be reduced by any practical methods that reduce aphid infestations in the grain fields, especially when the plants are young. Evidently there are considerable differences in the susceptibility of different varieties of barley, oats, and wheat, but definite recommendations cannot yet be made. 


\section{Diseases of Oats}

\section{Stem Rust \\ Puccinia graminis var. avenae}

Stem rust of oats attacks cultivated oats, wild oats and meadow fescue but does not attack wheat, barley, or rye. It is made up of a number of parasitically distinct strains (physiologic races) which vary in their distribution from year to year. Control is chiefly by means of growing rust-resistant varieties. Most varieties grown in earlier years were susceptible to all the rust races. At present there are available varieties with high stem-rust resistance such as Garry, resistant to all known races and Rodney, resistant to all but one of the races. (For a general discussion of stem rust, see under wheat.)

\section{Crown Rust}

Puccinia coronata var. avenae

Crown rust, sometimes called leaf rust, occurs on wild and cultivated oats and on several grasses throughout most of the agricultural area of Canada. It often causes much damage in Eastern Canada and in Manitoba and eastern Saskatchewan. In western Saskatchewan, Alberta and British Columbia it is rarely of any economic importance. This rust does not infect wheat, barley or rye. Timothy is the only important cultivated grass which crown rust attacks and it rusts timothy only weakly. The amount of infection by crown rust varies greatly from year to year.

Crown rust, like the other cereal rusts, consists of many parasitic races differing from one another in their capabilities of attacking various oat varieties. At least 65 races of crown rust occur in North America. A large number of oat varieties are resistant to many of these races but no one variety is known that is resistant to all of them. The oat varieties currently used in breeding for resistance to crown rust are susceptible to only a very few of the races and these races are, as yet, scarce.

Appearance - The summer stage of this rust produces elongate, orange rust pustules on the leaves, sheaths and glumes of the oat plant. As the plants begin to ripen the orange spore masses are replaced by the black spores of the winter stage which are formed beneath the leaf surface and present a shiny, black appearance. Each black spore has prong-like projections which form a kind of crown around its apex-hence the name crown rust.

Disease Cycle-The winter spores survive until spring or early summer when they germinate and produce very small spores which are discharged into the air. They cannot infect oats or grasses but they do infect several 
kinds of buckthorn (Rhamnus spp.) of which the common buckthorn, a large shrub originally imported from Europe, is the most widespread and important. The rust produced on the buckthorn cannot reinfect buckthorn but infects oats on which it produces the summer stage of the rust.

Susceptible buckthorns are prevalent in many areas in the Maritime Provinces, Ontario and Quebec and are frequently responsible for local outbreaks of the rust in these provinces. In Manitoba, buckthorn plantings are located mostly in the larger towns and are unimportant in the spread of crown rust. Common buckthorn is found more rarely in Saskatchewan and Alberta than in Manitoba.

The summer stage of crown rust can survive the winter in the southern United States. Observations indicate that the first crown rust infections that appear each summer in the Prairie Provinces are usually caused by wind-borne spores carried northwards from rusted fields in the United States.

Control-As with other cereal rusts, control is best accomplished by the use of resistant varieties. This cannot be achieved completely with respect to crown rust as no agronomically suitable varieties are available which are resistant to all the crown rust races. However, the varieties Rodney and Garry are highly resistant to a large number of these races. In the past several years they have had less than half as much crown rust infection as susceptible varieties.

Other measures helpful in reducing crown rust infection are early sowing, which gives the oat plants a chance to ripen before infection becomes heavy, and destruction of any buckthorn bushes in the vicinity of grain fields.

\section{Smuts}

\section{Ustilago avenae and Ustilago kolleri}

There are two kinds of smut on oats, a loose and a covered smut, but since their development and control are the same and even their appearance is not very distinctive, both are described under the same heading. Both smuts occur in all countries where oats are grown. The loose type is more prevalent in humid regions while the covered is more common in regions with drier climate.

Because seed treatment of coarse grain is not practised as regularly as with wheat, smuts of oats, as well as of barley, still cause considerable loss. It is not uncommon to find fields of oats in the Prairie Provinces with 10 to 20 per cent of the heads smutted.

Within each of the oat smuts there are a number of distinct races. These races may interbreed and thus develop new races.

Appearance-Infected heads emerge at the same time as heads of healthy plants. The loose-smut fungus destroys the seed and the chaff and replaces them with a powdery mass of spores. The spores of the covered smut fungus are enclosed in vestiges of the outer chaff. 
Disease Cycle-Both the covered and the loose smut of oats are carried over from season to season as seed-borne spores. The development of mycelium beneath the hulls during ripening and harvesting of the crop and the storage of the seed is common when sufficient moisture is available. When infested seed is planted the germ tubes originating from seed-borne spores or mycelium penetrate the very young oat seedlings. The smut fungus develops together with the host plant until the panicles begin to form. The smut destroys the flowers in the infected panicles and replaces the seed and most of the chaff with dark-brown spores.

Control-Seed treatment with recommended organic mercury seed disinfectants from six to eight days before seeding gives good control of oat smuts. Storage of the treated seed is necessary to enable the poisonous vapor of the disinfectant to penetrate under the hulls of the seed and destroy the smut spores or mycelium. It is very important that the seed disinfectant be thoroughly mixed with the seed in the proportion advised by the manufacturer.

The newer varieties of oats, such as Garry, Fortune and Rodney, are resistant to oat smuts.

\section{Bacterial Diseases}

\section{Pseudomonas coronafaciens \\ Pseudomonas striafaciens}

Two bacterial diseases of oats, halo blight and stripe blight, are fairly common, although not very destructive, on the oat crop in the Prairie Provinces. Both diseases attack the leaves chiefly. In severe infections, some of the seedlings may be killed outright. Older plants may be attacked on the sheaths and panicles as well as the leaves. Both of these diseases develop most rapidly during cool, wet weather.

Appearance-Halo blight produces light-green, oval spots the centers of which become water-soaked and darker than the margins (Fig. 13). The spots thus appear to be surrounded by pale-green halos. Later the whole spot, including the halo, turns brown. A number of such spots may join together to form an irregular blotch.

Stripe blight produces spots that are not surrounded by a pale-green margin and are often elongated into stripes. In late stages, the spots are brown, throughout, in both diseases and it is difficult to distinguish between them, except by laboratory methods.

Disease Cycle-The bacteria of both diseases are seed-borne and may also live over winter on infected crop remains. The first seedling infections develop from the bacteria on the surface of the seed. From these infections the disease can spread readily from leaf to leaf and from plant to plant in the cool, often moist, spring weather. In the late spring the disease in some fields may appear severe, but often a spell of warm, dry weather will check 


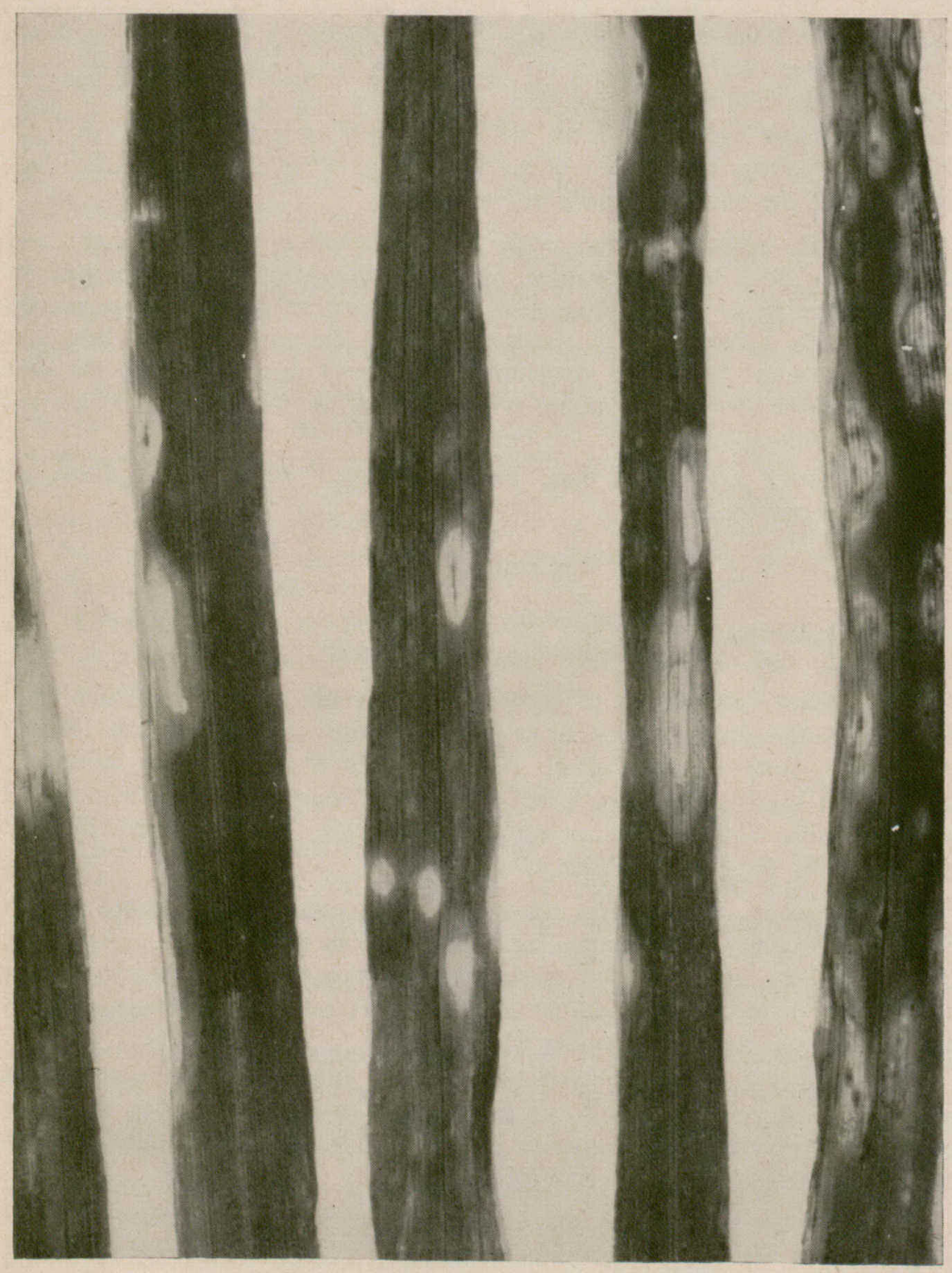

Figure 13.-Halo blight of oats. 
it and permit the new growth to be comparatively free of infection. During the growing season infection takes place through the water pores at the tips of the leaves, through breathing pores (stomata) distributed over the leaf surface, and through wounds.

Control-The most effective methods of control are the use of resistant varieties and seed treatment by hot water. Ordinary seed treatments which merely disinfect the surface are ineffective against these diseases, but satisfactory control may be obtained with a ten-minute steep in water held at $135^{\circ} \mathrm{F}$.

The varieties most commonly grown on the prairies at present are fairly resistant to these two diseases.

\section{Gray Speck}

\section{Manganese deficiency}

Gray speck is a disease caused by a lack of available manganese. Manganese is a mineral element essential to the growth of the plant. Even if plenty of it is present in the soil, it is of no use unless the crop can take it up. Some soils hold it in an insoluble form. Inside the living plant it is needed in the processing of the nitrogen from the soil into proteins which have food value to man and animals. Gray speck affects oats chiefly, but is sometimes seen also in wheat and barley.

Because the disease is the direct result of the scarcity of available manganese, its severity depends on the degree of the scarcity. Thus, under conditions of great manganese scarcity, the disease can become so severe that the crop will not even come into head. Furthermore, the growth that does take place will not even make good pasturage. Fortunately such conditions are rare on the prairies. Gray speck has been found in twelve districts of Manitoba and in at least one in Saskatchewan, but the acreages affected have been comparatively small. Although the damage has not been widespread, a farmer who happens to have a manganese-deficient field or farm may suffer seriously unless he learns to cope with this disease.

Appearance-An affected field may present an unthrifty, patchy or brownish appearance, which is noticeable even at a distance of several rods. The brownish appearance is attributable partly to the older, affected leaves which die prematurely and partly to the numerous small dead spots distributed along the leaves that are still green. At first such spots vary in color from light-green to gray and later from whitish to brown (Fig. 14).

The first signs of disease do not usually occur until the fourth or fifth leaf has developed. A characteristic sign is a breaking-over of the leaf at about two-thirds of the distance from the tip. This breaking-over occurs where an area of the leaf has been killed by the disease. As the disease progresses, series of small, oval, whitish spots appear between the veins of the younger leaves. A few spots on the leaves may have little effect on 

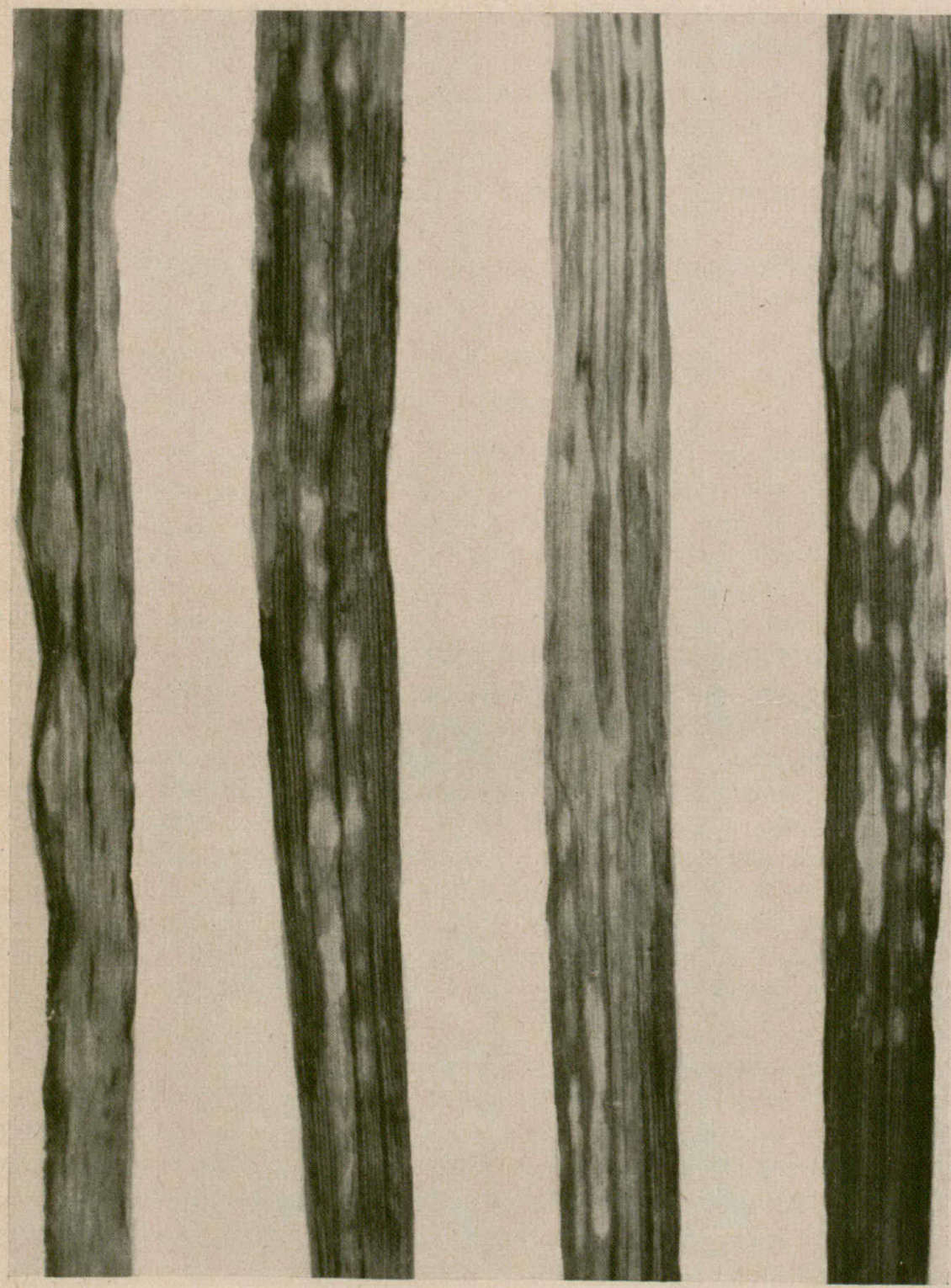

Figure 14.-Gray speck of oats. 
the grain. Moderately heavy leaf and sheath damage may reduce the set of seed. Very severe damage may prevent heading. Under conditions of very great manganese deficiency, the plant dies early.

Control-The disease can be controlled by fertilizing the crop with manganese in a soluble form; by means of soil amendments that make manganese available to the plant; and by the use of tolerant varieties. A tolerant variety is one that can take up manganese from the soil even when little is available to most varieties. Such tolerant varieties, including Ajax and Exeter, possess enough adaptability to yield satisfactorily under all but the worst of manganese deficiencies.

In experimental plots good results have been obtained by spraying the crop with a solution of manganese sulphate. This method requires an abundance of water and labor. On the farm, it is more convenient to apply the manganese at seeding time by drilling it into the soil at the rate of $100 \mathrm{lb}$. of feed-grade manganese sulphate $(65 \%)$ per acre. Such an application is usually good for one season only, with little or no carry-over to the next crop.

\section{Blast}

\section{A nutritional disorder}

Appearance-Oat blast is a condition familiar to most farmers because every field of oats displays, shortly after heading, a considerable number of panicles with blasted spikelets. Instead of all the spikelets containing two kernels, there are a number of empty spikelets, usually in the lower part of the panicle, that have withered before the kernels were formed. Only the partially formed, white empty glumes are left and it is these that are responsible for the characteristic appearance of the disease (Fig. 15).

Cause-To understand the cause of oat blast, it is necessary to consider how the panicle of the oat plant is formed within the plant. Several weeks before the panicle emerges, the plant begins to form the young spikelets. If growing conditions are good in this early stage of plant development, the plant will begin to grow many young spikelets. Under favorable conditions these spikelets will mature. If shortly before heading out, however, the growing conditions change greatly for the worse, as for example through a severe drought, the plant responds by sacrificing the spikelets on which it has expended the least energy. That is the reason why the blasted spikelets are usually located on the inner branches near the base of the panicle where the youngest spikelets are located.

Control-There is no known way of controlling blast. Late-sown oats often have more blast than those sown early. Early sowing results in larger panicles and, even if there is considerable blast, is likely to give better yields than late sowing. Some varieties tend to show less blast than others but they are not necessarily the best yielders. 


\section{Other Diseases}

Common root rot of oats is fairly prevalent but generally is not conspicuous except when it occurs as prematurity blight. In most respects it is similar to common root rot of wheat (See p. 27).

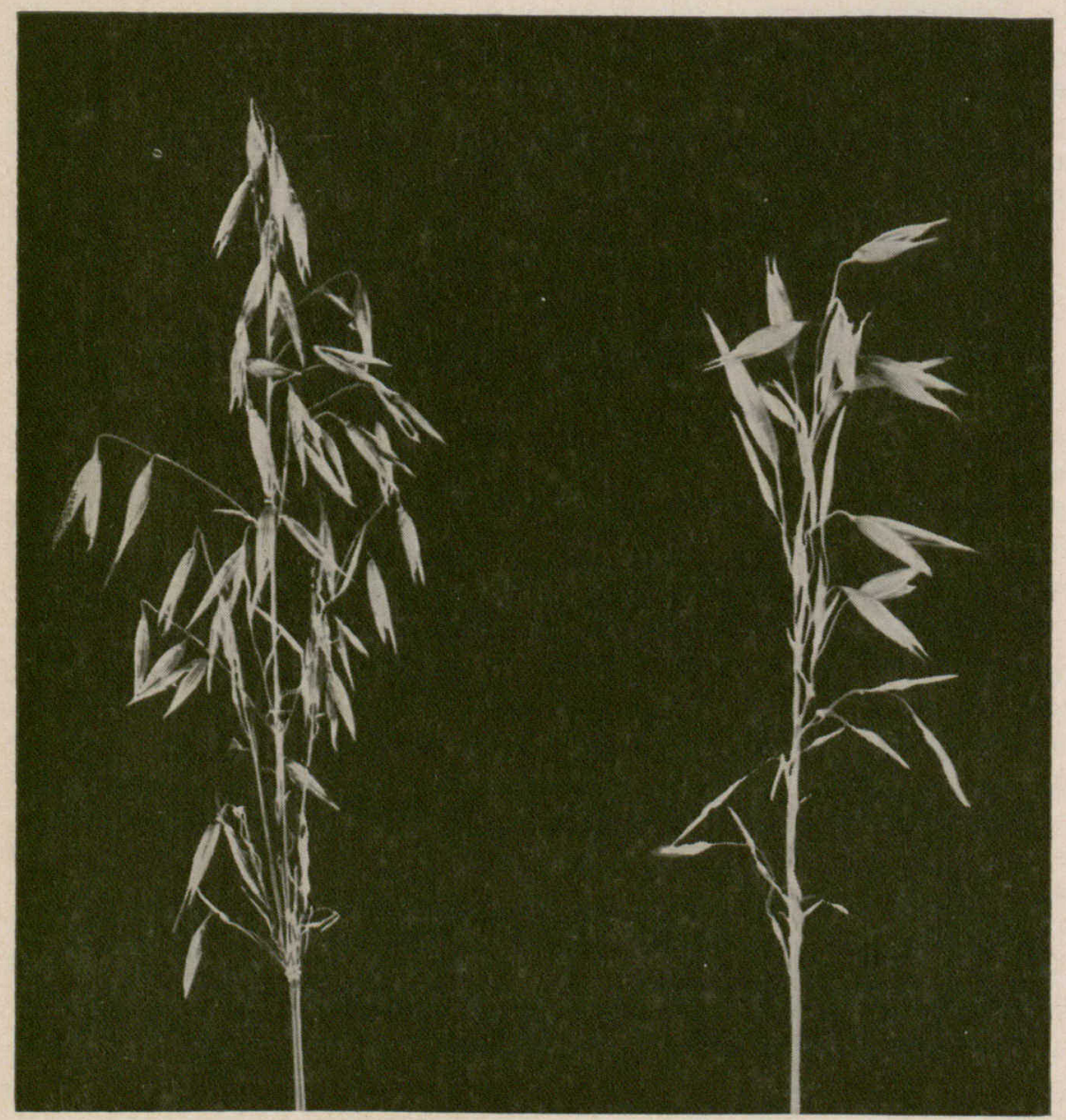

Figure 15,-Blast of oats. Left: blasted spikelets chiefly in lower part of panicle. Right: a more severe condition involving most of the panicle. 


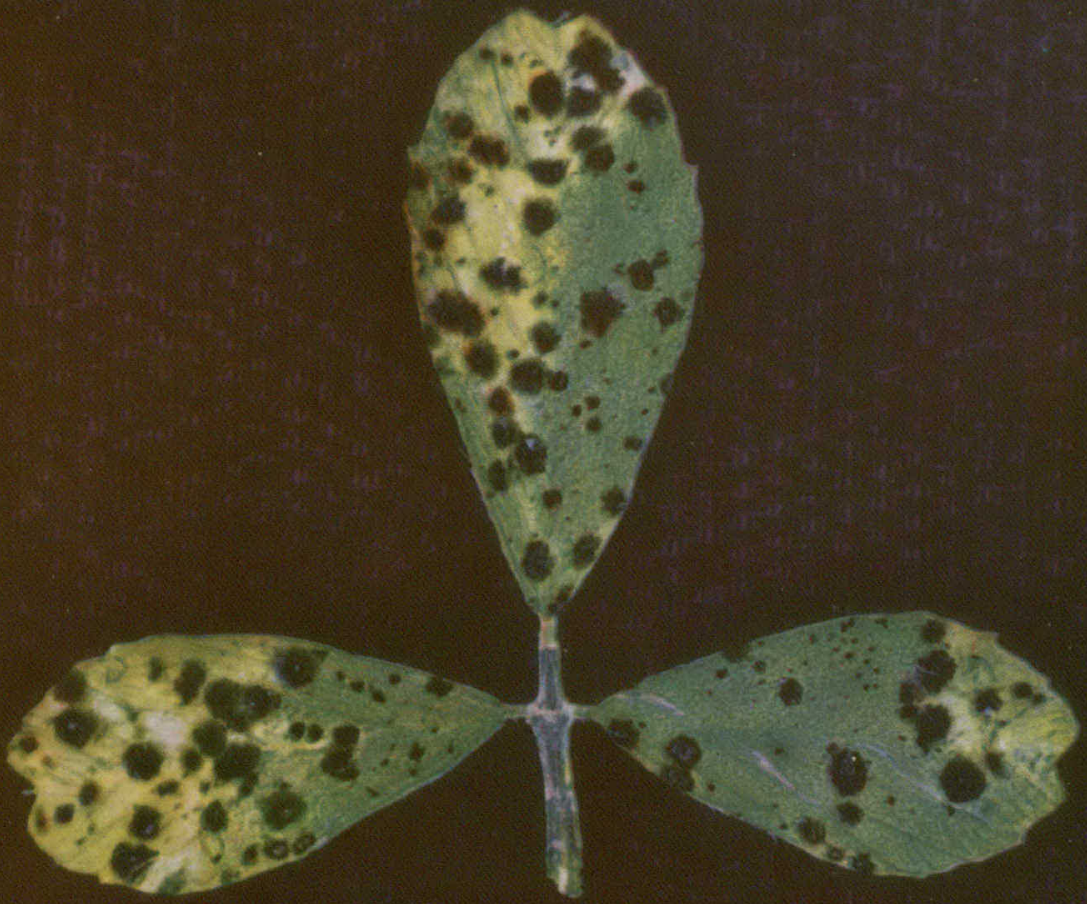

(1)

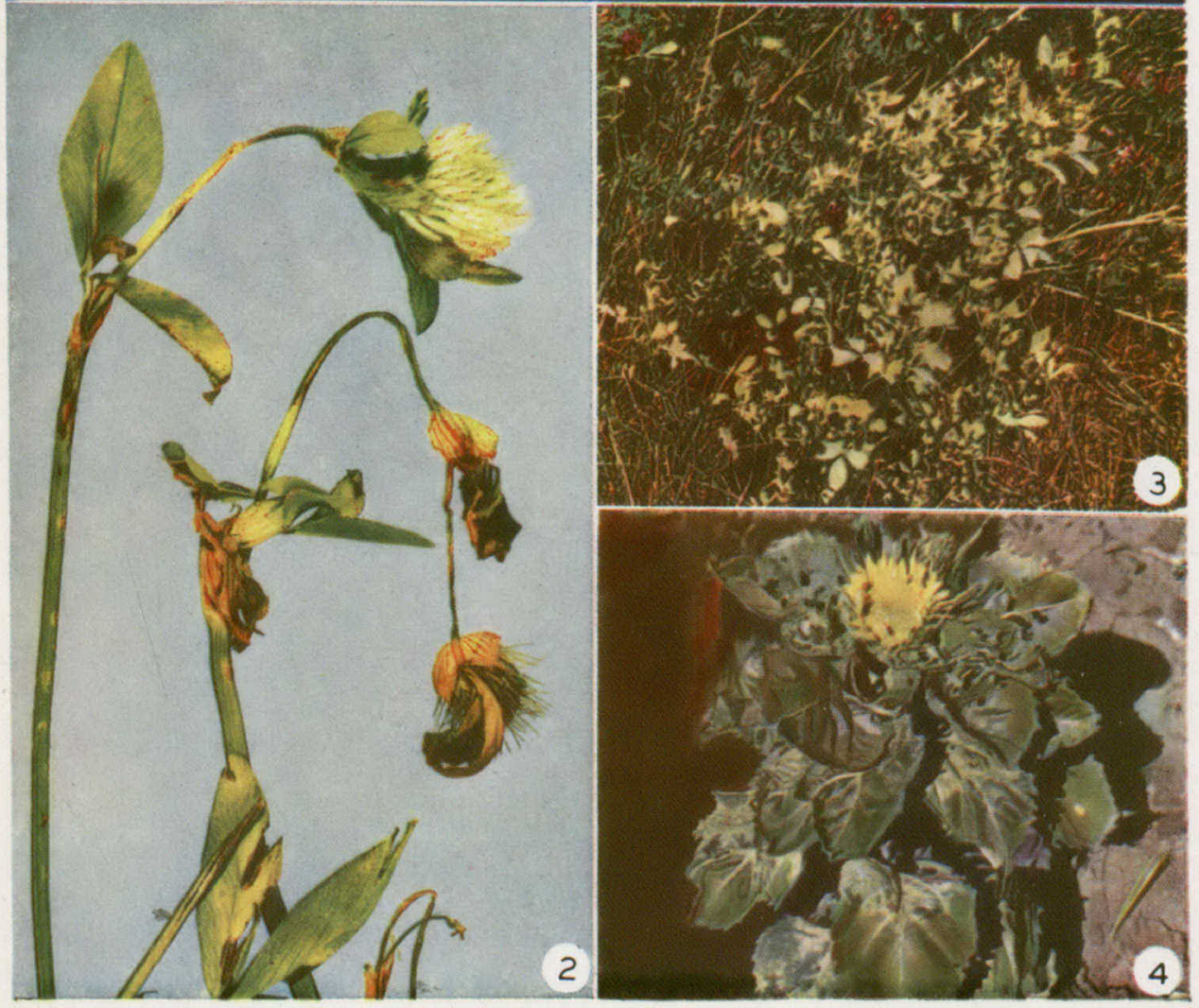




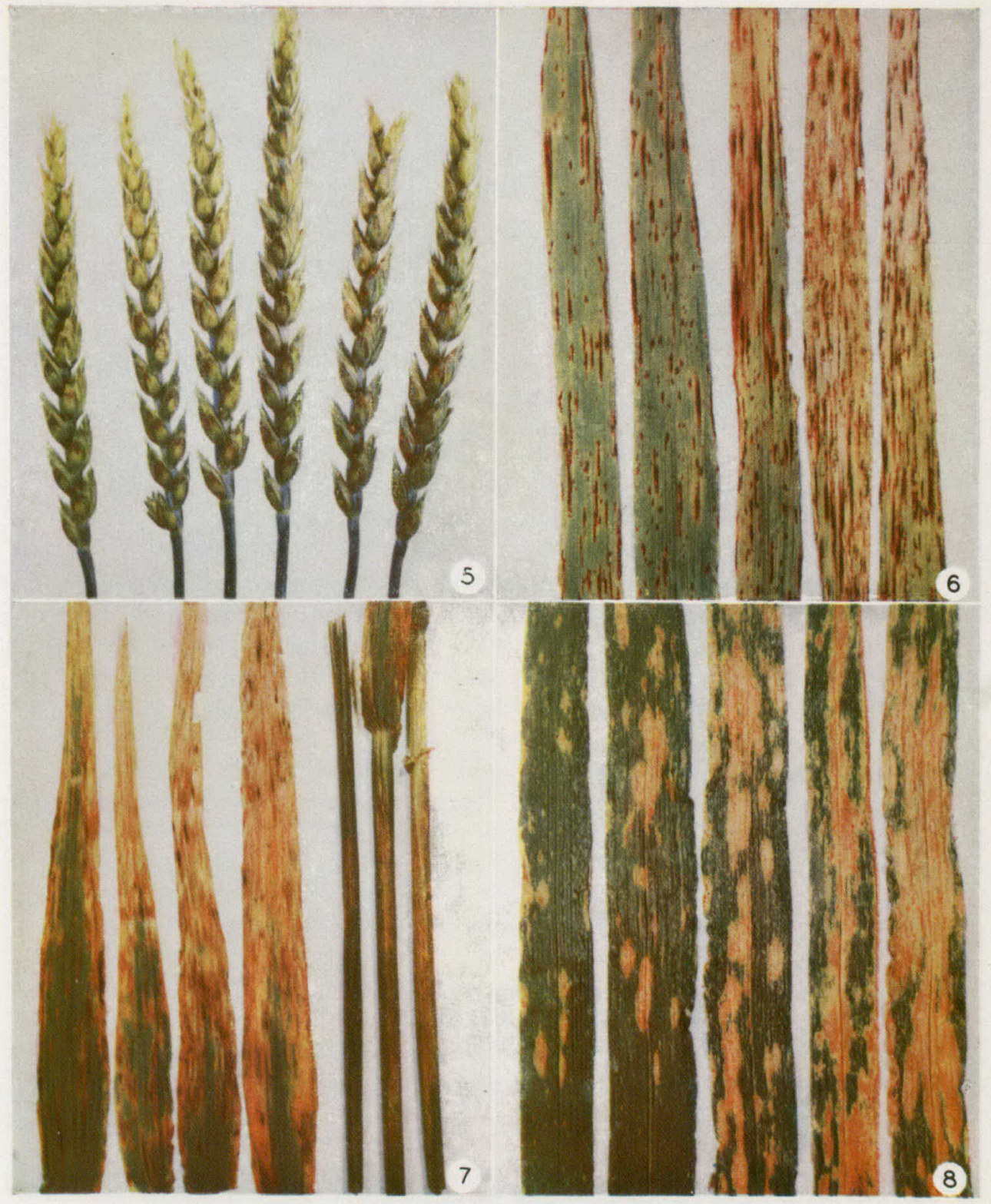

(1) Common leaf spot of alfalfa caused by Pseudopeziza medicaginis. (2) Northern anthracnose on red clover caused by Kabatiella caulivora. (3) Bacterial wilt of alfalfa caused by Corynebacterium insidiosum. (4) Downy mildew of sunflowers caused by Plasmopara halstedii. (5) Bacterial black chaff of wheat caused by Xanthomonas translucens. (6) Net blotch of barley caused by Helminthosporium teres. (7) Speckled leaf disease of wheat caused by Septoria avenae f. sp. triticea. At a later stage the diseased areas become speckled with the small black fruiting bodies. (8) Speckled leaf blotch of barley caused by 



\section{Diseases of Rye}

\section{Ergot \\ Claviceps purpurea}

Ergot attacks cereals and grasses and is usually more severe on rye than on any other cereal. It reduces both grade and yield. If the ergot bodies are eaten by animals they may cause abortion, loss of hooves, tails and ears and, in some instances, death.

Ergotism, caused in man by eating bread baked from flour contaminated with ergot was at one time known as St. Anthony's fire. Severe epidemics of ergotism have occurred in Europe following ergoty harvests.

The medicinal uses of ergot have been recognized for at least three centuries and there is a regular, though limited, demand by drug houses for ergot of high quality.

Appearance-The first sign of the ergot disease is the appearance of the sticky honeydew ooze on the affected heads. This usually forms about two weeks after the heads emerge. Soon the characteristically dark-colored ergot bodies develop and replace some of the seeds of the plant (Fig. 16). The shape and size of the ergot bodies are modified by the kind of plant on which they develop.

Disease Cycle-The ergot bodies fall from the ripened heads to the ground, where they mature during the winter period. In the spring, short stalks grow from these bodies and produce spores at about the time the susceptible grains and grasses are in the heading stage. These wind-borne spores germinate in the flowers of the plants and initiate the honeydew stage with its numerous smaller-sized spores which, in turn, may be spread to other plants.

Control-The most effective control measure is to cut the grasses along the borders of grain fields as soon as the grasses head out.

Rye should not be followed in the rotation by rye, wheat or barley. Oats, which seldom develop the disease, may be used to advantage in the rotation.

Clean seed should be used. Combine screenings containing ergot bodies should not be allowed to fall on the ground.

In fields contaminated with ergot bodies the soils should be worked so as to bury them to a depth of at least two inches.

\section{Bacterial Blight}

\section{Xanthomonas translucens}

Bacterial blight of rye is one of the more common of the diseases on fall rye in the Prairie Provinces. Infections so severe as to destroy as much as 60 per cent of the leaf area have been observed. 
DISEASES OF FIELD CROPS

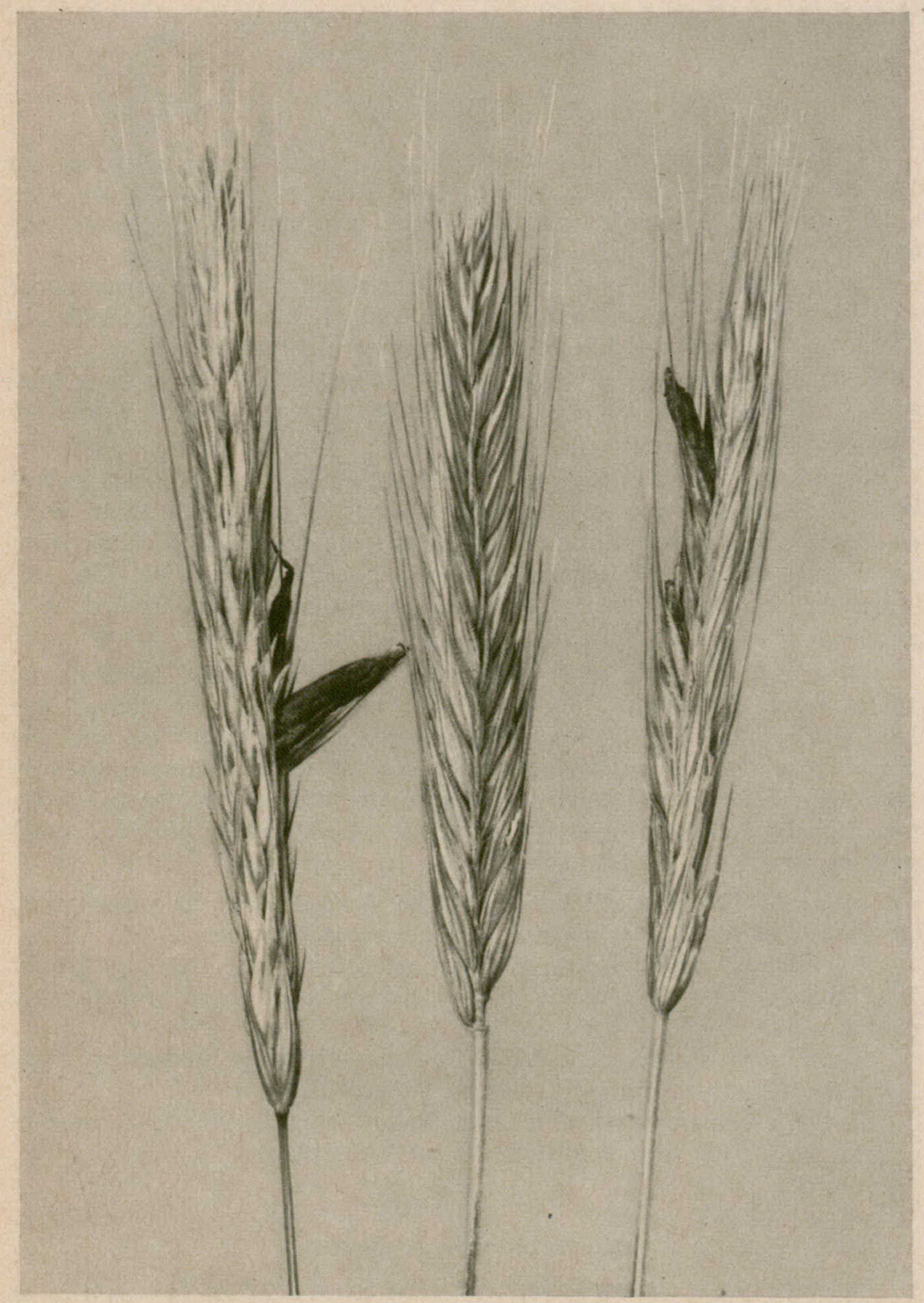

Figure 16.-Ergot in rye; healthy head in center.

- 
Appearance-The appearance of this disease is as in bacterial blight of wheat (p. 30) but the exudate is less often visible.

Disease Cycle-Overwintering is similar to that described under the bacterial blights of wheat but, in addition, bacterial blight of rye probably lives over readily in the fall-sown crops.

Control-(1) Whenever possible, seed from uninfected fields should be sown. (2) Crop rotation is helpful, but rye should not follow wheat. (3) Any measures taken to prevent the spread of the disease from infected grasses adjacent to the field will be helpful, for example, burning the grass at the time of fall sowing.

\section{Leaf Rust}

\section{Puccinia secalina}

Leaf rust of rye, sometimes called brown rust of rye, is not very destructive in Western Canada, chiefly because winter rye, which is widely grown, matures before the rust has had time to produce much infection. However, since the rust attacks both the leaves and the sheaths of the plants, it can, under conditions favorable to infection, cause considerable damage, especially to spring rye.

Appearance-The summer stage of the rust consists of elongated reddish-brown pustules on leaves and sheaths. These pustules contain powdery masses of the summer spores which continue to produce new infections as long as the plants remain green. As the plants ripen the pustules gradually change to a dark-gray color because of the production in them of spores of the black or winter stage.

Life Cycle-The black spores may germinate in the fall, or they may survive the winter and germinate in the spring to produce very small, colorless spores that cannot infect rye but can infect an annual herb known as bugloss (Lycopsis arvensis). This plant, however, is rare in North America and not often found infected. It is, therefore, scarcely a factor in perpetuating the rust which appears to survive from year to year by the overwintering of the summer stage. It is not certain that overwintering occurs in the Prairie Provinces but it doubtless occurs in more southerly areas from which wind-borne spores are carried north in early summer.

Control-Because of the small economic importance of the rust there has been no attempt made to produce rust-resistant varieties of rye, and, in any case, such an undertaking would be more difficult than it has been with other cereals on account of the cross pollination that occurs so readily in rye. Winter rye usually escapes damage through early maturity; early sowing of spring rye will generally enable that crop to ripen before much infection has taken place. 


\section{Stem Rust}

\section{Puccinia graminis var. secalis}

Stem rust of rye attacks not only rye but also barley, wild barley and couch grass. This rust is not important in the Prairie Provinces chiefly, perhaps, because much of the rye grown there is winter rye which usually ripens early enough to escape infection. Spring rye, which ripens later, is more frequently infected but not usually severely enough to result in much damage. The varieties grown at present are not rust resistant. (For a general discussion of stem rust, see under wheat.) 


\section{Diseases of Corn}

\section{Rust \\ Puccinia sorghi}

Corn rust does little damage in the Prairie Provinces. It occurs every year, however, and there is a possibility of greater damage, especially if the corn acreage is increased. The rust attacks the leaves and is usually most noticeable in August.

Appearance-The summer stage of the rust appears as oblong, reddish-brown pustules bordered by the broken edges of the leaf surface, These pustules contain the red, summer spores which are spread by wind and cause new infections as long as the leaves remain green. As the plants ripen, dark-brown, thick-walled winter spores are produced in these same pustules which then appear black in color.

Disease Cycle-The winter spores survive the winter and, in the spring, produce a crop of small, colorless spores which are discharged into the air. These do not infect corn but can infect several different kinds of wood sorrel (Oxalis spp.) on which they produce rust. Later the rust can spread to corn and there re-establish the summer stage. However, wood sorrel is seldom, if ever, infected in Western Canada and rust on corn reappears each year mainly from infection by summer spores carried north by air currents from the southern United States where overwintering of the summer spores occurs.

Control-Little attention has been given to control measures because the disease has not been destructive. No resistant varieties are available. Infection can be reduced by planting early to achieve maximum development of the crop before the arrival of wind-borne spores.

\section{Smut}

\section{Ustilago maydis}

Smut is probably the most widely distributed disease of field and garden corn. In districts where warm and moderately dry weather prevails, it is very destructive on susceptible varieties. The loss in yield resulting from smut varies with the time the plants become infected and with the size, number and location of the galls.

Corn smut differs from the other cereal smuts in causing local rather than systemic infections. It may attack any aboveground part of a plant that is actively growing, including stems, leaves, tassels, ears and even brace roots. The spores of this smut are very resistant to freezing and drying and, having a variable period of dormancy, they may remain viable 


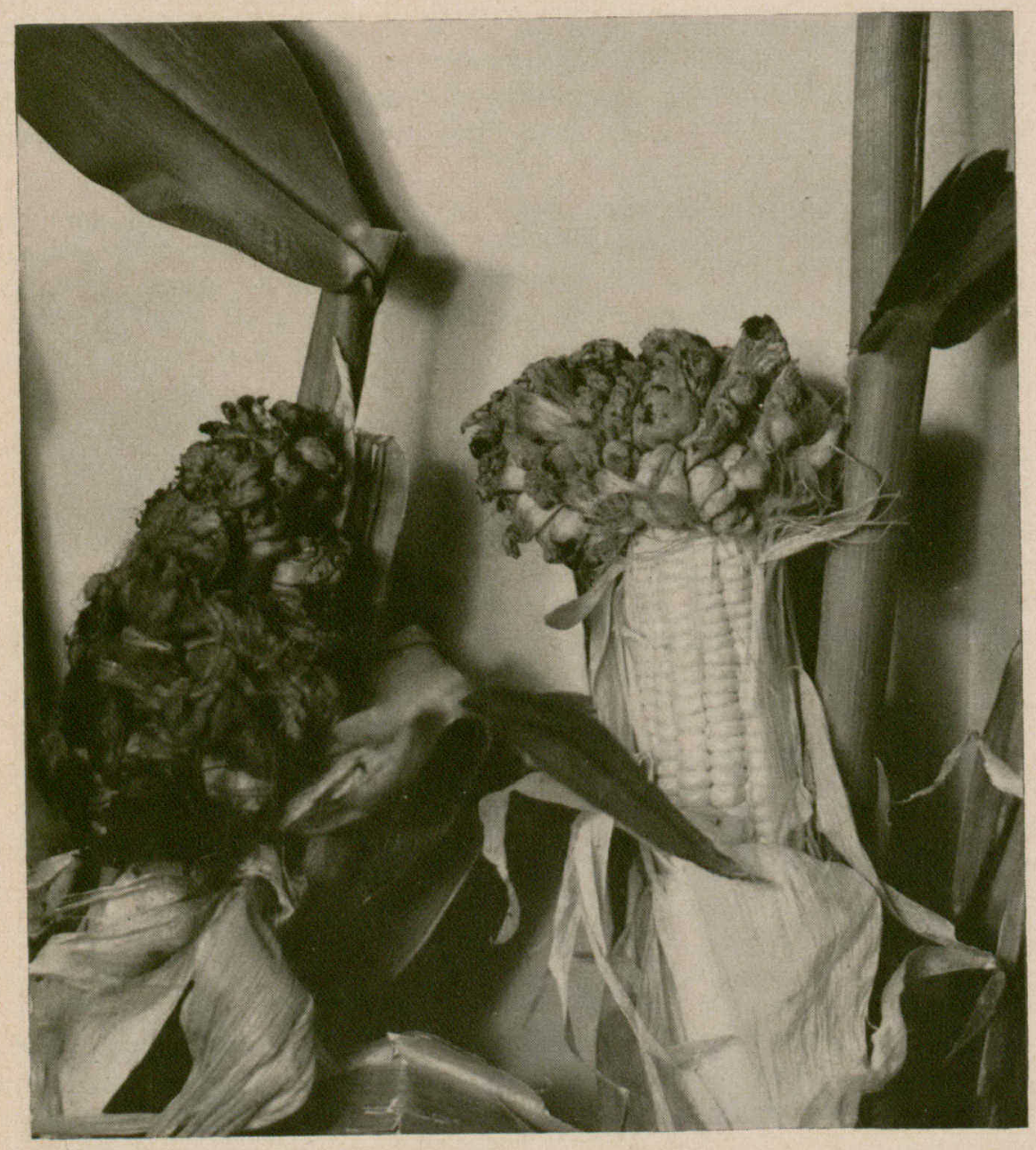

Figure 17.-Corn smut. 
in soil or crop remains for several years. The ability of the spores to produce large numbers of sporidia which are adapted to distribution by wind further increases the chance of infection of the plants.

Corn smut is not only very hardy but extremely variable. As a result, new races or strains arise frequently and, therefore, it is difficult to produce varieties of corn completely resistant to smut. Nevertheless, many of the more recent hybrid corn varieties are moderately resistant or, at least, highly tolerant to the disease.

Appearance-The mycelium of corn smut stimulates an excessive development of infected plant tissues, causing the formation of an overgrowth, or gall (Fig. 17). The young galls consist of plant tissues permeated by smut mycelium. Later, most of the plant cells in the infected parts die and the mycelium is transformed into spores. The galls are covered by grayish membranes that eventually rupture and release the powdery mass of olive-brown spores.

Disease Cycle-Smut spores on the surface of the soil or on crop remains germinate early in the summer, each producing 4 smaller spores known as sporidia. Under favorable conditions many sets of 4 sporidia may be produced by each overwintered spore. Both spores and sporidia may be carried about by air currents and when they fall on any part of growing corn plants they may start infections. This process may continue through the summer whenever favorable weather occurs. Later in the season, when early infections produce mature smut galls, the spores from the galls are also blown about by wind, thus increasing the number of spores in the air and giving rise to new infections.

Control-In areas where only small plots of corn are grown, destruction of smut galls before the spores mature helps to control the disease. Where corn is grown on large acreages, resistant or tolerant varieties offer the only satisfactory means of control. 


\section{Diseases of Flax}

\section{Rust \\ Melampsora lini}

Rust is a fungus disease of flax which attacks all the aboveground parts of the plant. It is of worldwide distribution and occurs in Canada wherever flax is cultivated. When moisture conditions and temperature are favorable, rust may completely defoliate flax plants and cause extensive stem infections. As a result the yield and quality of the seed and fiber are greatly reduced.

Appearance-The first infections, which usually appear in June, are inconspicuous pustules containing round, yellow masses of spores, on the under side of seedling leaves. Later, similar but larger orange spore masses appear on the leaves and stems. As the plants approach maturity the pustules darken because of the production in them of the black or winter spore stage. The black stage rarely occurs on the leaves, but may develop profusely on the stems, pedicels, and even on the bolls. Pustules of the black stage often girdle the stem, and may reach a length of several inches.

Disease Cycle-The black spores survive the winter and germinate in the spring to produce very small, colorless spores which are discharged into the air. These small spores infect the seedling leaves of flax and produce pustules of the yellow stage. Spores produced in these pustules cause further infections, in which the orange, or summer spores are produced. The summer spores are the ones which spread the rust from plant to plant and field to field throughout the growing season. The life cycle of the rust is completed by the formation of the black, winter spores on maturing plants. Flax rust goes through all its stages on the flax plant. It differs from the cereal rusts, whose overwintered black spores can attack some other kind of plant but cannot infect the kind of plant on which they were produced. Flax rust goes through a sexual stage in the first infections produced on the young flax plants early in the season. Since flax rust, like other rusts, consists of many different races, this sexual stage makes it possible for different races to cross and to produce new and perhaps more dangerous races.

Control-The most satisfactory means of control is the culture of rust-resistant varieties. In recent years, flax rust has been unimportant in Canada because of the widespread use of varieties which are resistant or immune to all the 40 races of the rust occurring in North America. However, there are races in South America, Australia, and New Zealand which can attack these varieties and it is possible that some of these dangerous races may be introduced accidentally into North America, or that races like 
them may be produced here through natural crossing of local rust races. Because rust overwinters on flax refuse, the disease can build up locally if flax is sown on the same field or nearby fields year after year. Destroying the plant remains from a rusted crop, sowing flax in widely separated fields, and rotating flax with other crops, all help to reduce or prevent flax rust. The black spores may be spread on bits of rusted straw mixed with the seed. Most of this rust is buried in seeding, but occasionally such spores can cause infection on young seedlings. This source of infection may be important, because it can spread dangerous races from one place to another. It is therefore important to clean carefully any flax to be used for seeding, and to treat all flax seed with a mercurial seed disinfectant.

\section{Pasmo}

\section{Septoria linicola}

Pasmo is a fungus disease that attacks all the aboveground parts of the flax plant. It has long been known in Manitoba and Saskatchewan but has been found only recently in Alberta. Early infection by pasmo can reduce the yield and quality of flax very markedly. Most of the loss is caused because infected plants ripen too fast and the seeds do not fill normally. Later infections cause less damage, and if pasmo does not attack the plants until the seeds are almost ripe, it may do very little harm. However, if such infected flax is left to be straight-combined after the other crops are harvested, heavy losses may result because of breaking-off of the diseased bolls by wind and rain.

Appearance-Early in the growing season, pasmo shows up as brown spots on the leaves of infected flax plants. As the infection develops, the diseased leaves die and usually drop to the ground, although they may stick tightly to the stems. Later in the season, as the flax begins to ripen, small brown spots appear on infected stems. These spots enlarge and join together to form brown bands that encircle the stem (Fig. 18). The brown bands formed in this way alternate with uninfected green bands to produce the mottled appearance which is typical of pasmo and makes it easy to recognize before harvest time. Severely infected plants turn completely brown and die. Flax flowers and young bolls are blighted if attacked by pasmo; older bolls may be discolored and the seeds in them may be shriveled or killed by the disease. The slender stems that support the bolls are weakened by pasmo infection, so that ripe bolls may be broken from the plants by strong winds or heavy rains.

Disease Cycle-The pasmo fungus survives the winter as small, black, fruiting bodies (which are barely visible to the naked eye) on the stubble from diseased crops. The fruiting bodies may also occur on the seed, particularly on light and shrunken seed from diseased crops, and on chaff and small bits of stems mixed with the seed. When such seed is sown, some 
DISEASES OF FIELD CROPS

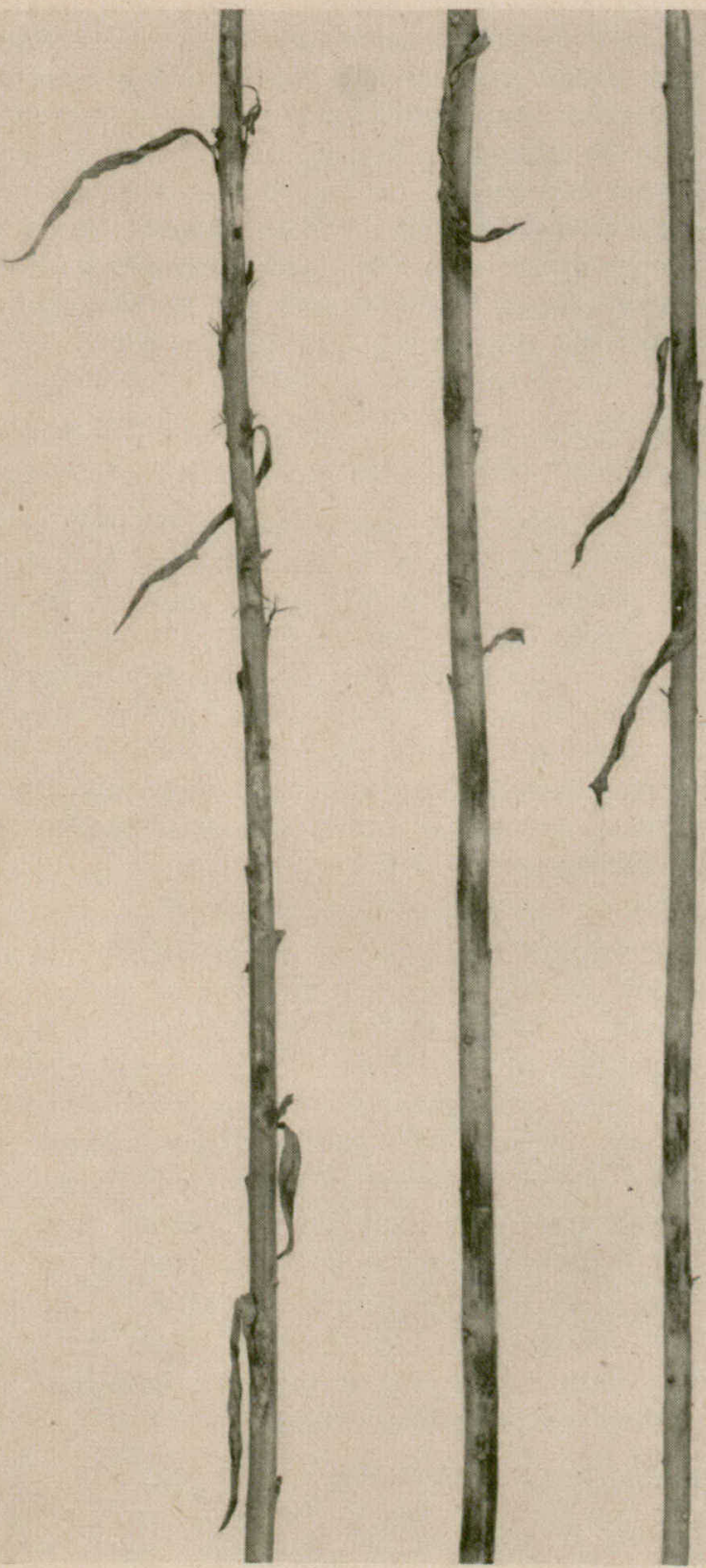

Figure 18.-Flax affected with pasmo disease. 
of the first leaves may be infected. More commonly, however, infections start from diseased stubble from a preceding crop. Large numbers of spores ooze out of the fruiting bodies, and are spread by wind and rain. The infections spread in the field to form small patches which turn brown. When temperatures are fairly high and there is sufficient moisture, the disease may spread very rapidly. The patches enlarge until the whole field may be affected, causing it to turn brown or ripen prematurely.

Control-No resistant varieties are known. Some varieties, such as Viking, are particularly susceptible, and should be avoided wherever there is danger of pasmo infection. Until pasmo-resistant flax varieties are available, other methods must be used in the effort to control the disease. As the fungus may be carried on or with the seed, it is important to use the best seed available, to clean seed flax very thoroughly, and to treat it with a good mercurial seed disinfectant. Flax should be sown as early as possible after danger of severe frost is past, to escape early infection. Flax crops should be spaced several years apart in the rotation to help control pasmo and other diseases that live over on the stubble. When flax follows flax on the same land, losses from disease may become severe.

\section{Heat Canker}

\section{Nonparasitic}

Heat canker is a nonparasitic disease of flax. It usually occurs after several days of excessively high temperatures in late June or July. The soil around the stems of young flax plants becomes hot enough to injure or kill the outer tissues which are important in the movement of food in the plant. In Western Canada damage is usually confined to a small percentage of the plants scattered throughout the field or in small patches, but losses up to 50 per cent have occurred. Damage is usually most severe in thin stands on light soils.

Appearance-Plants affected by heat canker are constricted or girdled at or near the soil line. The belowground portion of the stem is usually thin and dry, while the area above the girdling is enlarged as a result of the accumulation of food from the leaves. The enlarged portion is often rough and cracked, or cankered. Affected plants usually fall over. Young plants which are killed by the stem injury may dry up and not be noticed. Plants which survive the injury only to topple over later in the season, gradually turn yellow and die.

Control-Early seeding helps flax plants to pass through the most susceptible stage before the weather gets hot. The only other control measure is to protect the bases of young plants from direct exposure to the sun and consequent overheating and injury. This may be done by heavy seeding, and by sowing north and south, so that the plants shade each other from the sun during the hottest part of the day. 


\section{Seedling Blight and Root Rot}

Rhizoctonia solani, Pythium spp. and Fusarium spp.

Seedling blight of flax is common in flax fields throughout Western Canada in June. It may be caused by several different soil-borne fungi, the most important of which, Rhizoctonia, is particularly destructive in moist, warm soil following summerfallow. In most years the damage is relatively light, usually not exceeding one per cent. In some years, however, losses may be heavy; occasional fields are almost completely destroyed.

Root rot of older plants is rarely as conspicuous as seedling blight. Diseased plants may produce less seed than healthy plants, or may die before the seed is ripe. Root rot is caused by some of the same fungi which cause seedling blight.

Appearance-Plants affected by seedling blight may occur singly or in patches. The patches may involve only a few plants in a row, or may be many yards in diameter. Affected seedlings turn yellow, wilt, and die. If they are killed early in the season, they may be beaten into the ground by rain and disappear. The roots of recently attacked plants show reddish to brown areas, but shrivel and turn uniformly dark within a few days. Diseased seedlings are difficult to distinguish from those killed by the flax-wilt fungus.

Root-rot symptoms usually appear on plants after the flowering stage. The plants turn brown prematurely and usually set few or no seeds. The underground portion of the stem, and the roots, are discolored and may be stunted.

Control-No control methods can be depended upon to prevent seedling blight completely, but certain measures can be used to reduce losses. Good seed, as free as possible from cracks, should be used. Early seeding helps the young plants get past the most susceptible stage before conditions are favorable for rapid attack by the blight organisms. Rhizoctonia, the most common cause of seedling blight, is most destructive on loose, well-worked soil. Sowing flax on second-crop land, rather than summerfallow, and packing behind the seeder, help to provide a firm seedbed and to reduce seedling blight. Seed treatment with a recommended chemical helps to produce vigorous, fast-growing seedlings which may escape infection.

The conditions favoring flax root rot are not well known. As some of the fungi which may cause the disease tend to increase when flax is grown repeatedly on the same land, crop rotation should be practised, even though it cannot be depended upon to give complete control of the disease.

\section{Wilt}

Fusarium oxysporum f. lini

Flax wilt is caused by a soil-borne fungus which invades the plant through the roots. The fungus builds up and the disease becomes 
progressively more severe in land cropped repeatedly to flax, causing what was formerly known as 'flax-sick soil'. Before the cause of the disease was discovered in 1900 , flax was considered safe to grow only on newly broken land, because yields were often greatly reduced, or crops entirely lost, when flax was grown repeatedly on the same land. The knowledge of the cause of the disease, and the development of wilt-resistant varieties, made it possible to include flax in the regular cropping program even in long-established agricultural areas.

Appearance-The wilt fungus may cause a blighting of seedlings before they emerge from the soil, or the death of young plants, as well as the characteristic wilting of plants right up to maturity. Blighting of seedlings may cause gaps in the stand. Later attacks cause yellowing and wilting of the leaves, followed by wilting, browning, and death of the stems (Fig. 19). The tops of wilted plants often curve downward in the shape of a shepherd's crook. Wilted and dead plants may be scattered through the field, but more commonly they occur in patches. Frequently plants are only partly wilted, with a brown stripe extending from the soil line up along one side of the stem, while the leaves on the rest of the stem are quite healthy.

Disease Cycle-Once established in the soil, the wilt fungus may remain for many years. When susceptible flax is grown in infested soil, the roots are invaded and wilting results. Infection may occur in cool soil, but the disease usually develops best in warm weather. If susceptible flax is grown in the same soil for a number of years, there may be only traces of wilt in the first year, but in two to three years almost all the plants may be attacked. The mycelium and spores of the fungus survive most readily in the remains of diseased flax plants, but the fungus also seems able to maintain itself in the soil for a number of years even in the absence of flax. The fungus may be spread from field to field by wind-blown soil, or by run-off or irrigation water. It may also be spread as spores on the seed from a diseased crop. This is not usually an important source of infection, but it may serve to introduce the fungus into soil previously free of wilt, or it may bring in new and possibly dangerous races of the fungus.

Control-The most effective way to control flax wilt is to sow only resistant varieties. Most of the popular varieties now grown are resistant to wilt. No variety is immune to wilt under all conditions, however, and as there are many races of the wilt fungus which differ in their ability to attack the various kinds of flax, there is no assurance that a variety which is wilt-resistant when it is first released will remain resistant, or that it will be resistant when grown in areas where it has not previously been tested. Crop rotation is important because it prevents an increase of the wilt fungus in the soil. Seed treatment with recommended chemicals reduces the chances of introducing seed-borne spores of the wilt fungus. 


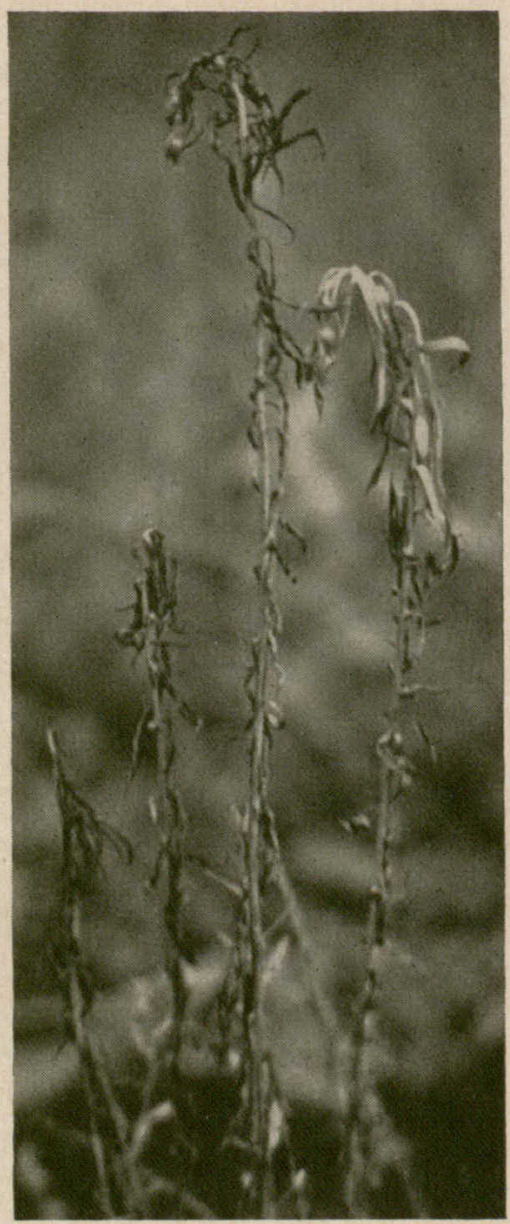

Figure 19.-Wilt of flax.

\section{Stem Break and Browning \\ Polyspora lini}

Stem break and browning are two forms of a disease, caused by a seed-borne fungus, which occurs in the park belt of Saskatchewan and Alberta and is responsible for appreciable damage in some years. The disease has been found in Manitoba but is not common nor destructive there.

Appearance-The earliest symptoms are water-soaked spots which develop very slowly on the first leaves. Plants are rarely killed in the seedling stage. The fungus spreads from the leaves to the first node of the stem and develops there. When the plants are in bud or flower, they may 
break over at the weakened first node (Fig. 20). They may live after falling over, but even if seed is set, it is usually lost in harvesting. Infections on the upper part of the stem appear as oval or elongate brown spots, about one-quarter inch long. The spots, which usually remain separate, are often surrounded by a narrow, purplish margin. Sometimes the spots are numerous enough to grow together and cover much of the stem. Patches of heavily infected plants appear brown, giving the disease the name 'browning'. The fungus may attack the bolls and penetrate into the seeds. If the seeds are infected while they are young, they may be killed. If they are attacked when they are relatively mature, the fungus grows into the seed coat and survives there.

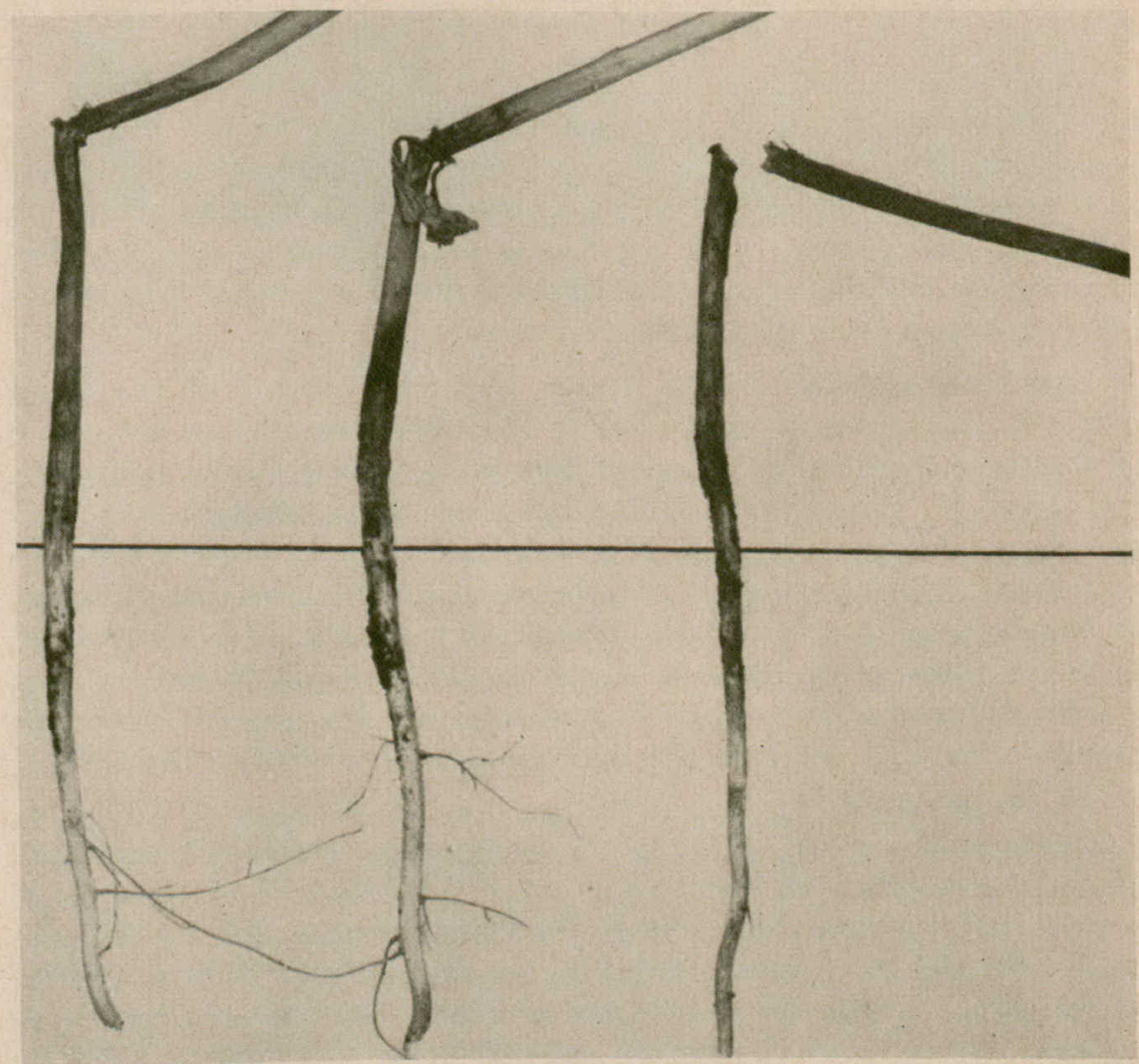

Figure 20.-Stem break of flax. The horizontal line represents the soil line. (Photograph by courtesy of Prof. T. C. Vanterpool.)

Disease Cycle-When diseased seed is sown and germinates, the seed-coats are carried above the soil by the seed leaves and spores from the seed coats start infections in the new crop. The fungus can also survive the winter on diseased stubble and produce spores, which may be spread by wind and rain. 
Control-Chemical seed treatment may kill the spores on the surface of the seed, but is not usually effective against the mycelium within the seed coat. As the disease is largely seed-borne, it is important not to use seed from a crop showing stem break or browning. Crop rotation reduces infection derived from diseased stubble. Early seeding reduces injury by helping the flax crop to develop rapidly and to ripen before the disease becomes severe. There are differences in the reaction of flax varieties to stem break and browning, but the disease is not sufficiently important in Western Canada to require the growing of resistant varieties.

\section{Seed Rot}

\section{Seed cracking}

The principal cause of seed rot in flax is the fracturing of seed by faulty threshing. A survey carried on for several years showed that on an average over 50 per cent of the seeds of flax produced in Western Canada are fractured. Large-seeded varieties of flax seem to be more susceptible than small-seeded ones. Seed rot due to seed-fracture is now the chief reason for the recommendation that all the flax in Canada should be treated with a protective fungicide before it is sown.

Appearance-Large breaks in the seed coat of flax may be seen without difficulty, but the much more common hairline cracks are almost invisible unless the seed is examined through a fairly powerful magnifying glass. Since the cracks are most abundant when flax is threshed during very dry weather, bright samples of seed are more likely to show injury than dull ones. The fractures are of different lengths, running inward from the edge of the seed, sometimes completely across it (Fig. 21). This illustration shows seeds which had been soaked in a caustic soda solution to make the cracks more visible. Although very narrow, the cracks are generally deep, and penetrate the dormant seed leaves within the seed, as well as the seed coat.

When fractured seed is sown it is attacked by a wide variety of soil microorganisms which enter the cracks and grow into the seed embryo. If the fractures are many and conditions for germination are unfavorable, then the seed does not even begin to germinate but rots quickly. When conditions are favorable, the fractured seed may germinate but produces only weak seedlings with small, brown spots on the seed leaves. These spots are areas invaded by soil organisms. There is less seed-rotting in sandy soil than in clay soil. Soil temperature is a relatively unimportant factor for this disease.

Control-The best way to prevent seed rot is to treat the seed with a protective seed disinfectant. The rate of application must be double or treble that used for seeds of cereal crops. 


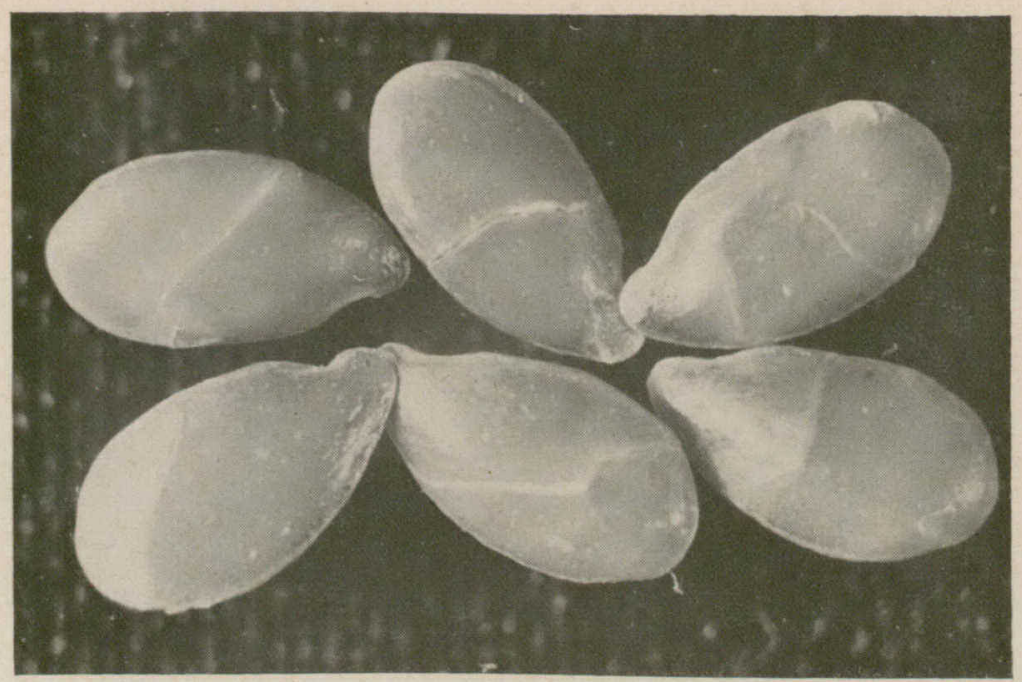

Figure 21.-Cracks in the seed coat of flax seed caused by injury in threshing during dry weather.

\section{Other Diseases}

Chlorosis (Nonparasitic) - A yellowing or chlorosis of young flax plants is common in many areas in Manitoba and Saskatchewan. Sometimes this condition is due to lack of aeration in water-logged soil. The lack of aeration results in a temporary nitrogen deficiency in the soil. When chlorosis occurs in the higher parts of fields, as well as in the low, wet spots, it may be a sign of iron deficiency. This deficiency is induced by an excess of lime in the soil, which makes the iron unavailable to the plants. There are no practical control measures.

Boll Blight (Nonparasitic)-The buds, flowers, and young bolls of flax plants often fail to develop, particularly when warm, dry weather follows a cool, moist spell (Fig. 22). Blighting of 30 per cent or more of the bolls commonly occurs. The cause of the trouble is not definitely known, but it seems to be a response by the plant, which sacrifices some of the bolls that were formed earlier during favorable conditions, but that cannot be brought to maturity because of drought, disease, or other factors.

Top Dieback (Nonparasitic)-The upper portions of flax plants may turn brown after a hot spell during the ripening period. Usually the discoloration involves the upper third of the stem, but sometimes the whole plant may turn brown. The seeds of affected plants are usually thin and light. The discolored plants often occur in patches, but sometimes most of the plants in a field are affected. 


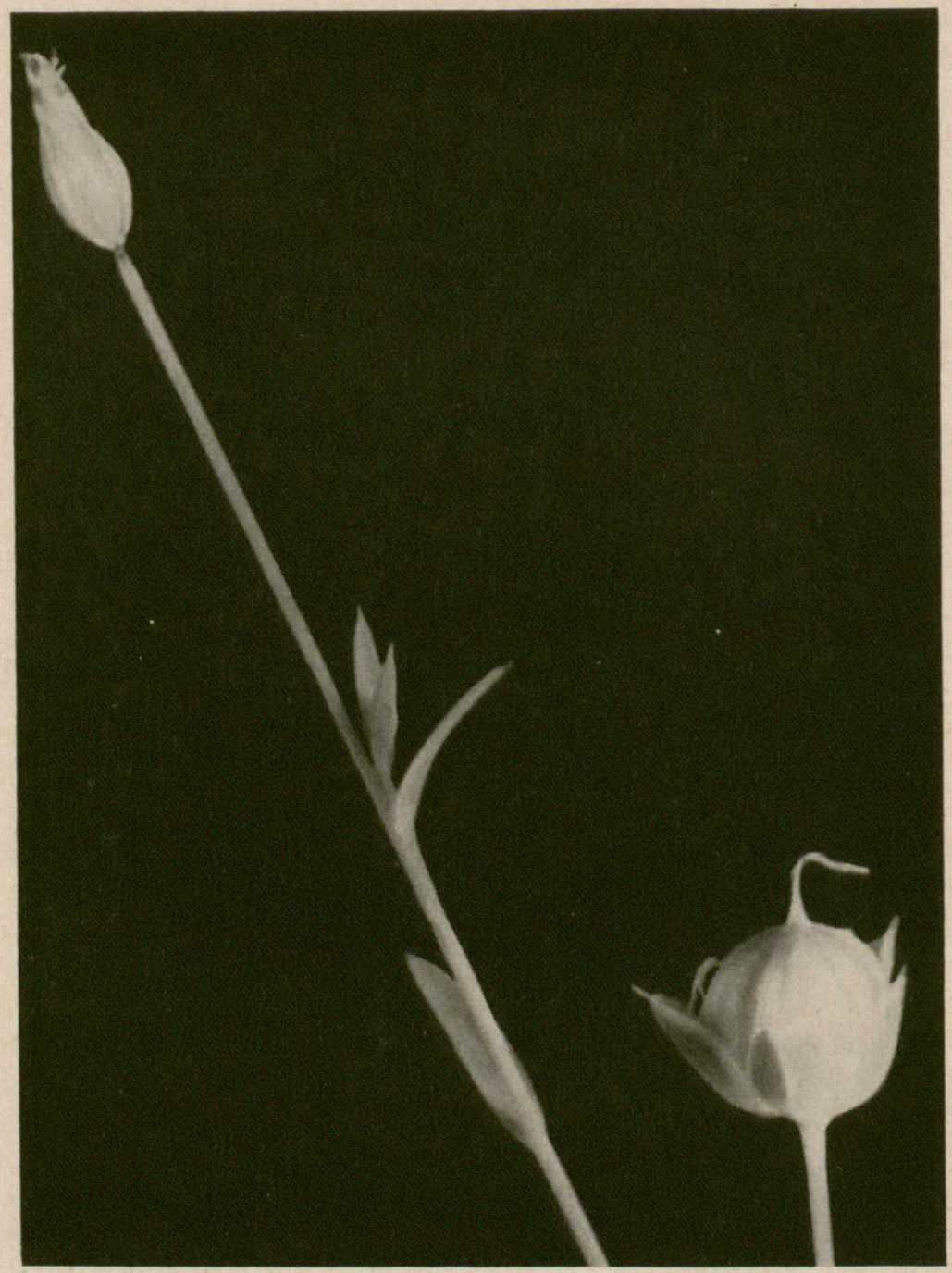

Figure 22.-Boll blight of flax, a nonparasitic disease.

Virus Yellows (Aster yellows virus, suspected)-A virus disease, spread by leafhoppers, has been widespread in Manitoba and Saskatchewan since 1952, but has not caused appreciable losses. It causes stunting, yellowing and bunching of the upper leaves, and distortion of the flower parts (Fig. 23). The petals remain greenish and leaf-like. Affected flowers do not set seed. Destruction of weeds in and near the flax crop may help to reduce the amount of virus and the numbers of the leafhoppers which carry it.

$$
=
$$




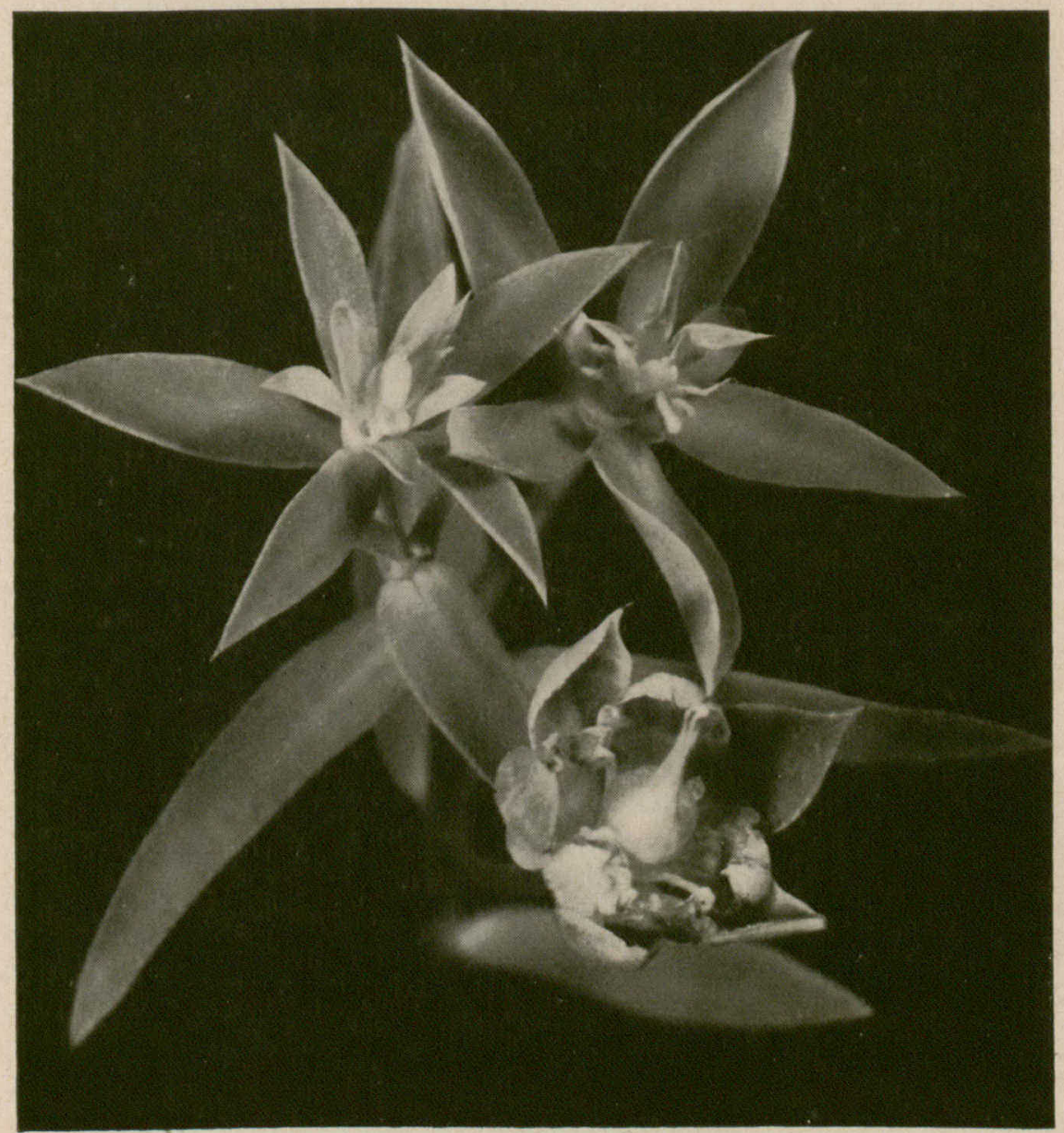

Figure 23.-Aster yellows in flax, a disease caused by a virus. The photograph shows the distorted floral parts, much magnified. 


\section{Diseases of Sunflowers}

\section{Rust}

\section{Puccinia helianthi}

Sunflower rust is a fungus disease that affects the leaves and sometimes the stems and lower surface of the head. The rust occurs wherever sunflowers are grown. It has been known in Manitoba, the main sunflower-growing region in North America, for more than 30 years, but did not cause serious losses until sunflower production became intensive over a fairly large area. Rust severity increased from 1949 to 1951 , then decreased sharply with the decrease in sunflower acreage in 1952 and 1953. Damage caused by the rust depends on the stage at which the crop is attacked. Early infection of susceptible varieties may reduce yields of seed by 25 to 50 per cent. The very susceptible inbred line, S37-388, used as the female parent in producing Advance hybrid seed, was rusted so heavily in some fields in 1951 that it did not produce any seed. Late infections usually cause appreciably less damage.

Appearance-The first rust infections usually occur in mid-June on volunteer seedlings as small clusters of pale-yellow or orange spots on the upper surface of the first leaves. These are followed by yellow or orange spots on the lower surface of the leaves. The most conspicuous stage of the rust usually begins to develop in July and August as dark-brown, small, dusty spots on both surfaces of the leaves (Fig. 24). In bad rust years, almost the whole surface of the leaf may be rusted. The lower leaves usually show more rust than the upper leaves, as the infection commonly starts there. Heavily rusted leaves dry up and die prematurely, sometimes before the seed has filled. As the plants ripen, the rust spots on the leaves turn darker brown. Spots on the stems turn black.

Disease Cycle-The sunflower rust fungus attacks only cultivated and wild sunflowers; it does not have an alternate host like the cereal rusts. The dark-brown or black spores, which are produced late in the season, overwinter on dead leaves and stems. In the spring, these overwintered spores germinate and produce spores which infect volunteer sunflower seedlings, or young plants of the new crop in nearby fields. The first and second spore stages produced on young leaves are inconspicuous. As the brown summer-spore stage develops and spreads, it causes infections on other plants in the same field and in nearby fields. In warm, moist weather, new spores may be produced in seven to ten days after infection takes place. The spores are carried by the wind, but as sunflowers are grown on a small area compared with the acreage sown to wheat, the number of spores in the air is relatively small, and long-distance spread by wind does not seem to be important. As the crop ripens, the summer spores are replaced by the overwintering spores, which are produced in the same rust spots. 


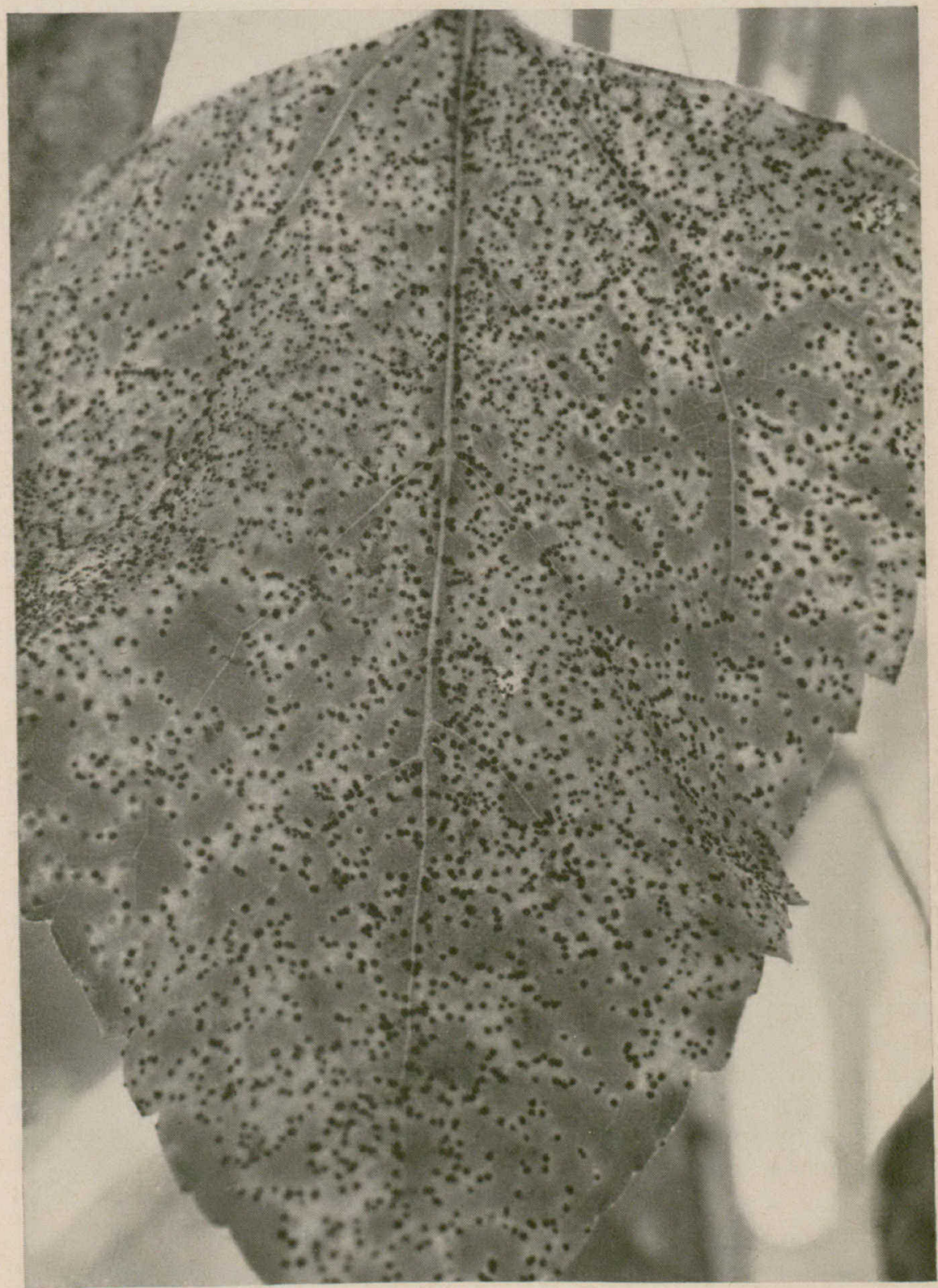

Figure 24.-Sunflower rust. 
Control-The first rust-resistant sunflower variety, Beacon, was licenced in 1954 for distribution in 1955 in the Red River Valley area of Manitoba. Earlier and more widely adaptable varieties may be produced later. Because rust infection of sunflowers is usually of local origin, the disease may be controlled to a large extent by crop rotation, by destroying volunteer seedlings and the overwintered remains of the previous crop before the new crop has emerged, and by locating sunflower fields as far as possible from the fields where the crop was grown the preceding year.

\section{Sclerotinia Wilt}

\section{Sclerotinia sclerotiorum}

Wilt, stem rot, root rot and head rot of sunflowers are caused by a soil-borne fungus which also attacks a large number of different kinds of broad-leaved crop plants and common weeds. It is world-wide in distribution. The sunflower wilt disease has been known in Manitoba for many years. Almost every year traces of Sclerotinia wilt occur in most sunflower fields; in a few fields 5 to 10 per cent of the plants may be killed; occasionally about 50 per cent of the plants are destroyed. Although the loss to individual growers is sometimes heavy, the percentage of the total crop lost in any year is usually not very great.

Appearance-Sclerotinia wilt usually appears in sunflower fields at about flowering time. Diseased plants may occur singly, in small groups, or in large patches. Some young plants show wilt symptoms early in the season, but results in experimental plots indicate that wilt develops most rapidly following the warm weather of July and early August. The upper leaves of infected plants droop as if they were suffering from a shortage of water (Fig. 25). Within two or three days, all the leaves wilt and dry out. In a very short time the plant dies. Young, wilted plants often turn almost black; mature plants usually remain straw colored. The stems of wilted plants often appear shredded, are weakened, and may break over at the soil line or at any point along the lower half of the stem. At the base of diseased plants, sometimes extending for an inch or two above the soil line, there is often a mass of cottony-white mycelium of the fungus, containing dense white structures called sclerotia, which develop a hard rind and turn black as they mature. Sclerotia are also produced inside infected stems and in sunflower heads rotted by the fungus. The size and shape of the sclerotia vary according to the tissues in which they are produced. They may be almost round, from an eighth to a quarter of an inch in diameter, or long and narrow if formed inside the stem, or wide and flat if formed in the head.

Disease Cycle-The sclerotia are the overwintering stage of the fungus. They can survive in the soil for one or more years. When conditions are suitable, they germinate by producing mycelium which can infect the roots of susceptible plants, eventually forming more sclerotia which may remain 


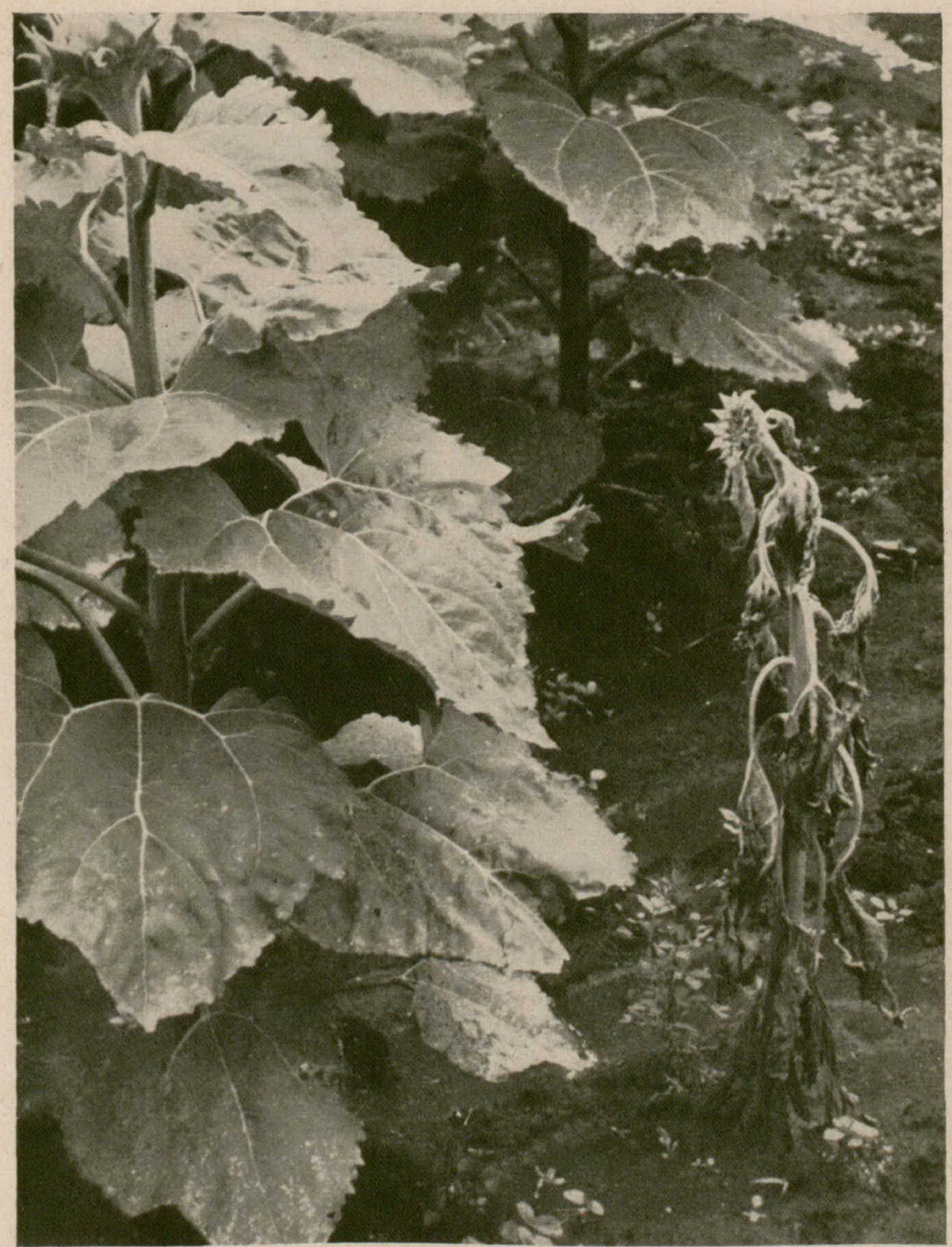

Figure 25.-Sclerotinia wilt of sunflowers.

in the soil. In moist, cool seasons, the sclerotia may produce small fruiting bodies which liberate spores into the air. The spores produced in this way are important in starting infections in some areas, but seem to be quite unimportant under Manitoba conditions, where the spread of the fungus seems usually to be limited to the distance that the mycelium can extend through the soil. 
Control-There are no varieties of sunflowers resistant to Sclerotinia. Many of the broad-leaved crops such as rape, field peas, and some vegetables, and common weeds such as pigweed and Canada thistle, are quite susceptible and the fungus can survive or increase on them. Cereal grains and grasses are not susceptible. Losses can usually be kept down to minor proportions by controlling the susceptible weeds, and by sowing cereals or seeding down to grass between susceptible crops in the rotation.

\section{Downy Mildew}

\section{Plasmopara halstedii}

Downy mildew is caused by a soil-borne fungus which attacks sunflowers and closely related plants. Infected plants seldom produce any seed. There has been relatively little downy mildew damage in Manitoba until recently, although the disease has been known there for many years. In 1953 and 1954, possibly as the result of a succession of wet years, the disease was more prevalent than usual, and caused severe losses in two or three fields.

Appearance-Plants affected by downy mildew show the disease at almost any stage. Diseased plants may occur singly, in groups, or in large patches. Infected seedlings have a pale-green or yellowish area spreading out from the midribs of the leaves. In moist weather, the under surface of the pale portion may be covered with a downy growth of the white mycelium and spores of the fungus. As the plants grow older, there may be some wrinkling and distortion associated with the pale color of the leaves, and the plants are usually stunted. At flowering time, when unaffected plants are four to five feet tall, mildewed plants may be from six inches to two or three feet tall. Stunted plants usually produce heads, sometimes normal in size, but as they contain only empty seeds and are light, they remain upright, instead of bending over as normal sunflower heads do. (Color Fig. 4).

Disease Cycle-The downy-mildew fungus has a resting-spore stage which can survive in the soil over winter, and possibly for many years. These spores germinate in moist soil and can attack the roots of young sunflowers. The mycelium of the fungus spreads throughout the plant, producing a systemic infection. In moist weather, the mycelium grows out from the under surface of diseased leaves and produces spores which can infect other plants, but this type of secondary infection is slight in Manitoba. The overwintering spores may be produced in the roots, stems, or leaves of diseased plants, and are released into the soil when the diseased tissues rot. It has been suggested that the overwintering spores may also form on sunflower seeds and may transmit the disease when the seeds are sown, but the results of experiments to test this possibility have been inconclusive. Viable seed is rarely produced on systemically infected plants. When such seed is sown, it does not give rise to mildewed seedlings. 
Control-Sunflowers should not be included in a rotation oftener than once in three or four years. Although the downy-mildew fungus and some other disease-producing organisms may survive in the soil for several years, the chances of heavy infection are greatly reduced when susceptible crops are sown only at fairly long intervals. Susceptible weeds, such as ragweed, wild sunflowers, and thistles, should be controlled. Because the fungus develops and spreads in moist soil, sunflowers should not be sown in low, wet fields.

\section{Other Diseases}

Powdery Mildew (Erysiphe cichoracearum)-Powdery mildew usually appears on sunflowers in Manitoba shortly before harvest, too late to affect seed yield. It is caused by the growth on the leaves of a fungus whose pale-colored mycelium and whitish spores give the leaves a dusty or powdery appearance.

Leaf Mottle (Cause unknown) - This disease, first observed in Manitoba in 1948, was more severe in 1954 than in previous years. Some fields with a high percentage of mottled plants gave lower seed yields than neighboring, apparently healthy fields. Affected plants may occur singly, in groups, or in large areas. The disease shows up first on the lower leaves and develops gradually on leaves higher along the stem. The tissue between the veins of affected leaves becomes pale green, then yellow, and finally dies and turns brown, giving the leaf a blotchy or mottled appearance. No control is known, but early seeding may possibly help plants escape some of the damage.

Stalk Rot (Various causes)-Plants with discolored stems occur in varying amounts in sunflower fields in late August and September. Stem discolorations appear as brown or black blotches extending out from the leaf stalks, or may involve the whole stem. The pith inside such discolored stems is often discolored and rotted. Some of the external discoloration seems to be the result of attack by fungi which grow out from tunnels made in the pith by boring insects; some of it is apparently the result of infection by bacteria; some does not seem to be associated with any obvious cause.

Premature Ripening (Various causes)-Prematurely ripe, brown plants are conspicuous in sunflower fields in some seasons, when the heads of normal plants are still two to three weeks from maturity. Affected plants usually have smaller heads, with lighter seeds, and the heads are soft and flabby, instead of firm like those of normally ripened plants. Prematurely ripe plants sometimes occur, along with plants showing stalk rot, in fields in which leaf mottle was conspicuous earlier in the growing season, but they also are found frequently where no mottle was seen. The condition is often associated with stalk rot, but has also been seen on plants with sound, 
white pith. Some cases of premature ripening have been associated with severe rust damage, some with poorly drained or alkaline patches in fields, but others could not be explained at all.

Virus Yellows (Aster yellows virus, suspected) -A distortion of sunflower heads was found on a few plants in a number of fields in 1953 and 1954. The virus that is suspected of causing the disease affects many kinds of plants, including weeds, and is spread only by a common species of leaf hopper. The flowers in a wedge-shaped portion, or sector, of the head remain green, grow larger than the rest, and do not set seed. As the disease develops, the sector turns brown and dies. The brown discoloration extends downward as a narrow stripe along the stem, at first only on the surface, but later in the deeper tissues as well. Some of the affected plants are stunted, some break over as the result of the weakening of their stems, but others survive and set seeds on the apparently normal portion of the head. Although no practical control is known, keeping down the weeds on which the virus and the insects may overwinter is good farm practice. 


\section{Diseases of Peas}

\section{Bacterial Blight \\ Pseudomonas pisi}

The total field pea production in the Prairie Provinces does not rank in importance with that of a major cereal crop, but to a farmer whose pea crop occupies a substantial proportion of his acreage, bacterial blight of peas may seem more important than stem rust of wheat. Whether the pea plants are in a commercial field or a small garden, damage caused by bacterial blight is objectionable and to be avoided wherever possible.

Appearance - The disease causes dark-green, water-soaked spots on any or all the aboveground parts of the plants: leaves, stems, leaf stalks and pods. Later these spots may dry and turn a light-brown color. In a severe infection, the flowers may be attacked so that the young pods either fail to form or shrivel up at an early stage. Older pods become more or less heavily spotted. Injuries such as those caused by hail facilitate the spread of the disease. Fields may be rendered worthless because of the spread of infection in the wounds caused by the hailstones.

Disease Cycle - Infected seed (Fig. 26) may initiate the disease in the spring and the secondary spread from the infected seedlings may take place rapidly in moist weather. In severe attacks, the whole vine may be killed without producing any seed. Under drier conditions, the disease may damage the plants and result in a reduced yield of seed, a proportion of which will be either infected or surface-contaminated. The organism lives readily on the dry seed for long periods.

Control-The best means of control is to sow seed from disease-free fields. Disease-free seed is most satisfactorily produced in irrigated areas in which the rainfall is less than half an inch during the growing season. Such conditions do not occur anywhere in Canada. Much of the seed for the canning pea crop is imported from irrigated areas in Idaho where the summer rainfall is low. Such seed is not always completely free of bacterial blight, but carries so little infection that the disease does not become excessive in the single crop grown for canning.

Disease-free seed of field peas is not available. The seed is usually produced locally under somewhat moist conditions and the disease builds up so as to cause considerable losses in wet years. It seems likely that if sufficient demand existed for field-pea seed grown under dry air conditions, it would be possible to produce comparatively disease-free seed as is the common practice with canning peas. 


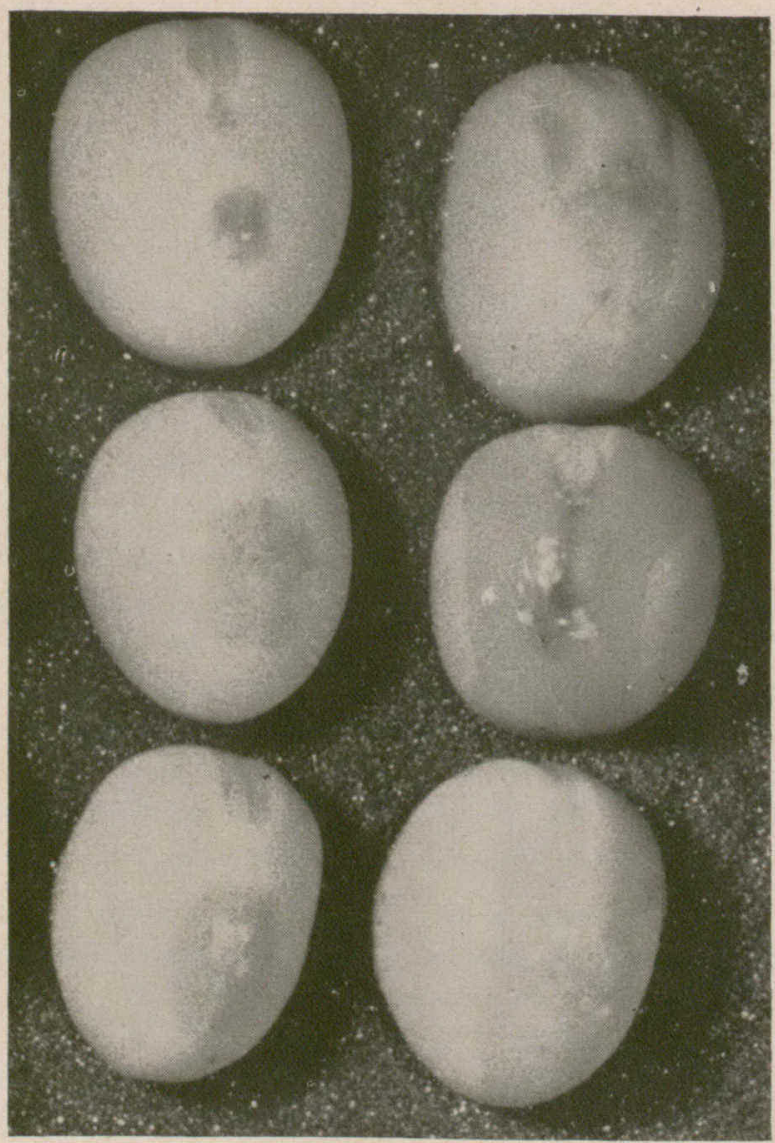

Figure 26.-Pea seeds affected by bacterial blight. Note watersoaked areas.

\section{Ascochyta Blight}

Ascochyta pisi, A. pinodella, and Mycosphaerella pinodes

Ascochyta blight is caused by one or more of the fungi named above. This disease is widespread and, occasionally, has been a serious threat to the seed and green-pea industries in areas of abundant moisture.

Appearance-Somewhat similar though distinguishable, symptoms are caused by the three parasites. The leaf spots caused by $M$. pinodes are purplish with indefinite margins. Fusion of the spots results in irregular brownish-purple blotches. The blotches on the stems are elongated at first; later, fusion of the blotches gives the entire lower stem a bluish cast. When small, pin-point infections appear on the flower parts, blossom drop commonly follows. The symptoms caused by $A$. pinodella on the plant are 
like those of $M$. pinodes but less severe, yet it causes a more severe foot rot, that is, the base of the plant is more severely attacked. The sunken spots caused by $A$. pisi on the leaves have clear-cut margins. The spots are tan or brown in the center and a darker shade of the same color at the margin. A. pisi may also cause a foot rot.

All three fungi infect the seed through the pod. Infected seed may have either no visible symptoms or it may show various degrees of shrinkage and discoloration.

Disease Cycle-The three fungi can survive in the seed and thus become spread over long distances. They can also live over winter in infected pea straw but not in soil free of plant remains. On the straw, spores are produced which are spread about chiefly by the splashing of raindrops. One of the fungi, $M$. pinodes, develops also a kind of spore that is shot out forcibly and carried in wind currents. These spores serve to spread the disease over wide areas.

The disease may appear on the very young seedling at the point of attachment of the seed; such an infection is usually fatal to the seedling. Later, infections may occur anywhere on the seedlings, and from the infected seedlings the disease may spread in wet weather to nearby plants. Thus the disease may build up from a scattered infection in the early summer to a severe infection later in the season.

Control-The disease is best controlled by the use of disease-free seed, crop rotation and sanitation. Seed grown in semiarid, irrigated areas is likely to be free of infection. A 4- or 5-year rotation will largely eliminate the organisms from the soil. Every effort should be made to locate new plantings as far as possible from those of the previous season, and as much as possible of the pea straw and trash should be destroyed.

\section{Root Rot}

\section{Aphanomyces eutiches, Fusarium solani, Pythium ultimum,} Rhizoctonia solani

Root rot of peas is caused by a number of fungi which singly or together attack the outer layers of the root. The damage varies with the season. The disease may act as a seedling blight or it may attack late in the season. One year the crop may fail; the next year, on the same piece of land, the crop may be healthy.

Appearance-Aphanomyces causes a watery, soft rot of the outer layers of the stem and roots near the soil line. In time this tissue collapses and dies and all that remains is the woody tissue. Young plants usually die; older plants are stunted and their leaves turn yellow and die from the ground up.

Fusarium root rot usually starts on the seedling at the junction of root and stem, where the seed is attached. The rot extends upwards on the 
stem and downwards on the root as a reddish-brown area. In time the stem becomes girdled. The disease is most damaging at high temperature $\left(80^{\circ} \mathrm{F}\right.$.) and on later crops.

Rhizoctonia root rot is primarily a seedling disease in which a yellowish-brown rotting occurs near the point of seed attachment. The fungus frequently attacks the growing point of the seedling, killing it before it emerges. A soil temperature of $60^{\circ}$ to $65^{\circ} \mathrm{F}$. is most favorable to the fungus.

Most of the damage from Pythium results from seedling injury and seed decay. Affected plants show a water-soaked, somewhat translucent and softened tissue extending above and below the region of seed attachment. The disease develops best in wet soil.

Disease Cycle-Aphanomyces and Pythium survive in the soil by means of thick-walled resting spores. These germinate and infect young tissue. Rhizoctonia and Fusarium survive as mycelium in the soil.

Control-Seed treatment largely controls seed decay and damping-off caused by Fusarium, Pythium and Rhizoctonia but it does not control infection beyond those stages. Aphanomyces root rot is not controllable by seed treatment. Crop rotation keeps the fungi from building up in the soil. No resistant varieties are available. 


\title{
Diseases of Alfalfa and Sweet Clover
}

\author{
Black Stem \\ Ascochyta imperfecta on alfalfa \\ Ascochyta meliloti on sweet clover
}

Black stem is essentially a leaf and stem disease, but may also cause blighting of seedlings and diseased areas on the crowns of mature plants. Losses are caused by reduction in stands through seedling blight, crown tot, and stem killing, by reduction in seed yield through blossom and pod drop and seed infection, and by reduction in hay yield through destruction of leaves. The disease is present in almost all areas where alfalfa and sweet clover are grown, and is especially severe in northern seed-growing areas where heavy dews, frequent rains, and low evaporation are common.

Appearance-The disease appears in early summer as small irregular dark-brown or black spots on the lower leaves. There may be similar spots on the crown buds and at the bottom of the young stems, some of which are killed in their early growth. Spots may run together to form large, blackened areas which often girdle and kill older stems. Severe spotting on the leaves causes defoliation. During cool, moist weather infection may spread to the flower stalks causing the blossoms or pods to drop off. Pod and seed infections also occur. Severely infected seed is shriveled, and usually is lost during threshing.

Disease Cycle - The fungus persists on seed, on fallen leaves, pods, and straw, and in the crown tissues. The fruiting bodies of the fungus mature on dead plant tissues during the fall and spring and produce spores which are spread by water to new growth. The fungus will survive on dried plant material and seed for several years, but in the absence of the plants it usually does not persist more than two years in the soil.

Control-Hay crops should be cut before many of the leaves are destroyed by leaf spot. Burning the stubble of seed crops in the early spring destroys the fungus growing on the dead plant material and usually reduces spring infection to some extent. This method of control should be used with caution as the crop may be badly damaged by burning after spring growth has begun.

\section{Bacterial Wilt of Alfalfa}

\section{Corynebacterium insidiosum}

Bacterial wilt has been the most important disease of alfalfa in the United States for many years. It has also proved very destructive in the irrigated areas of southern Alberta since it became established there about 
1939. This disease greatly reduces the yield and shortens the life of stands of Grimm and other susceptible varieties. It is favored by abundant moisture and is usually most severe in low, poorly drained spots. Although it has spread into central and northern Alberta, Saskatchewan, and Manitoba, severe general damage is still confined to the irrigated areas. Local outbreaks, however, occur in other areas well supplied with moisture, especially after one or more seasons of heavy rainfall.

Appearance-A gradual stunting and yellowing of alfalfa plants in the second or third year of growth is usually the first sign of bacterial wilt. The stems are shortened and bunched, and the leaves are smaller than normal, pale, and curled upward at the edges. Wilting of the tips of the shoots of whole plants sometimes occurs during warm weather. As the disease progresses, plants with all degrees of stunting, ranging from extremely dwarfed to nearly normal, appear in the field. The severely affected ones soon die and the others are progressively weakened (Color Fig. 3).

Bacterial wilt can be identified, even before the top symptoms appear, by examining the roots of suspected plants. If the bark of the main tap root of an infected plant is peeled, a yellowish-brown discoloration or streaking can be seen on the woody cylinder beneath, in contrast to a creamy white color in the roots of healthy plants: This discoloration becomes darker and extends into the branch roots as infection develops. It appears as a brown ring in a cross-section cut from the root of a severely infected plant.

Disease Cycle-The bacteria overwinter mainly in diseased alfalfa roots and in plant remains in the soil. They are carried by soil water and enter healthy plants in the spring through wounds produced by winter injury, insects, or mechanical damage. As the bacteria develop inside the root, the water-conducting tissues become clogged and this results in stunting, yellowing, and eventual death of the plant. In the advanced stages of the disease, the bacteria accumulate in the crown and basal stems and are released when these tissues start to decay.

Control-The use of resistant varieties of alfalfa is the only satisfactory way of controlling bacterial wilt. In southern Alberta and Saskatchewan, the partially resistant variety Ladak is being recommended until a more resistant, hardy variety is available. Stands of Ladak will last from one to two years longer than those of Grimm in wilt-infested, irrigated land.

Certain cultural practices may aid in delaying the spread and development of the disease. In the irrigated areas only enough water should be used to secure good growth of the alfalfa. The water should not be allowed to run from a diseased stand to a young, healthy one, and all young stands should be cut before the mower is taken into the older, diseased stands. Cultivation of diseased stands is seldom advisable since it will 
wound the alfalfa roots and spread the bacteria. Fields that have been severely damaged by bacterial wilt should not be reseeded to alfalfa for at least two years. Cereals or other crops can be grown in the meantime since only alfalfa suffers damage under natural conditions.

\section{Common Leaf Spot}

\section{Pseudopeziza medicaginis}

Common leaf spot is caused by a parasitic fungus and is one of the major foliage diseases of alfalfa. Crop losses occur through killing of leaves and reduction in the quality of hay from infected fields. The disease is of less importance on sweet clover although local outbreaks may cause some damage. It is found in all parts of Western Canada.

Appearance-Common leaf spot may be recognized by the small, dark-brown, circular spots which develop on the leaves (Color Fig. 1). When the spots become mature, a small, raised disk appears in the center of each. This is the fruiting body of the fungus, and its presence distinguishes the spots from those caused by the black-stem fungus. The plants are not killed by the disease, but when severely infected the majority of the lower leaves may drop off.

Disease Cycle-The fungus overwinters in the infected leaves. In the spring, spores are discharged from the fruiting body in the center of the spot and are carried by wind to new growth. These spores infect the leaves, and new spots, fruiting bodies, and spores are produced. This cycle is repeated throughout the summer except during periods of prolonged dry weather. Infection and disease development are favored by cool, wet weather.

Control-Hay crops in which the leaves of the plants become badly spotted should be harvested before defoliation becomes severe. Resistant alfalfa varieties have been produced but they are not adapted to conditions in Western Canada.

\section{Winter Crown Rot or Snow Mold}

\section{Unidentified basidiomycete}

Winter crown rot or snow mold of alfalfa is caused by an unidentified fungus. This fungus is responsible for extensive winter crown rot damage to alfalfa and other forage crops in Western Canada. The severity of winter crown rot varies greatly from year to year. Severe damage occurs in west-central Alberta, and relatively slight damage in southern Alberta. The disease has also been found in British Columbia, Saskatchewan and Manitoba, but it has not yet been reported outside of Western Canada.

Appearance-The disease may be recognized in the spring by the irregular patches of dead plants in alfalfa and clover fields. Sometimes, partial rotting of the crowns (Fig. 27) and weakening of alfalfa plants may 
occur rather than killing of the plants in patches. Aboveground parts of the plant are often killed or greatly weakened when only the crown buds and a small portion of the crown are affected, while the main root remains sound. White remnants of the fungus are sometimes found on the crowns of dead or damaged plants when the snow melts.

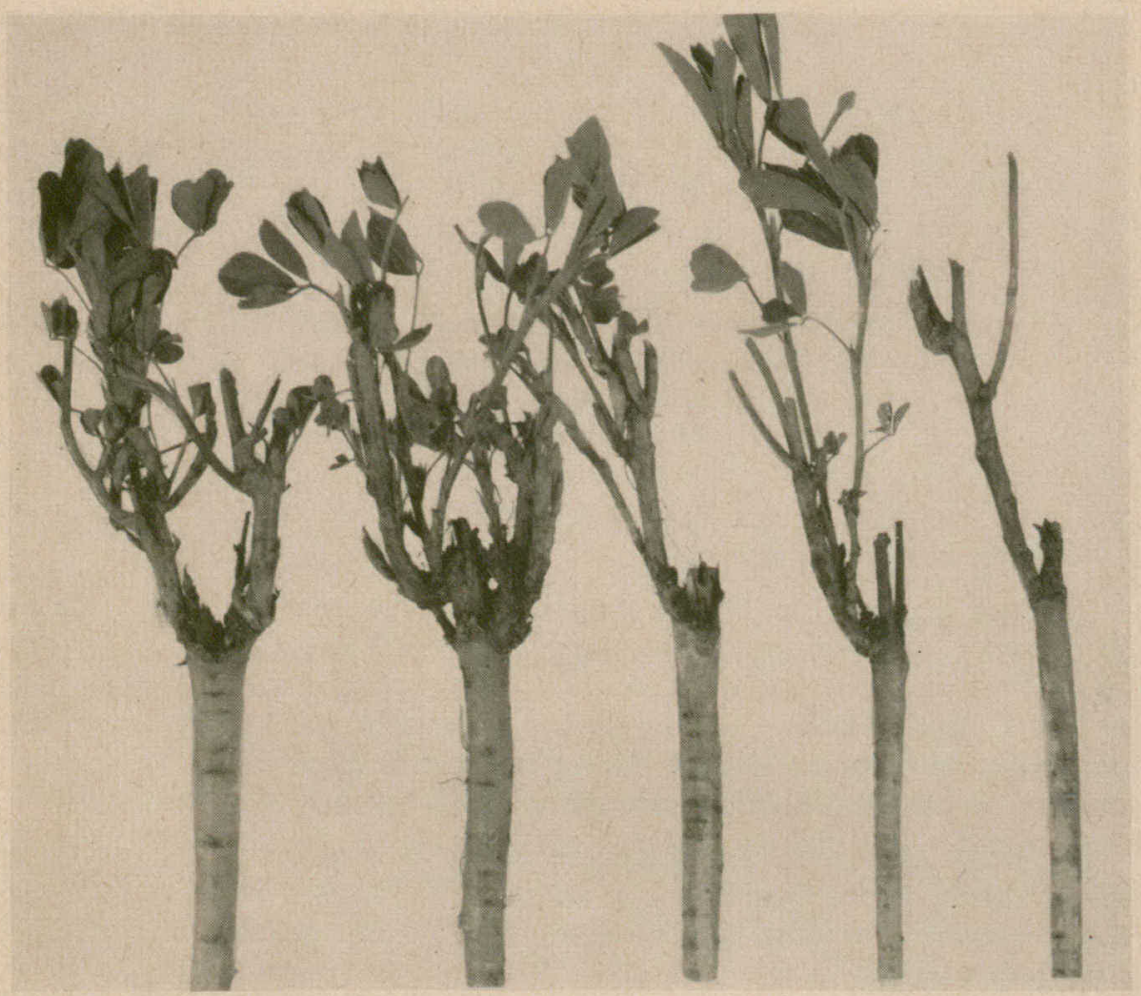

Figure 27.-Winter crown rot injury to alfalfa plants.

Disease Cycle - The crown rot fungus appears to spread by means of mycelium, since no spores or fruiting bodies have yet been found. It may spread both above and below the surface of the ground. It requires a period of growth before freeze-up in the late fall in order to inflict severe damage on the plants during the winter. As the soil temperature rises in the spring the fungus becomes relatively inactive until conditions are again favorable for growth in the fall.

Control-Following severe damage, crop rotation is the most valuable method of controlling winter crown rot. The fungus does not persist to any extent for longer than two or three years in land which has been summerfallowed or planted to annual crops or resistant grasses. Spring-sown cereals, brome, or crested wheat grass can safely be planted in heavily infested land. 
Most of the commonly grown varieties of alfalfa are highly susceptible, but progress is being made in a breeding program in which Medicago falcata and varieties derived from it are being used as a source of resistance.

\section{Crown and Root Diseases}

\section{Various soil-borne fungi}

Root- and crown-rotting fungi often attack alfalfa and sweet clover during the growing season and may cause serious losses. The damage is distinct from that caused by the previously described snow mold or winter injury in dormant plants. Several soil-inhabiting fungi, acting singly or in combination, cause varying degrees of damage in different areas and from season to season.

Crown bud rot is the most important disease of this type. It is caused by several soil-inhabiting fungi which rot the crown buds and young shoots, particularly in moist soils. The disease develops and spreads most rapidly during the early part of the growing season, and it occurs commonly in all irrigated fields after the first season. There is a progressive decline in stand and yield as the plants become partially devoid of crown buds and stems.

Root rots are sometimes destructive in sweet clover, especially in the southern areas. The damage occurs most commonly in the second season of growth. Extensive rotting of the roots by fungi results in sudden wilting and death of the plants. This damage may occur early in the spring or during the summer.

Appearance-Crown bud rot can be recognized by the brown spotting and eventual death of the young buds and shoots near the soil surface. This rotting may later extend into the underlying crown tissues.

Root rots cause rotted areas of varying size, depth, and color on the tap root and secondary roots. Other symptoms include surface injuries or root canker, collar rot, heart rot, and tip rot.

Disease Cycle-The fungi overwinter in the diseased roots and crowns or in the soil. Young succulent tissues such as crown buds may be attacked directly as soon as the soil temperature rises sufficiently in the spring to allow growth of the fungi. Other tissues such as roots, which have a layer of protective cells, usually must be wounded in some manner before the fungi can penetrate. Such wounds may be caused by insects, winter injury, or mechanical damage.

Control-The fungi involved in this type of disease are difficult to control under field conditions. Crop rotation will usually aid in reducing the damage because the more important of these fungi do not attack cereal crops. Alfalfa or sweet clover should not be reseeded for two or three years on land in which severe damage has occurred. Good cultural practices that promote vigorous growth such as proper fertilization and cutting procedures are of great value in decreasing losses. Alfalfa should be allowed sufficient 
time after the last cutting of the year to make about 10 inches of new growth before freeze-up. Late fall cutting does not leave the plants sufficient time in which to manufacture and store in the roots the reserves necessary for their winter survival and spring growth. Such plants are susceptible to winter injury and subsequent invasion by soil-borne fungi. Cultivation of alfalfa stands generally is of little value, and in fact may be harmful because injuries caused by machinery to the roots and crowns may facilitate infection by fungi.

\section{Stem Canker or Goose Neck of Sweet Clover}

\section{Ascochyta caulicola}

This disease occurs in all three Prairie Provinces but usually causes little loss.

Appearance-Silvery-white cankers form on the stems, leaf stalks, and occasionally on the midribs of the leaves. The fruiting bodies of the fungus are readily seen as small black dots on the centers of the cankers. The lower part of the stem may be girdled with large cankers. Heavily infected stems often appear swollen, are retarded in development, and have fewer and smaller leaves. They also tend to twist and bend at the top.

Disease Cycle-Similar to black stem of alfalfa and sweet clover.

Control-Control measures are not usually necessary.

\section{Seedling Blight \\ Pythium spp., Fusarium spp., Rhizoctonia solani}

Seedling blight of sweet clover and alfalfa is responsible for much of the reduction occurring in new stands and its severity depends largely on the weather. With favorable moisture conditions and temperature these fungi build up and cause heavy losses.

Appearance-Seeds, young seedlings and roots are attacked by species of Pythium. Many of the diseased plants fail to emerge. Later, as young plants emerge, they may be damped-off by other fungi attacking at the soil line. The young plants wither and soon disappear, leaving gaps in the rows. Little damage is done after the plants reach the 4- or 5-leaf stage.

Disease Cycle-Pythium persists as resting spores in the soil and under very moist conditions it may cause serious seed rotting and pre-emergence blight. As temperatures rise to $60^{\circ}$ or $65^{\circ} \mathrm{F}$., Rhizoctonia attacks at the soil line and at higher temperatures, $75^{\circ}$ to $85^{\circ} \mathrm{F}$., Fusarium causes a similar type of damage. These fungi persist as mycelium in the soil.

Control-Seed treatment with nonmercurial fungicides prevents a certain amount of pre-emergence blighting but is ineffective against fungi which attack at the soil line. The use of sound seed, shallow seeding, and 
good preparation of the seedbed are recommended. No varietal resistance is known at present. Experiments have shown that the disease is most severe on sweet clover when it is sown after sweet clover, alfalfa and red clover, and less severe when it is sown after soybeans, corn and wheat.

\section{Other Foliage Diseases}

Several other diseases occur on the leaves and stems of alfalfa and sweet clover but they are not so damaging as common leaf spot or black stem. They are found in all parts of Western Canada but generally are important only when conditions are favorable for their development.

Gray Leaf Spot (Stagonospora meliloti) -Although widely distributed this fungus seldom causes serious damage to the leaves. The spots on alfalfa and sweet clover are gray and roughly circular in outline and about $\frac{1}{8}$ to $\frac{1}{4}$ inch in diameter. In the centers of the gray-colored spots the fruiting bodies of the fungus appear as numerous, small, black dots. Similar spots may appear occasionally on the stems. This fungus also attacks the roots causing a crown and root rot. The fungus overwinters in diseased crop remains. Control measures are the same as those recommended for black stem.

Downy Mildew (Peronospora aestivalis) - This disease occurs on alfalfa during wet or humid weather, particularly in the spring. Sweet clover is seldom attacked by downy mildew. Infected leaves at the top of the plant appear light-green in color and on the underside of such leaves a grayish-white fuzz can be seen. This moldy growth is made up of fungus threads and spores. When the disease is severe, growth of the stems is retarded and the leaves become twisted and rolled. The fungus grows through the whole plant and overwinters in the crown buds. It may also overwinter in dead leaves. The control measures outlined for black stem are effective in reducing spring infection.

Yellow Leaf Blotch (Pseudopeziza jonesii)-This fungus attacks only alfalfa. The disease occurs in all parts of Western Canada and often causes severe defoliation, particularly in the northern seed-growing areas. It appears as yellow or orange blotches which run parallel to the leaf veins and on which are scattered very small orange or brown dots which are fungus structures. In the fall, the fruiting bodies of the fungus are formed on the lower sides of the leaves where they remain in the dead tissues until spring. Control measures are the same as those recommended for black stem.

White Spot (Nonparasitic) - The appearance of white spots on the leaves of alfalfa usually indicates a physiological disorder in the plant and is not the result of infection by fungi or bacteria. The spots are seldom so numerous as to damage the leaves seriously but they often indicate a disorder from which crop losses could occur. Three types of white spotting have been found. The first occurs in scattered plants in a field and is a genetic or 
hereditary character of the plant. The second occurs in most of the plants in a field and may be caused by irrigation or heavy rainfall after a period of dry weather. The third and most important type is that induced by a deficiency of potassium in the soil. When this occurs the plants become less productive and a row of white spots appears just inside the margin of the leaf. This deficiency can be corrected by the application of fertilizer containing potash.

\section{Other Diseases}

Witches'-broom of Alfalfa (Virus) - This is a disease that occurs mainly in the intermountain regions of the western United States and British Columbia, and in adjacent areas in central and northern Alberta. The plants are dwarfed and have a bunchy, upright growth consisting of numerous short shoots. The symptoms resemble those of bacterial wilt but there is no discoloration in the roots. Infected plants decline rapidly and usually die within two years. The damage is seldom severe except in relatively small, thin stands in localized areas. Such stands should be removed and new ones should be thickly planted and maintained in a productive condition.

The Stem Nematode of Alfalfa was found for the first time, in Canada, in 1950 in several irrigated fields in southern Alberta. The disease, caused by microscopic, wormlike nematodes, can be recognized by the thickened, deformed crown buds which usually do not elongate into stems. Severely infested plants are dwarfed and unthrifty. Stem nematode injury is severe in localized areas in the United States. It can be best controlled by crop rotation or by using resistant varieties, when suitable ones are available. This disease did not spread or cause any appreciable damage in southern Alberta, and it has not been found in other alfalfa-growing areas in Canada.

Sweet Clover Mosaic (Virus) - This disease has been reported from all three Prairie Provinces. Usually only a few infected plants are found in a field but large patches may occur. The leaves of infected plants appear mottled, are usually smaller than normal and may be crinkled. Severely infected plants, most noticeable in the spring, are dwarfed. The virus overwinters in sweet clover plants and may be spread from them by aphids to other susceptible crops such as peas and beans. As the disease on peas and beans is even more important than on sweet clover, these crops should not be sown near sweet clover fields. No control measures are available for sweet clover.

Summer Black Stem of Sweet Clover (Cercospora davisii) - Severe outbreaks of summer black stem in sweet clover seed crops were reported in Manitoba during 1954 and 1955. The disease has not been reported 
from Saskatchewan or Alberta. The fungus that causes the disease infects leaves, stems, pod stalks, seed pods and seeds in late summer during warm, humid weather. The leaf spots are large, roughly circular, and ashy-gray to tawny in color. Infected leaves soon shrivel and drop. The spots on stems and pod stalks are reddish brown and under favorable conditions enlarge rapidly and fuse together. Much of the stem will appear dark-brown to black when infection is severe. Infection of the pod stalks causes the seed pods to drop off prematurely. During wet weather new infections develop rapidly from wind-borne spores. No control methods are available. 


\section{Diseases of Clover}

\section{Northern Anthracnose}

\section{Kabatiella caulivora}

Northern anthracnose occurs on red clover in the cooler sections of North America, Europe and Asia. It has been very destructive to red clover stands in central and northern Alberta in the recent cool, summer seasons. Red and crimson elovers appear to be the only ones infected to any appreciable extent but alsike and white clover are not entirely resistant.

Appearance-The fungus causes brown, sunken areas on the stems and leaf stalks of the plant. The leaves and flower heads usually lop over, presenting a shepherd's crook appearance, after which they wilt and die and are broken off by the wind. Cracking of the stem tissue is often pronounced. (Color Fig. 2).

Disease Cycle-The fungus overwinters on diseased stalks and leaves. In the spring, spores are produced which infect neighboring plants and young seedlings. The disease does not appear to be transmissible through the seed or by the soil.

Control-Growing resistant varieties appears to be the best method of keeping the disease under control. The variety Dollard has shown moderate resistance and progress is being made in developing a variety resistant to both powdery mildew and northern anthracnose.

\section{Root and Crown Rot}

Various soil borne fungi

Root and crown diseases of clovers are of major importance in Western Canada. Most clovers are highly susceptible to snow mold (see alfalfa diseases), and severe damage often occurs in the central and northern areas, particularly in alsike clover. During the growing season a root-and-crown-rot complex may result from successive attacks by several soil-inhabiting fungi. Second-year plants are usually most severely affected. In red clover, this damage is often associated with winter injury. Wounding by cultivation or by insects feeding on roots favors entrance of the fungi and development of crown and root rots.

Appearance-As with alfalfa, the symptoms vary greatly, depending on the fungi involved. The crown or root is usually severely rotted before the top starts to wilt or die. In other cases the plant is weakened through partial rotting of the crown or tap root.

Disease Cycle and Control-See alfalfa diseases. 


\section{Powdery Mildew \\ Erysiphe polygoni}

Powdery mildew is probably the most serious disease of red clover in North America and is prevalent in Western Canada. Severe epidemics lower the quality of hay and cause reduction in yield.

Appearance-The disease is easily recognized by the light-gray powdery layer of mycelium and spores of the fungus found on the upper surface of the leaves. Leaves become yellow and turn brown when infection is severe. Clover plants attacked during early growth are dwarfed.

Disease Cycle-The fungus persists on the foliage and overwinters as mycelium, or possibly as spores. Dispersal of spores during the growing season may spread the disease rapidly. The disease is favored by moderately dry weather, although it has sometimes been severe in central Alberta during wet summer seasons.

Control-Powdery mildew is difficult to control in the field. Sulphur dusting has proved effective in some countries, but control is more practical by the use of resistant varieties. No resistant variety, however, is adapted to Western Canada.

\section{Other Diseases}

Various fungi, etc.

Several other diseases occurring on clovers in Western Canada are usually of minor economic importance. Seedling blight is caused by several fungi including species of Pythium, Rhizoctonia and Fusarium, as recorded under diseases of alfalfa. At least five distinct leaf diseases cause spotting of the leaves and may result in some defoliation. Black stem occurs on red clover but it is seldom as severe as on alfalfa. Sooty blotch, which appears as small black pustules on the underside of the leaves, is most common on alsike and white clovers, and rarely appears on red clover. Rust occurs commonly on clovers but usually appears too late in the season to cause serious damage. These diseases are generally favored by cool, wet weather.

Mosaic is the most common virus disease on clovers. The leaves are mottled and the plants may become stunted if infection is severe. Witches'-broom, another virus disease, produces dwarfing and a bunchy growth. Most virus diseases of clovers can also infect peas, beans, and several other plants.

Control-No practical control measures have been developed for most of these diseases. 


\section{Diseases of Grasses}

Grass diseases are prevalent throughout Western Canada but the losses which they cause are difficult to determine. Much of the hay crop is harvested from mixed stands or from naturally seeded wild meadows, and in such cases diseases usually do not become epidemic as they do in cereal crops where large areas are planted to one variety. Most of the many diseases of grasses are similar to those already described on the cereal crops and no detailed description of all the individual diseases will be attempted.

Root Rots - Snow mold may cause severe damage in cultivated and native grasses in the central and northern areas (Fig. 28). The appearance of the disease is similar to winter crown rot of alfalfa and clovers, which is caused by the same fungus. Crop rotation with a spring-sown cereal crop is the best method of control. Brome and crested wheat grass are highly resistant and can be safely planted in infested land. Common root rot, browning root rot and take-all occur on the grasses as well as on cereals.

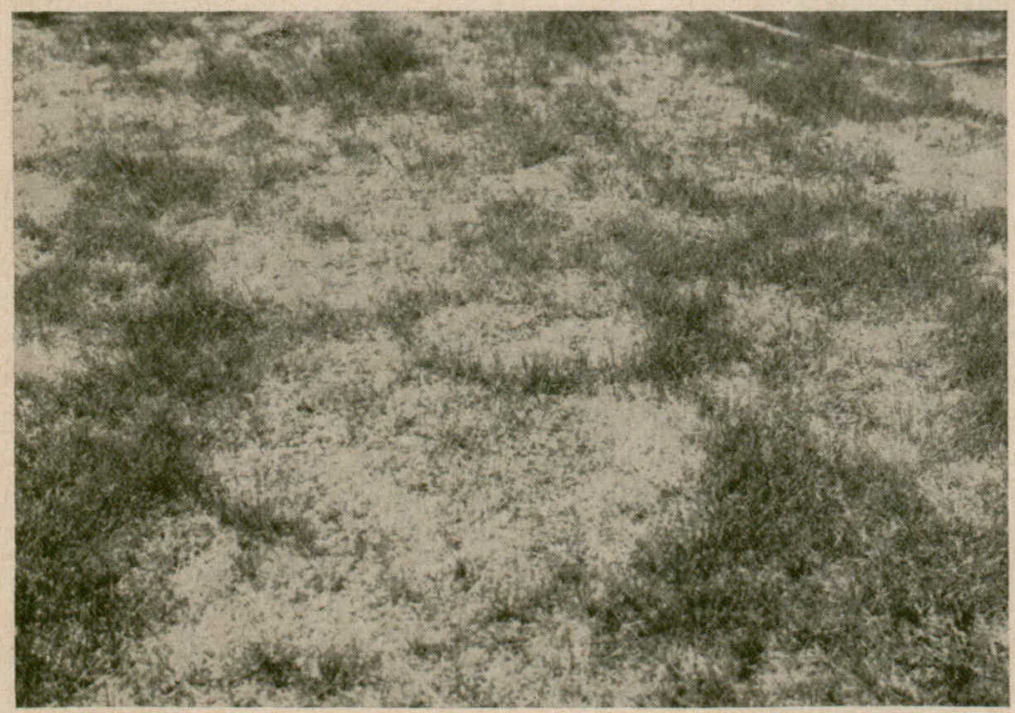

Figure 28.-Winter crown rot (snow mold) injury to lawn grass.

Smut-Head smut (Ustilago bullata) is widely distributed in Western Canada on a large number of grasses and sometimes causes serious losses to the wheat grasses. Diseased heads appear dark brown to purple black. All or part of the floral structures may be destroyed by the smut fungus and usually the heads on all the stems produced by an infected plant are diseased. Seedling infection occurs from seed contaminated with spores during 
harvesting. In perennial grass species the mycelium of the smut fungus overwinters in the dormant tissues of the plant and invades the new growth the following spring. Infection occurs only in the seedling stage. Therefore, seed treatment with recommended seed disinfectants will control the disease.

Ergot-There are several reasons for the importance of the ergot disease on grasses. Severe losses in seed production of some grasses have occurred through attacks of this fungus. Ergot poisoning may result when livestock are allowed to graze heavily infected heads of grass or are fed contaminated seed screenings. Ergot infection of cereal crops can often be traced to diseased grass plants growing wild along the headlands of cereal fields. The disease affects a wide variety of grasses in Western Canada. For further details see the discussion under diseases of rye.

Rust-Several rusts occur on grasses including stem rust (Puccinia graminis), leaf rust (Puccinia rubigo-vera) and crown rust (Puccinia coronata). The appearance and disease cycle of these rusts are similar to those described on cereals. Stem rust does not occur on brome grass.

Bacterial Blights-Halo blight (Pseudomonas coronafaciens var. atropurpurea) causes characteristic purplish-brown spots with lighter-colored borders on the leaves of brome and other species of grass. It is similar to halo blight of oats. Bacterial blight (Xanthomonas translucens) is another minor leaf disease of brome and some of the wheat grasses. The appearance is described under bacterial blight of barley.

Powdery Mildew-Powdery mildew (Erysiphe graminis) occurs on many wild and cultivated grasses including fescues, orchard grass and brome grass. It is generally more severe on seed crops than on those cut for hay. This is the same fungus which causes mildew on cereals.

Helminthosporium Leaf Spots-Many of the wild and cultivated grasses are attacked by species of Helminthosporium. In general the spots on the leaves are brown in color. The most widely distributed spot of this type is brown leaf spot of brome grass caused by Helminthosporium bromi. The disease appears early in the spring as elongated, brownish spots scattered over the young leaves. The spots increase in size and develop a yellow halo surrounding the diseased area. As the spots enlarge and join together, the tip of the leaf becomes yellow and begins to wither. The leaf is gradually killed from the tip downward. The disease does not warrant extensive control measures.

Septoria Leaf Spots-The fungus Septoria attacks many wild and cultivated grasses causing symptoms similar to those caused by species of the same fungus on cereals. Selenophoma bromigena, a closely related fungus, is 
restricted to brome grass and may be destructive in local areas when weather conditions are favorable for its development. Mature spots caused by this fungus usually have a dark-brown border with lighter-colored centers in which tiny black dots can be seen. These are the fruiting bodies of the fungus which contain a large number of spores. The fruiting bodies may drop out of the spots leaving small holes in the central area. When infection is severe spots also appear on sheaths, stems, and on the floral parts. The spores overwinter in the fruiting bodies in which they are produced and are spread in the spring by wind and rain to new growth. Where the disease is of economic importance crop rotation is recommended for its control. 


\section{Definition of Technical Terms}

Bacterium ( $p l$. bacteria) - A microscopic, one-celled organism. Some bacteria cause plant diseases.

Canker-A sharply bordered, either sunken or raised, diseased area.

Chlorosis-An unnaturally pale-green or yellow condition in green plants.

Damping-off-A diseased condition characterized by wilting and sudden dying.

Embryo-The undeveloped plant enclosed within the seed.

Floret-A small flower such as that of wheat, barley, oats and grasses. Each floret contains male and female elements that must unite before a seed can develop.

Fungus ( $p l$. fungi) - A plant belonging to certain groups that lack ehlorophyll. Most parasitic fungi are microscopic in size.

Germ tube-The fine, tubular structure produced when a spore germinates.

Glume-One of the two chaffy envelopes at the base of the spikelet.

Host-A living plant on which a particular parasite may grow.

Microorganism-A general term used to include fungi, bacteria, viruses and other organisms of microscopic size.

Mold-A fungus that produces a conspicuous mycelium; spores of the fungus may also be present.

Mycelium ( $p l$. mycelia) - The fine, cottony growth produced by molds and other fungi.

Rachis-The prolongation of the stem that forms the central axis of the heads of wheat, barley, and certain grasses.

Spore-A single-celled or many-celled reproductive body produced by fungi and certain other microorganisms.

Sporidium ( $\mathrm{pl}$. sporidia) - One of the small spores, usually four in number, produced when the overwintering spore of a rust or a smut germinates.

Spikelet-One or more florets with two empty supporting glumes. In wheat, a spikelet with several florets occurs at each joint of the rachis. In barley, three spikelets, each with one floret, occur at each joint.

Stoma ( $p l$. stomata) - A small pore on the surface of green leaves.

Virus-An infective agent that frequently produces a mottling of the leaves. Virus particles are too small to be seen with even the most powerful of optical microscopes. 



\section{INDEX}

Main page references are in boldface

(For sectional headings see Contents)

Aceria tulipae, 33

Advance sunflower, 76

Ajax oats, 55

aldrin, 17

alkali injury, 11

Alternaria tenuis, 31

antibiotics, 18

Anticarie SD, 17

Aphanomyces eutiches, $\mathbf{8 5}$

aphid control, 48

Ascochyta blight of peas, 84

Ascochyta

caulicola, 92

imperfecta, 87

meliloti, 87

pinodella, 84

pisi, 84

bacteria, 11

bacterial black chaff, 31

bacterial black tip, 31

bacterial blight

of barley, $\mathbf{4 5}$

of grasses, 99

of peas, 83

of rye, $\mathbf{5 7}$

of wheat, $\mathbf{3 0}$

bacterial diseases of oats, $\mathbf{5 1}$

bacterial wilt of alfalfa, 87

barberry, 22

basal glume rot, 31

basidiomycete, unidentified, 89

Beacon sunflower, 78

beans, 16

black chaff of wheat, 11

black spores of stem rust and leaf rust of wheat, 22,23

black stem of alfalfa and sweet clover, 87

blast of oats, $\mathbf{5 5}$

boll blight of flax, 73

bordeaux mixture, 14

browning root rot of wheat, 28

buckthorn, 50

bugloss, 59

bunt of wheat, $10,17,23$

Bunt-no-more, 17

burning, not always advisable, 18 captan, 17

Cercospora davisii, 94

Ceresan M, 17

chloranil, 17

chlorosis, $\mathbf{7 3}$

Claviceps purpurea, 30, 57

Corynebacterium insidiosum, 87

crown and root diseases

of alfalfa, 91

of clovers, 96

crown rust

of grasses, 99

of oats, 49

disinfectants, 14

Dollard red clover, 96

downy mildew

of alfalfa, 93

of sunflower, $\mathbf{8 0}$

dusting, 18

dwarf bunt of wheat, 23

ergot

of barley, 10

of grasses, 10, 99

of wheat, $10, \mathbf{3 0}$

of rye, 10,57

Erysiphe

cichoracearum, 81

graminis, 99

graminis tritici, 46

polygoni, 97

Exeter oats, 55

false stripe of barley, 11, 45

formaldehyde, 17

Fortune oats, 51

fungicide, $14,15,17$

Fusarium

oxysporum f. lini, 68

solani, $\mathbf{8 5}$

spp., 27, 42, 68, 92, 97

Garry oats, $49,50,51$

goose neck, 92

gray leaf spot of alfalfa and sweet clover, 93

gray speck of oats, 13, 53

Grimm alfalfa, 88 
halo blight, 51

head discolorations, $\mathbf{3 1}$

heat canker, 67

Helminthosporium

bromi, 99

sativum, 10, 27, 31, 42

teres, 43

hexachlorobenzene, 17

hot water treatment, $27,41,53$

Husky barley, 36

iron deficiency, 13

Kabatiella caulivora, 96

Ladak alfalfa, 88

late blight epidemics, 13

leaf mottle, $\mathbf{8 1}$

leaf spot, 18,89

lindane, 17

Lycopsis arvensis, 59

manganese deficiency, 13,53

manganese sulphate, 13,55

Medicago falcata, 91

Melampsora lini, 64

mercury, organic, 17,25

mildew

downy

of alfalfa, 93

of sunflower, $\mathbf{8 0}$

powdery

of clover, 97

of grasses, 99

of sunflower, 81

of wheat, $\mathbf{3 4}$

mosaic, 97

sweet clover, 94

wheat streak, 11, 32

Mycosphaerella pinodes, $\mathbf{8 4}$

nematode, stem, 94

net blotch, 43

nitrogen deficiency, 11

northern anthracnose, 96

nutritional diseases, $11, \mathbf{5 5}$

Ophiobolus graminis, $\mathbf{2 8}$

Ornithogalum umbellatum, 36

overwintering, 18

Oxalis spp., 61

Panogen 15, 17

pasmo, 65

peas, 16

pentachloronitrobenzene, 17

Peronospora aestivalis, 93

phosphate fertilizer, 30

Plasmopara halstedii, $\mathbf{8 0}$

Polyspora lini, 70 premature ripening of sunflower, 81 prematurity blight, 27

Pseudomonas

atrofaciens, $\mathbf{3 0}, \mathbf{3 1}$

coronafaciens, $\mathbf{5 1}$

coronafaciens, var. atropurpurea, 99

pisi, $\mathbf{8 3}$

striafaciens, $\mathbf{5 1}$

Pseudopeziza

jonesii, 93

medicaginis, 89

Puccinia

coronata, 99

coronata, var avenae, 49

graminis, 31, 99

graminis, var. avenae, 49

graminis, var. secalis, 36,60

graminis, var. tritici, $\mathbf{2 0}, 36$

helianthi, 76

hordei, 36

rubigo-vera, 99

secalina, 59

sorghi, 61

triticina, 22, 99

Pythium

spp., 28, 68, 92, 97

ultimum, $\mathbf{8 5}$

race $15 \mathrm{~B}, 20$

race 56,20

races, rust, 20

Redman wheat, 22

Regent wheat, 22

resistant varieties, $14,15,22,27,31,34$, $36,48,64,67,69,80,88,89$

Rhamnus spp., 50

Rhizoctonia solani, 68, 85, 92, 97

Rhynchosporium secalis, 44

Rodney oats, $49,50,51$

root rot

diseases, 18

of barley, $\mathbf{4 2}$

of clover, 96

of flax, 68

of grasses, 98

of oats, $\mathbf{5 6}$

of peas, 85

of wheat, 27

rotation crop, $18,27,28,33,35,43$, $44,45,57,59,68,69,80,81,85,86$, 90, 91

rust

corn, 61

crown

of grasses, 99

of oats, 49

flax, 64 


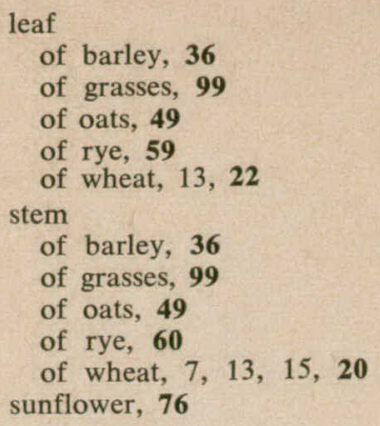

St. Anthony's fire, 57

sanitation, 18

savings from disease prevention, 14

scald, $4 \mathbf{4}$

Sclerotinia sclerotiorum, $\mathbf{7 8}$

sclerotinia wilt, 78

seed

cracking of, 72

disease-free, $16,40,47,59,83,85$

examination of, $16,17,40$

rot, 17,72

soundness of, $15,16,68,92$

treatment, $16,18,28,40-42,43,51$, $68,72,86,92$

seedling blight, 17, 68, 92

Selenophoma bromigena, 99

Septoria

avenae, f. sp. triticea, 35

linicola, $\mathbf{6 5}$

nodorum, 31

passerinii, $\mathbf{4 3}$

slurry, 17

smut

chemical control of, 17

corn, 61

covered

of barley, 37

of oats, $\mathbf{5 0}$

false loose, of barley, $\mathbf{3 7}$

head, of grass, 98

loose

of barley, 10, 16, 40

of oats, $\mathbf{5 0}$

of wheat, 25

snow mold, 89

sorrel, wood, 61

specialization, parasitic, $20,22,25,34$,

$36,49,64$

speckled leaf

disease, 35

blotch, 43

Spergon, SL, 17

sporidia, 22, 23,63

spot blotch, 42 spraying, 14, 18

spring plowing, 27

Stagonospora meliloti, 93

stalk rot, 81

star-of-Bethlehem, 36

stem break and browning, 70

stem canker, 92

stem nematode, 94

S37-388, 76

stripe blight, 51

stripe mosaic virus, 31, 45

sulphur, 18, 22, 34, 97

summer black stem of sweet clover, 94

sweet clover mosaic, 94

take-all, 28

Thalictrum, 23

Thatcher wheat, 22

Tilletia

caries, 23

foetida, $\mathbf{2 3}$

top dieback, 73

Tritisan C, 17

Ustilago

avenae, $\mathbf{5 0}$

bullata, 98

hordei, 37

kolleri, $\mathbf{5 0}$

maydis, 61

nigra, 37

nuda, 40

tritici, $\mathbf{2 5}$

Vantage barley, 36

Vantmore barley, 36

Viking flax, 67

virus, $11,43,147,148$

virus yellows

of flax, 74

of sunflower, $\mathbf{8 2}$

water soak, 15, 58

weather, relation to bacterial blight of wheat, 31

white spot, 93

wilt

of flax, 68

sclerotinia, 78

winter crown rot, 89

witches'-broom of alfalfa, 94

wireworm injury, 17

Xanthomonas translucens, 30, 31, 45, 57, 99

yellow dwarf of barley, 47

yellow leaf blotch, 93 








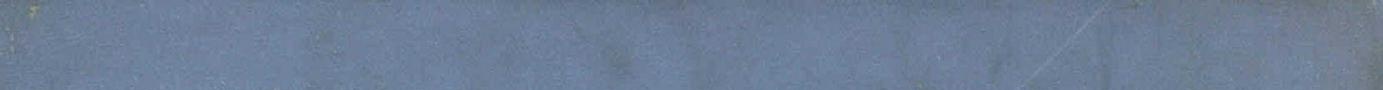

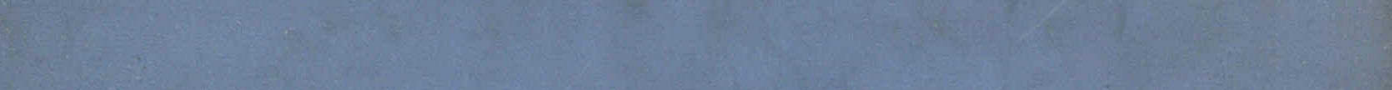

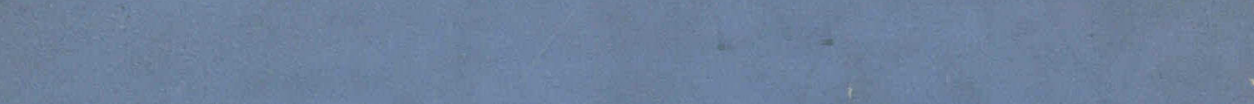

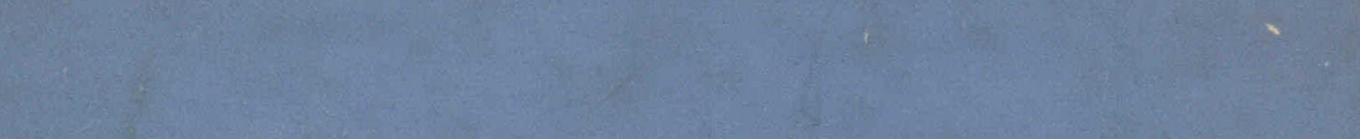

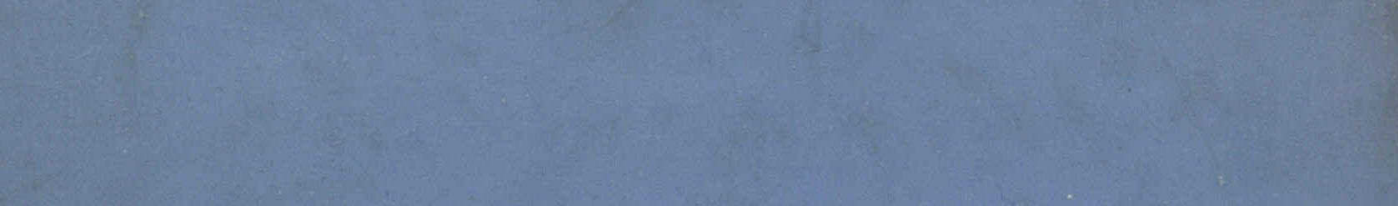

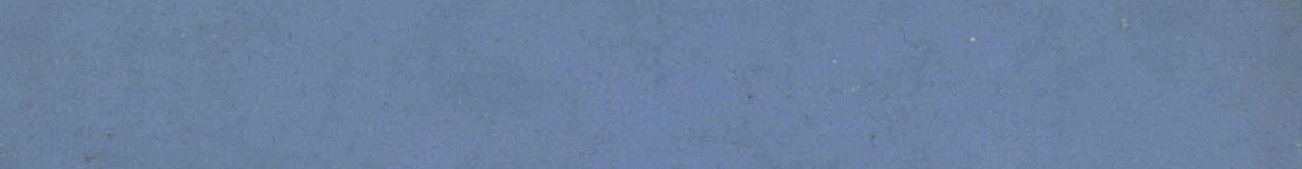

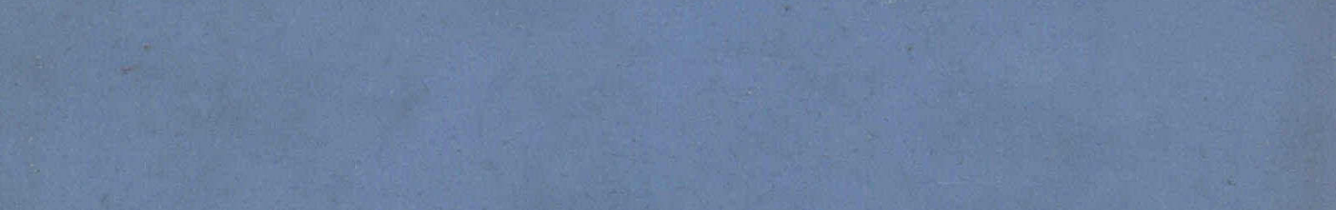

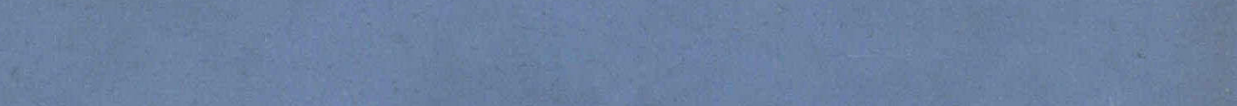

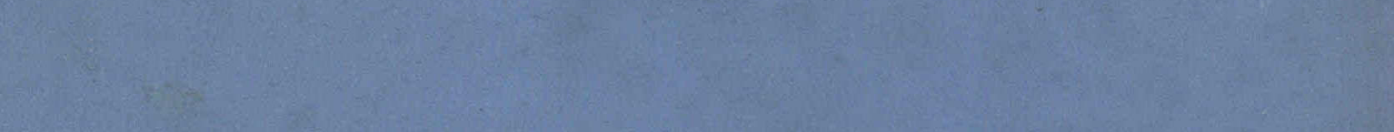
(2.

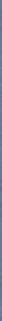

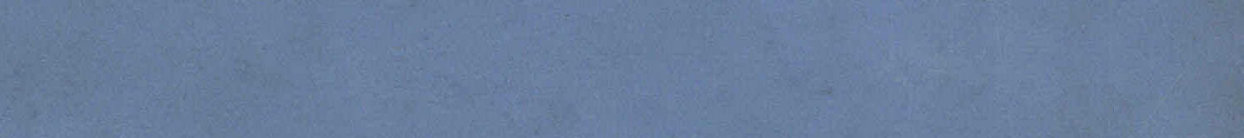

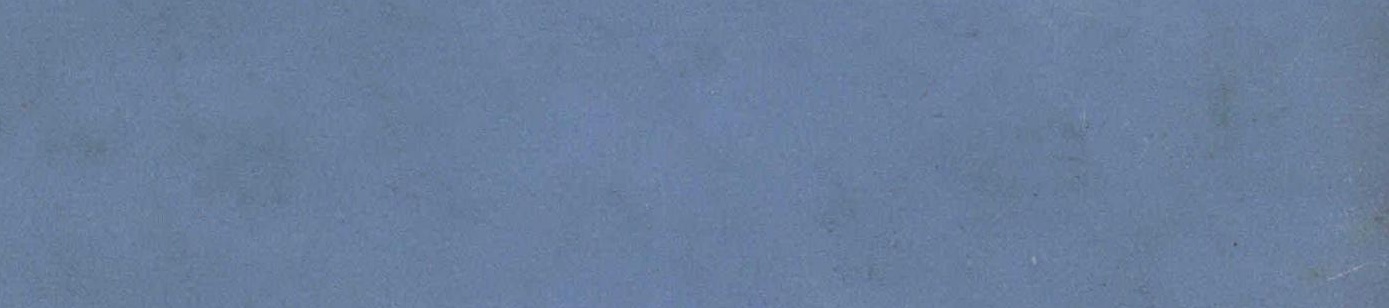

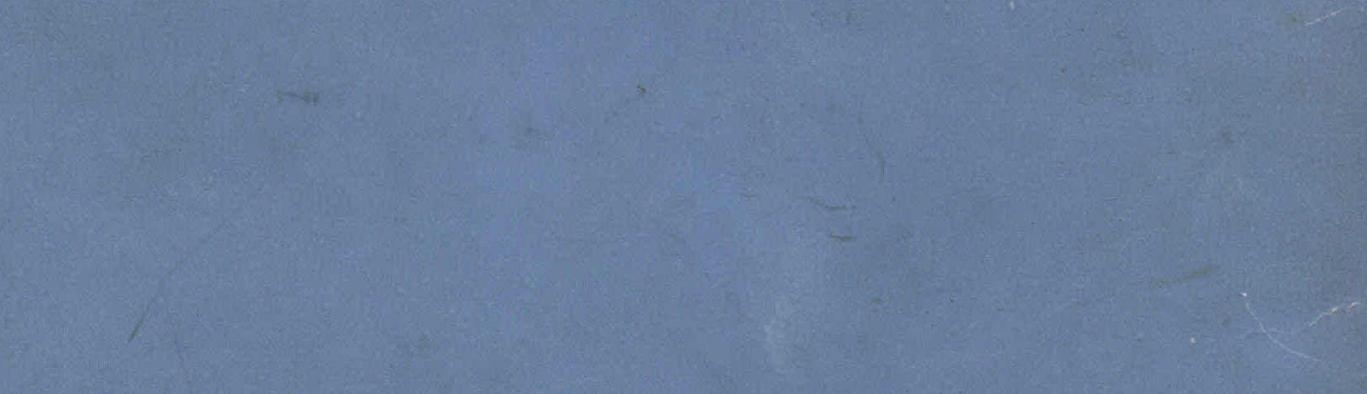
2.: $: 0$

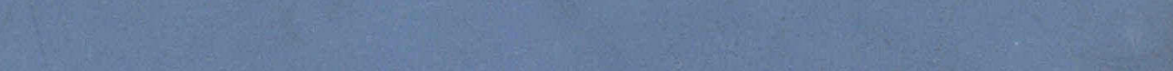

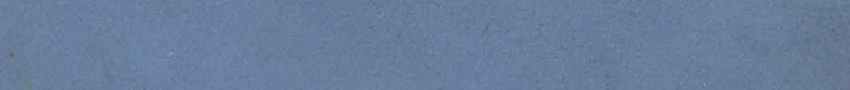

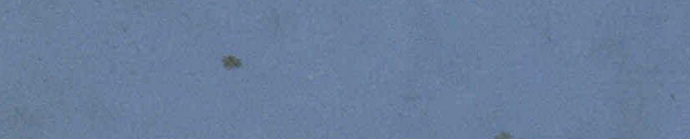

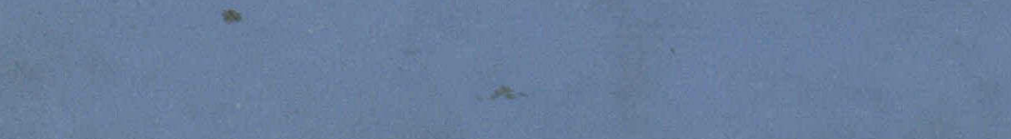

